\title{
Information Technology and Returns to Scale*
}

\author{
Danial Lashkari ${ }^{\dagger}$ \\ Arthur Bauer \\ Jocelyn Boussard $\$$
}

September 26, 2019

First Draft: May 17, 2018.

Please Click Here for the Latest Version

\begin{abstract}
This paper investigates the role of IT in shaping recent trends in market concentration, factor income shares, and market competition. Relying on a novel dataset on hardware and software investments in the universe of French firms, we document a robust within-industry correlation between firm size and the intensity of IT demand. To explain this fact, we argue that the relative marginal product of IT inputs may rise with firm scale, since IT specifically helps firms deal with organizational limits to scale. We propose a general equilibrium model of industry dynamics that features firm-level production functions compatible with this mechanism. We estimate the production function and find evidence for the nonhomotheticity of IT demand and for an elasticity of substitution between IT and other inputs that falls below unity. Under the estimated model parameters, the cross-sectional predictions of the model match the observed relationship of firm size with IT intensity (positive) and labor share (negative). In addition, as a response to the fall in the relative price of IT inputs in post-1990 France, the model can explain about half of both the observed rise in market concentration and the observed market reallocations toward low-labor-share firms.
\end{abstract}

*Acknowledgements: We are grateful to Giuseppe Berlingieri, Johannes Boehm, Antonin Bergeaud, Sara Calligaris, Chiara Criscuolo, Oleg Itskhoki, Samuel Kortum, Claire Lelarge, Eduardo Morales, Michael Peters, Stephen Terry, and seminar participants at Bank of Italy, Banque de France, Columbia, Dartmouth, ESSEC/THEMA, INSEE, Princeton, Rochester, and Yale for insightful feedback and comments. We also thank the economics department of INSEE, and in particular Sebastien Roux and Dominique Goux for making this project possible by facilitating our access to the data. Parts of this research were performed as Danial Lashkari was a visitor at the Structural Policy Division of the OECD and the Cowles Foundation for Theoretical Economics at Yale University.

†Boston College. Email: danial.lashkari@bc.edu. Website: https://sites.google.com/view/ danial-lashkari/home.

¥ENSAE-CREST. Email: arthur.bauer@insee.fr.

\$Banque de France. Email: jocelyn.boussard@banque-france.fr. Website: https://sites.google.com/site/ jocelynboussardhome/home. 


\section{Introduction}

The rise of Information Technology (IT) has drastically lowered the quality-adjusted prices of computing and information-intensive tools over the past few decades (Byrne and Corrado, 2017). The resulting adoption of IT among firms has allowed them to coordinate their activities more effectively, both internally and in relation with their sellers and buyers, and to engage in more complex production processes. To account for the macroeconomic consequences of these transformations, we typically consider IT as a form of productivity-enhancing capital in the production function of firms. Indeed, empirical studies have found a crucial role for IT in fueling aggregate productivity growth (Oliner and Sichel, 2000; Jorgenson, 2001; Stiroh, 2002; Jorgenson et al., 2005). This role has been so pronounced that one can explain different growth experiences across advanced economies over 1990s and 2000s based on their success in realizing the potentials of IT (e.g., Basu et al., 2003; van Ark et al., 2008; Bloom et al., 2012).

More recent work has begun to examine the distribution of the benefits of these IT-fueled productivity gains between workers vis-à-vis owners of capital (and firms). ${ }^{1}$ As firms substitute IT for other factors, they can raise the share of aggregate income accrued to capital, as opposed to labor. Under the case of a macro capital-labor elasticity of substitution exceeding unity, Karabarbounis and Neiman (2014) have argued that falling prices of IT capital may have contributed to a global decline in the labor share. ${ }^{2}$ Further evidence based on the US micro-level data paints a more nuanced picture: rather than a within-firm fall in labor share, reallocations of market shares toward large, low-labor-share firms appear to explain most of the observed fall in the aggregate labor share (eg., Autor et al., 2017a,b; Kehrig and Vincent, 2017). This evidence first implies that micro capital-labor elasticity of substitution may well be below unity, in line with available firm-level estimates (see, e.g., Oberfield and Raval, 2014; Doraszelski and Jaumandreu, 2018). Moreover, it ties the evolution of aggregate labor share to a rise in industry concentration, calling for a better understanding of the potentially heterogeneous impacts of IT across firms. ${ }^{3}$

\footnotetext{
${ }^{1}$ The distributional impacts of IT across workers depending on their skill levels has indeed been the subject of a large literature (e.g., Autor et al., 1998, 2003; Acemoglu and Autor, 2011; Akerman et al., 2015). Perhaps the most relevant to the arguments presented here is the work of Krusell et al. (2000) who suggest variations between the elasticities of substitution between (IT) capital and different skill groups may have contributed to the rise in the skill premium. Relatedly, Eden and Gaggl (2018) have applied this line of reasoning to the study of the income share of high skilled and low skilled workers.

${ }^{2}$ Since Karabarbounis and Neiman (2014), a sizable body of work has revisited the evidence on the fall of the labor share to examine the potential explanations, or whether this fact is robust to the relevant details in the construction of the labor share series (e.g., see Elsby et al., 2013; Koh et al., 2015). In this paper, we focus on the compositional aspects of the evolution of labor share across firms, i.e., the changes within and across firms, rather than the aggregate labor share. In fact, we do not find an aggregate fall in the labor share in France beginning in the 1990s.

${ }^{3}$ For instance, Autor et al. (2017a,b) suggest that IT may have created network effects and facilitated more effective product comparisons for consumers, therefore helping superstar firms gain larger shares of the market. This explanation, as well as other alternatives such network effects of IT or the potential effects of IT on the competition
} 
In this paper, we offer a simple framework for understanding the role of IT in shaping aggregate productivity, factor income shares, and industry concentration at both the micro and macro levels. We introduce a production function that distinguishes IT from other types of capital and allows for its marginal product (relative to that of other inputs) to systematically vary with firm size, resulting in the nonhomotheticity of IT factor demand. We motivate our approach based on a new fact that we document using firm-level data from France: a robust, within-industry, cross-sectional correlation between IT intensity and firm size. We estimate our proposed production function in the firm-level data, and find evidence both for the nonhomotheticity of the production function and for an elasticity of IT capital-labor that falls below unity. We then develop a dynamic general equilibrium model with heterogeneous firms that features the estimated production function, and show that the equilibrium of the model matches cross sectional facts on the relationships of firm size with labor share and IT intensity. In response to the fall in relative prices of IT observed in the French data, our model can explain about half of the observed rise in industry concentration, and around half of the fall in the aggregate labor share caused by the resulting cross-firm market reallocations.

The key novel mechanism that shapes our results is the effect of IT in shifting how aggregate income is distributed between firm profits and payments to other factors. We will show that the identified parameters of our flexible production function imply cross-sectional variations in returns to scale (scale elasticity) across firms, which in turn translate into variations in profit shares. In particular, the model predicts that larger firms have lower scale elasticities, higher profit shares, and therefore lower labor shares. When the price of IT falls, firms leverage IT to raise their scale elasticity, which translates into a rise in their labor shares. However, larger firms disproportionately benefit from this shock, due to the bias of their factor demands toward IT. In response, they can lower their prices and raise their market shares, raising the industry's level of concentration. Since these larger firms have lower labor shares, this reallocation also lowers the aggregate labor share. ${ }^{4}$

in the product or input markets, may require us to depart from the benchmark in which IT simply acts as an input in the production function of firms.

${ }^{4}$ Profits in our setting are the returns to the fixed, firm-specific factors that distinguish firms (particularly the larger and more productive ones). Within each firm, the rise of IT lowers these returns, but across firms it is biased toward the firms that pay a larger share of their income to this factor. We also note that our model shares this core mechanism with the results of (Basu and Fernald, 1997) who study business cycle fluctuations where cyclical expansions of output are biased toward firms with higher scale elasticities. They find that in such an environment the aggregate scale elasticity (profit shares) is cyclical (countercyclical) and the aggregate and micro estimates of the scale elasticity diverge. 


\section{Overview of the Paper}

Empirically, our point of departure is the introduction of novel datasets that detail micro-level software and hardware investments among French firms, covering a broad set of manufacturing and service industries. We rely on this data to construct stocks of software and hardware capital for French firms between 1995 to 2007. This is a period that witnessed a substantial and widespread rise in the adoption of IT among French firms. Figure 1 shows the aggregate series for the user cost of IT equipment (relative to that of non-IT capital) and the ratio of IT equipment capital to non-IT capital across the entire market economy in France. Between 1990 to 2015, we observe a fall of over $50 \%$ in the relative user cost of IT and sizable shift in the composition of capital of firms toward IT equipment. We assume that the fall in the price of IT is driven by exogenous technological progress, and aim to examine its consequences for industry concentration and aggregate factor shares.

We add to our IT data standard sources that detail balance sheet information, including sales and labor share, for the universe of all French firms. We use this dataset to revisit the evolution of market concentration and labor share, as well as the cross sectional relationship between labor share and firm size in France. Our data suggests patterns similar to those recently documented using the US firm-level data as well as a number of other advanced economies (eg., Andrews et al., 2016; Autor et al., 2017a,b). We first find a sizable rise in industry concentration, when measured in terms of a number of different standard proxies. In addition, we find that the implied market reallocations toward larger firms have indeed contributed negatively to the aggregate labor share (accumulating to a total of around 4 percentage points between 1990 and 2007). This finding is not surprising given the fact that we also document a negative within-industry, cross-sectional correlation between labor share and firm size. However, we also find positive within-firm contributions to the aggregate labor share over the same period, stemming from upward shifts in the distribution of labor share (similar to patterns found by Kehrig and Vincent, 2017). In France, the negative across-firm contributions to the aggregate labor share appear to be completely compensated by the positive within-firm contributions, leaving the aggregate labor share seemingly intact in the post-1990 period.

Next, we examine the heterogeneity in IT inputs across French firms. We document that the firm-level demand for IT inputs relative to other inputs grows in the firm's scale of operation. This finding is robust to different measures of IT intensity, whether IT is proxied by software or hardware, whether by investment or capital, and whether intensity is measured relative to labor inputs or to non-IT capital. The results are also robust to using different measures of firm scale, whether scale is measured by employment, value added, sales, or by more eclectic measures such as the number of plants, the depth of organizational structure, the number of exporting markets, or the number of exported products (the latter two measures only in the sample of exporting 
firms). We find this relationship to hold across a wide range of industries and classes of firm size, from small firms with just a few workers to large multinationals hiring tens of thousands of workers.

To structurally account for these facts, we construct a general equilibrium model that features monopolistically competitive firms producing output with a nested nonhomothetic CES (nhCES) production function (Sato, 1974, 1977; Comin et al., 2015). Software and hardware constitute a bundle of IT inputs while non-IT capital and labor constitute a bundle of non-IT inputs. The two bundles are combined using a nhCES production function to produce firm-level output. We assume that firms are heterogeneous in terms of two productivity states, one factor-symmetric and one IT-biased, and the two evolve over time according to a simple Markovian process.

First, we investigate the cross-sectional predictions of the model. The nonhomotheticity of the production function implies that the returns to scale of firms should vary with their size. Interestingly enough, the relationship between returns to scale and size crucially hinges on the elasticity of substitution between IT and non-IT inputs. In particular, if we assume that this elasticity is below unity, then the theory predicts lower scale elasticities for larger firms. Next, we derive the general equilibrium predictions of the model in response to an exogenous fall in the price of IT inputs. We find two counteracting forces: the direct substitution effect that raises the scale elasticity (and factor income shares) for all firms, and a reallocation effect that shifts market shares toward larger firms operating with lower scale elasticities (and factor income shares). In addition, the pass-through of the lowered IT inputs is higher into the marginal cost of large firms, leading to a shift of market allocations toward larger firms.

We bring the model to the data in two steps. First, we employ an identification strategy based on standard timing assumptions to estimate our production function in the micro data. We combine this method with a strategy that relies on shift-share instruments for the price of software relative to wages (following Oberfield and Raval, 2014) to estimate the full nhCES production function, including the IT-non-IT elasticity of substitution. We find that the core parameter of our model, governing the output elasticity of IT intensity, which in turn controls the relationship between IT intensity, scale elasticity, and labor share, is positive and significant. We find this to be the case whether we pool the data data across all industries, across manufacturing industries, or across any 38-industries industry codes. Crucially, we also find estimates for the elasticity of substitution between IT and non-IT inputs that are below unity and are therefore compatible with our mechanism: the estimated elasticity is $0.39(0.48)$ in the sample of all (manufacturing) industries. ${ }^{5}$ Finally, our estimated parameters implies values for the returns to scale that are very close to unity for the average firm, while still leading to sizable variations in the cross section

\footnotetext{
${ }^{5}$ These numbers are close to recent micro-level estimates of the elasticity of substitution between capital and labor (see, e.g., Oberfield and Raval, 2014; Doraszelski and Jaumandreu, 2018).
} 
depending on the firm's IT intensity.

Armed with these estimates, we perform a simple calibration of our general equilibrium model to gauge its quantitative success in explaining the evolution of industry concentration and labor share in France. In this exercise, we study the response of the model in moving from an initial stationary equilibrium of the calibrated model to a second involving a lower relative user cost of IT. We consider a change in the relative user cost of IT in line with official aggregate price series from 1990 to 2007. The calibrated model predicts a rise in the market concentration (proxied by the market share of top $1 \%$ and $5 \%$ of firms) that is about half of the rise observed for those proxies in the data. The model also predicts positive within-firm and negative acrossfirm contributions to the aggregate labor share, both by around 2 percentage points, which again accounts for about half of the components of the observed trends in the data. Finally, our model also predicts a sizable fall in the rates of entry as a part of response to this shock. We conclude that the rise of IT can explain a substantial part of the rise in industry concentration and the resulting reallocations toward low-labor-share firms in France.

\section{Prior Literature}

Our paper contributes to a large literature that has studied the impacts of IT at both the micro and the macro levels. We already touched on the macro side of this literature, which has focused on isolating the contribution of IT to aggregate productivity growth (see Stiroh, 2008, for a review of the evidence). On the micro side, this literature has further documented strong productivity gains for firms adopting IT (e.g., Brynjolfsson and Yang, 1996; Erik Brynjolfsson, 2003; Aral et al., 2006; Draca et al., 2009). ${ }^{6}$ While in this paper we focus on the aggregate consequences of the nonhomotheticity of IT demand, our results also have important implications for the micro side of this literature. ${ }^{7}$ In particular, the fact that the relative IT demand grows in firm size may in fact explain a part of the observed relationship between productivity and IT intensity.

In this paper, we focus on linking a micro account of a firm's choice of IT inputs, at a production function level, to an aggregate macro model. Therefore, we do not take a stance on any specific underlying forces that result in an increasing relative marginal product of IT among larger firms. However, one can motivate such a relationship in a number of different ways. For instance, we can draw insights from organizational theories of firm (Garicano, 2000; Garicano and Rossi-Hansberg, 2006) that provide sub-micro foundations for the firm production function

\footnotetext{
${ }^{6}$ More recent papers in this line of work rely on exogenous variations in the costs of IT adoption as a strategy for identifying the elasticity of output and productivity with respect to IT (e.g., DeStefano et al., 2014, 2016; Akerman et al., 2015).

${ }^{7}$ In two recent papers, Harrigan et al. (eg., 2016, 2018) have studied the rise of what they refer to as "techies," the specialized and technically oriented labor inputs that may constitute complementary inputs to IT, in the context of the French labor market. They argue that the shifts in the composition of labor hired by French firms toward techies has played an important role in labor market polarization and skill-biased productivity growth.
} 
that generates nonhomotheticity patterns similar to those uncovered here (Caliendo and RossiHansberg, 2012; Caliendo et al., 2015a,b). In this framework, larger firms use more complex organizational structures, which may in turn require more information exchange and communication across firms. ${ }^{8}$ In addition, there is some evidence for the effects of IT on the integration and supply-chain management of firms (Fort, 2014; Basco and Mestieri, 2018), which may provide an alternative ground for the higher benefits of IT for larger firms. ${ }^{9}$

Our paper further contributes to the literature that studies a number of recent secular macroeconomic trends across advanced economies. A number of papers have documented growing industry concentration and within-industry dispersion in firm outcomes (CEA, 2016; Andrews et al., 2016; Berlingieri et al., 2017). Indicators of business dynamism, such as the rate of startup formation, appear to be in decline across many advanced economies, particularly in the United States (Decker and Haltiwanger, 2013; Haltiwanger, 2015; Decker et al., 2015; Andrews et al., 2016; Decker et al., 2016; Karahan and Pugsley, 2016; Gutiérrez and Philippon, 2017). In parallel, there is a large body of work on a global fall in the labor share across many industries (Elsby et al., 2013; Karabarbounis and Neiman, 2014; Koh et al., 2015; Barkai, 2016; Grossman et al., 2017).

As we already discussed, IT capital has been put forth as a potential explanation for the trends above, ${ }^{10}$ and in particular for the fall in labor share through its potential substitution with labor (Karabarbounis and Neiman, 2014; Gaggl and Wright, 2017). However, another line of work in the literature questions the potential explanatory power of the substitution channel, given that most available estimates of the capital/labor elasticity of substitution are below unity (Lawrence, 2015), and given the micro evidence on the rise of labor share for the average firm (Kehrig and Vincent, 2017; Autor et al., 2017b,a). Our paper provides a mechanism that combines these two lines of thinking: as with the former, we take a production-side view for the macro effects of IT. As with the latter, we focus on firm heterogeneity and provide an explanation that rationalizes the cross-industry relationship between the rise in concentration and the fall in the labor share. In addition, our framework further allows us to account for potential responses in the aggregate

\footnotetext{
${ }^{8}$ For a direct application of this theory to the impacts of IT, see Bloom et al. (2014).

${ }^{9}$ Yet another explanation for the higher relative marginal product of IT among larger firms involves the life cycle process of product development. The idea is that early in the development of products, the process is heavy in customization for the (typically few) available customers. As the product develops and finds its position in the market, there is a shift of emphasis from customization toward standardization to save on costs and to effectively accommodate the growing number of customers. The process of standardization may in fact be a highly IT-intensive process, thereby implying that large and growing firms rely more heavily on IT compared to small and stagnating firms.

${ }^{10}$ We note that IT is one among the several mechanisms offered in the literature as the potential drivers of the observed macroeconomic trends. For instance, Crouzet and Eberly (2017, 2018), Gouin-Bonenfant (2018), Martinez (2018), Akcigit and Ates (2019), Hopenhayn et al. (2018), and Liu et al. (2019) have proposed the rise of intangible capital, productivity dispersion, automation, and the decline in knowledge diffusion, population growth, and interest rates as potential channels for these trends, respectively.
} 
profit share to the rise in the price of IT (Autor et al., 2017b; Barkai, 2016). ${ }^{11}$

Two recent theoretical papers that have proposed alternative mechanisms through which IT can provide an explanation for the recent secular macroeconomic trends. Aghion et al. (2019) provide a model of growth, innovation, and industry dynamics that interprets the rise of IT as a fall in the costs of operating multiple product lines. Mariscal (2018) develops a model of internal firm organization, in line with the literature discussed above, with an explicit role for IT in the managerial span of control. As with the model proposed here, both of these papers implicitly provide a role for IT in shaping variations in returns to scale across heterogeneous firms. Our paper constitutes a complementary contribution in that we provide micro-level empirical evidence on the patterns and an empirical model that allows us to interpret the observed patterns and to examine their implications.

The remainder of this paper is organized as follows. Section 2 presents the sources of the data, and Section 3 discusses our key empirical facts. Section 4 presents the theory, and Section 5 discusses our identification strategy for estimating the nhCES production function and the calibration results. Finally, Section 6 concludes the paper.

\section{Data}

For our empirical analysis, we rely on several sources of firm-level micro data produced by the French Institute of Statistics (INSEE). First, the Annual Survey of Firms (EAE) provides information on software investment at the firm level. Second, the RSI and BRN datasets, which are based on the firms' tax records, provide standard balance sheet information for firms below and above certain size thresholds, respectively. The BRN data further includes information on hardware investment of the firms within its coverage. Additionally, we rely on the employee-level DADS data and the Customs data for constructing certain proxies for the scale and scope of operation of firms. Finally, the unique firm identifier SIREN allows us to match these different sources of data at the firm level. In addition to these micro-level sources, we also rely on some aggregate and sectoral series for France based on data from INSEE National Accounts or the KLEMS dataset (Jäger, 2017). ${ }^{12}$ Below, we discuss these sources of data in more detail (Section E in the Appendix provides further details about the sources of the data used).

\footnotetext{
${ }^{11}$ Note that, in contrast to a number of recent other accounts of the fall of the labor share (e.g., De Loecker and Eeckhout, 2017; Baqaee and Farhi, 2017; Aghion et al., 2019), our model features efficient allocations and therefore our mechanism does not involve any changes in the level of allocative distortions.

${ }^{12}$ The dataset is available online at http://www.euklems.net.
} 


\subsection{Sources of Micro Data}

BRN and RSI are our two principal sources of data on firm activity in the universe of French firms. These datasets are based on administrative fiscal forms and are available starting 1984. They cover firms affiliated with the two main French tax regimes: BRN (Bénéfice Réel Normal) and RSI (Régime Simplifié d'Imposition). The BRN is the standard regime and the RSI is a simplified regime intended for small firms. Depending on their domain of activity, firms with revenues above a certain threshold must be affiliated with the BRN regime. ${ }^{13}$ These datasets provide information on the firm's number of employees, sales, value added, total and tangible investment, year of creation, industry, and location. Information on the disaggregated components of firm investment by asset types, including hardware investment, is available in the BRN files starting in 1989. While we rely on the whole sample of RSI and BRN firms for our measures of concentration and aggregate labor shares, we restrict our analysis of IT investment to firms that appear at least once in the BRN dataset, that have one or more employees, and that report positive value-added and wage bill (including taxes on labor). We also exclude outlier observations in which the firms report more investment and book value of capital (per employee) above certain thresholds. ${ }^{14}$ This data is broadly representative of the aggregate French economy: firms in our sample account for $74.9 \%$ of private value-added and $81.9 \%$ of private employment. ${ }^{15}$

The EAE (Enquete Annuelle d'Entreprises) is a survey-based dataset collected every year from 1982 to 2007 . The survey is conducted separately for each broad sector of the French economy (trade, transport, construction, manufacturing \& utility, agrifood, and services), with some variation in the list of questions asked and the sampling methods used. Overall, the data comprehensively covers medium and large firms, i.e., those with more than 20 employees, and surveys a sample of the smaller ones. ${ }^{16}$ Moreover, in more recent years, large firms are surveyed with a more comprehensive questionnaire that includes questions about software investment of firms. ${ }^{17}$

Most of our micro-level analyses in the paper rely on the two sources above. For a number of further analyses, we use two additional sources. We use the employee-level DADS data to find information on the number of plants and the organizational structure of the firm in terms of the occupational mix of employees. We also use the Customs data (after matching with the firm-level

\footnotetext{
${ }^{13}$ In 2007 , the thresholds were 763,000 euros if the firm operates in trade or real estate sectors, and 230,000 euros otherwise.

${ }^{14}$ For details about our trimming procedure, see Section $\mathrm{E}$ in the Appendix.

${ }^{15}$ Tables 1-3 in the online appendix present some summary statistics on the representativeness of the BRN dataset for the aggregate private sector of France, excluding agriculture, real estate, and finance.

${ }^{16}$ The only exception is manufacturing \& utility, in which only the large firms are surveyed.

${ }^{17}$ The criterion for inclusion is based on the employment size of the firm at the end of the previous year. This more comprehensive questionnaire has been applied in select sectors starting in 1989, and has been extended to all sectors starting in 1995. For more details on the criteria for coverage in EAE (as well as the other datasets used in the paper), see Section 2.2 in the online appendix.
} 
sources above) for information on the number of exported products and destination countries, as additional proxies for the scope of operation of firms (see Appendix $E$ for further information).

\subsection{Measures of IT Input}

The EAE files contain information on the investment of firms in software (Frouté, 2001). For three broad sectors of manufacturing, trade, and services, the survey further includes a disaggregation of software investments to those corresponding to: 1) software purchased from outside, 2) software created in-house, and 3) the investment made in existing software. ${ }^{18}$ For all other sectors, the survey only asks for the total investment in software, inclusive of all three components. We rely on the latter variable to maximize coverage. However, we also use the information on the disaggregated components of investment, when available, to ensure that they are compatible with the reported value of total investment in software.

The BRN files report the total investment of firms in office and computing equipment (Barbesol et al., 2008; Chevalier and Luciani, 2017). Despite including non-IT investment components such as office furniture, this component of investment in the BRN data provides, to our knowledge, the closest measure for hardware investments of firms in the universe of French firms. Therefore, we use this variable as our measure of investment in hardware and as our second indicator of IT investment, acknowledging the potential for measurement error due to the presence of non-IT components.

For each measure of investment, we proceed to construct measures of capital stock based on the observed investment flow measures. ${ }^{19}$ We employ asset-specific price deflators, depreciation rates, and aggregate level of capital stocks (distinct values for software, hardware, and the other components of capital) based on industry-level information available in the KLEMS dataset and the series constructed by INSEE. We use the EU KLEMS (September 2017 release, Jäger, 2017) to obtain depreciation rates by asset type for France. We rely on the INSEE Annual National Accounts (May 2018 release) for gross fixed capital stocks in current prices and gross fixed capital formation prices. This data provides the two measures at the level of 38 industries and for a number of different asset types. Section E.2 in the Appendix provides the complete details of the procedure for construction of capital stock variables and presents the information on price deflators and depreciation rates used.

In our analysis, we restrict attention to the following sectors: manufacturing, mining, utility, construction, trade, transportation, accommodation and food services, information and com-

\footnotetext{
${ }^{18}$ For the food sector, the information on sources of financing of the investment (either exterior or internal to the enterprise) is also provided in the survey.

${ }^{19}$ Our procedure closely follows that used by Bloom et al. (2012), who construct capital stock measures based on various surveys of IT expenditure in the UK. We note that the coverage of our IT data among French firms appears to be wider than that in the case of UK establishments (see Table 1).
} 
munication, and professional services, excluding agriculture, real estate, finance, public administration, education, and health. We focus on the period of 1995-2007 in our analysis, over which the coverage and representativeness of our IT investment measures appear stable. However, in our procedure to construct the stocks of capital discussed above, we initialize the corresponding stocks at the firm level for all firms that are present in the BRN data in 1989.

\subsection{Measures of Local Wages}

As we will discuss in Section 5.1, in our identification of the production funciton we rely on the series for the price of software relative to wages at the local level. The BRN and RSI files contain information about the municipality where the headquarters of the firm are located, as well as the 5-digits industry to which the firm belongs. We use this information to construct measures of average wages by 2-digits industry at the level of local employment area (Zone d'emploi). ${ }^{20} \mathrm{We}$ further rely on an instrument for the relative price of IT that follows the standard logic of Bartik (1991), relying on local variations on the industrial composition of employment. We compute an instrument capturing the predicted change in the labor demand in each employment area, based on the interaction of the initial composition of the wage bill in each employment area and the change in each industry's employment at the national level.

\subsection{Overview of the Data}

Table 1 presents the summary statistics of the main variables in our data. The table separately shows the summary statistics for the full sample, on the left, and for the sample of manufacturing firms, on the right. In the full sample, we have about 6.6 million firm-year observations, 5.9 millions of which are in the BRN files. We have observations of hardware investment (and capital) for this set of firms. For a subset of over 1.1 million firm-year observations, we also have corresponding observations in the EAE dataset that allows us to observe firms' software investments.

First, note that the average value of labor share (across firms) is fairly high and around $80 \%$, similar between manufacturing and non-manufacturing, and does not show strong skewness (since mean and median values are fairly close). Still, the data also suggests substantial heterogeneity in labor share across firms, with a standard error of around $34 \%$. In the next section, we will explore the extent to which the variations in labor share (within the industry) are driven by variations in firm size.

As the table shows, the distribution of both types of IT investment is highly skewed, much more so than that of the total investment. The modal firm invests zero in both software and hard-

\footnotetext{
${ }^{20}$ There are 364 employment areas, defined in 1990 as geographical units with more than 25,000 workers within which most of the workforce commutes. See the online appendix for details about the construction of local wages.
} 
ware, whereas the average firm invests over $10,700 €$ in software and $6,600 €$ in hardware annually (conditional on being surveyed). The values of investment are higher in manufacturing compared to other sectors. However, manufacturing firms are on average larger than non-manufacturing firms. As we will see below, the differences between sectors is less pronounced when we examine proxies of software and hardware intensity of firms.

Table 2 reports the intensive and extensive margins of software investment, separately for different classes of firm employment (in year 1996). ${ }^{21}$ The likelihood of reporting nonzero investment values is larger among larger firms. Conditional on reporting non-zero investment in software, both the median and mean of the values reported are also greater among larger firms. This relationship appears in all years in our data, e.g., we can observe it in 2006 (cf. Table 9 in the online appendix). Examining the data on hardware investment also shows a similar pattern (cf. Tables 10 and 11 in the online appendix).

As with the investment measures, our constructed measures of capital in Table 1 show evidence of skewness. The median firm has zero stocks of software and hardware capital, while the mean values of software and hardware capital stock are around 15,500€ and 23,300€, respectively. ${ }^{22}$

In our analysis, we introduce a number of proxies for IT intensity of firms. For both software and hardware, and for each of the investment (flow) and the capital (stock) measures, we define two proxies for intensity: first, intensity per worker (where we divide the values by the number of workers), and second, relative intensity (where we divide the values by the respective total value of investment or capital of the firm). As Table 1 shows, these intensity measures also inherit the skewness of the original measures: when in per-worker terms, the average investments in software and hardware are 50 and $200 €$, respectively, and those for software and hardware capital stock are $80 €$ and $469 €$, respectively. The medians are zero in all four cases. The averages of relative intensity measures are fairly small, with software constituting an average of only $2 \%(0.4 \%)$ and hardware of just above $6 \%(3.5 \%)$ of total investment (capital).

In general, these patterns may be driven by the differences in the industrial composition of different size classes. In the next section, we will investigate the relationship between IT intensity measures and different characteristics of firms such as size, age, and industry.

\footnotetext{
${ }^{21}$ The drop in the coverage of the data (as reflected in the number of observations) for firms with less than 20 employees is due to the design of the EAE survey.

${ }^{22}$ see Tables 12, 13, 14, and 15 in the online appendix for the values of IT capital stocks disaggregated by size class.
} 


\section{Facts}

In this section, we begin by using our data to revisit in the context of the French economy a number of trends that have been recently uncovered about the evolution of industry concentration and labor share in the US and across other OECD countries (Andrews et al., 2016; Autor et al., 2017b; Kehrig and Vincent, 2017; Berlingieri et al., 2017).

Next, we shift our attention to our newly constructed measures of IT intensity and document a number of facts on the heterogeneity in IT demand across firms. Here, we relate our measures of software and hardware intensity to firm size, age, industry, and a number of different indicators of the firms' scale and scope of operations. Finally, we explore the cross-sectional relationship between labor share and firm size.

\subsection{Macro Trends in France}

First, we examine the trends in the averages of a number of indices of market concentration across different industries in France in the period of 1990-2007. We compute for each 3-digit industry the share of total industry sales for the top $1 \%$, top $5 \%$, and the largest, the top 4 largest, the top 10 largest, and the top 20 largest of firms (all according to the distribution of sales within the industry). We then average those shares across all industries, weighting industries by their share in total sales. Figure 2 shows that the top $1 \%$ and $5 \%$ shares increased by around 8.1 and 6.4 percentage points on average across industries, while the shares of the top 1, 4, 10, and 20 largest firms increased by 2.3 to 4.1 percentage points. ${ }^{23}$

Second, we look at the evolution of the labor share in France within the same period. Figure 3 shows the cumulative change in the aggregate wage bill (including payroll taxes) as a share of aggregate value added for our sample of all BRN and RSI firms. In addition, it shows the contribution to this change of a within-industry (as opposed to cross-industry) component, when we keep industry shares of total value added constant from one period to the next. Over the course of the entire period, the aggregate labor share and the within-industry component have not substantially fallen in our data, with the former remaining around $70 \%$ of value added. However, our decomposition also shows that starting in 1995, the typical industry began experiencing a fall in sectoral labor share.

Following the strategy used recently by Kehrig and Vincent (2017) for the US data, we further decompose the average within-industry changes in labor share into that stemming from, first, the shifts in the industry's distribution of firm-level labor shares (keeping shares of firm-level value

\footnotetext{
${ }^{23}$ The initial value of the weighted averages of the top $1 \%$ and $5 \%$ share measures across industries in 1990 are $43.4 \%$ and $65.0 \%$, respectively. The corresponding numbers for the shares of the top 1, 4, 10, and 20 largest firms are $14.0 \%$ to $41.3 \%$ in that year.
} 
added constant), and second, the within-industry reallocations in value-added shares of different quantiles of labor share. Appendix $\mathrm{C}$ provides the full details of this decomposition exercise. Figure 3 presents the results of this decomposition and shows that, while for the typical firm the labor share increased by around 3.4 percentage points over the entire period (by 4.3 percentage points until 2006), the reallocations of market shares had a negative contribution of around -3.9 percentage points to the aggregate labor share.

Finally, Figure 4 shows that the two patterns above are linked. The correlation between 5-year changes in industry-level labor shares and concentration measures is negative, when the former is

proxied by each of the measures discussed above. In other words, the labor share has been falling relatively more in those industries where market shares have shifted more toward larger firms.

To summarize the evidence presented in this section, we find that starting in the 90s different measures of industry-level sales concentration rise in France. This is in line with the evidence cited earlier from US and several other OECD economies. We also find that, in contrast to the US and other OECD economies, the aggregate labor share does not appear to substantially fall in France. Nevertheless, we still come across strong similarities in the observed patterns from the perspective of heterogeneity across firms. When we decompose the evolution of the aggregate labor share to the component driven by the shift of the (unweighted) distribution of labor share and that driven by reallocations of value added across firms, a pattern similar to the US emerges. The distribution of labor share shifts to the right while the reallocations shift market shares toward low-labor share firms. In addition, just like the US, the labor share falls relatively more over time in industries where the concentration rises more.

\subsection{IT Intensity and Firm Scale}

In this section, we will provide evidence that the IT intensity of firms has a strong cross sectional correlation with the scale of operation of firms. We use different proxies for the firm's scale of operation, considering firm employment, sales, value added, and also more eclectic measures such as the number of plants, occupational layers, exporting products and destinations.

We begin our analysis by investigating the cross-sectional relationship between firm size and the intensity of IT demand across firms. For a firm $i$ in an industry $k$ at time $t$, we apply regressions of the form

$$
\text { IT Intensity } \text { it }=F E_{\text {Size }_{i t}}+F E_{k t}+F E_{a}+F E_{c}+v_{i t} \text {, }
$$

where IT Intensity ${ }_{i t}$ denotes a measure of the relative demand for IT inputs, $F E_{\text {Size }_{i t}}$, denotes the class-size dummy corresponding to the firm- $i$ 's number of employees at time $t$, and $F E_{k t}$ stands for a flexible set of industry-time fixed effects (at the 3-digit level). In addition, we further 
add age $F E_{a}$ and cohort $F E_{c}$ dummies to control for potential patterns of IT adoption in some specifications. ${ }^{24}$

Figure 5 shows the fixed effects of different size classes for each of our proxies of software and hardware intensity. ${ }^{25}$ In all cases, the fixed effects are computed relative to the fixed-effect of the size class corresponding to $0-5$ workers. We find a strong relationship between the software intensity of firms, both in terms of investment and capital, and their employment size. In per worker terms, a typical firm with more than 5,000 workers has a software investment (capital) intensity close to $€ 200(€ 300)$ per worker higher than firms with 0-5 workers. Relative to total investment (capital), a typical firm with more than 5,000 workers has a software investment (capital) intensity 3 percentage points ( 0.5 percentage points) higher than firms with $0-5$ workers. The IT intensity premium of larger firms is fairly sizable considering that, as we saw with the statistics provided in Table 1, the average software investment (capital) intensity of all firms is around $€ 50(€ 80)$ per worker or $4 \%(0.4 \%)$ of total investment (capital). Large firms therefore have a software intensity gap relative to the smallest firms in our data of around 1 to 4 times the average software intensity, depending on the measure. ${ }^{26}$ We find that the patterns above also broadly hold in the case of hardware. In per worker terms, large firms have hardware investment (capital) $€ 250(€ 1,000)$ per worker higher than small firms, or 1 to 2 times the average hardware intensity. ${ }^{27}$

Table 3 investigates the relationship between the firms' scale of operation and IT intensity using measures of firm output (rather than employment). The tables report the results of regressions like those in Equation (1), replacing firm employment dummies with the log of firm sales

\footnotetext{
${ }^{24}$ It is well-known that one cannot jointly identify age, cohort, and year fixed effects due to their collinearity. For this exercise, we apply one of the normalizations suggested by Deaton (2018) and attribute the growth of the dependent variable to year and cohort effects, and use the age effect to capture fluctuations in the dependent variable that average to zero over the life of the firm. In effect, this consists in rewriting the set of age dummies $F E_{a}$ as follows: $F E_{a}^{*}=F E_{a}-\left[(a-1) F E_{a=2}-(a-2) F E_{a=1}\right]$ and regressing (1) excluding all dummies corresponding to the first year, the first cohort, and ages 1 and 2 . The results do not change with or without including theses cohort/age/year fixed effects.

${ }^{25}$ Figure 3 in the online appendix shows the fixed effects of cohorts. In some cases, there appears to be a upward trend in newer cohorts of firms (e.g., software or hardware capital intensity) but we do not find a robust pattern in terms of IT intensity across firms.

${ }^{26}$ Note that the results include the variations in IT intensity both along the intensive and the extensive margins. The differences in IT investment patterns as a function of firm size also emerge if we only consider the extensive margin. Figure 2 in the online appendix shows that the extensive margin of investment grows in firm size for both software and hardware.

${ }^{27}$ The main exception is the relative intensity of hardware investment that initially rises but then somewhat falls among the largest firms. We believe this pattern is most likely driven by the fact that our measure of hardware investment includes non-IT related office equipments. The mentioned pattern is to a great extent driven by a group of mid-size firms that report $100 \%$ of their investments to be in office and computing equipment. When we restrict our analysis to the sample of 38,410 observations for which we are able to distinguish between computing equipment and non-IT office furniture equipment (firms in the agrifood industry sampled in EAE), computing investment relative to total investment or to hardware investment (computing plus office furniture) is increasing in size (see Figure 1 in the online appendix).
} 
or the log of value added. The regressions keep the industry/time fixed effects and controls for firm age and cohort of entry. As with the figures, Table 3 shows a strong effect of the scale of operation on the IT intensity of firms. From columns 1-2 of the table, raising the scale of firm output by a factor of 2 raises its software investment intensity by around $€ 14$ (against a mean of $€ 50$ ) in per worker terms, or by 0.3 percentage points (against a mean of around $0.4 \%$ ) relative to total investment. The corresponding numbers for the case of hardware investment intensity are around $€ 41$ (against a mean of $€ 200$ ) in per worker terms, and around 1 percentage point (against a mean of around $11 \%$ ) relative to total investment.

Columns 5-6 of the table show the same results with the logarithm of IT intensity of capital on the left-hand-side. ${ }^{28}$ The coefficients are in the 0.2-0.4 range, suggesting that raising the scale of firm output by a factor of 2 raises its capital intensity by about $20 \%$ to $40 \%$, with elasticities similar for software and hardware. Columns 3-4 and 7-8 show results for alternative measures of IT intensity, either over the wage bill or tangible capital. The coefficients remain sizable, significant, and comparable with our main measures of intensity in every case.

As we explained in Section 2.1, the EAE dataset only contains a representative sample of firms with below 20 employees. Similarly, the BRN dataset only includes a selected sample of firms below certain size thresholds. To the extent that our sample of small firms deviates from representativeness, one might expect that the observed firms should have higher IT intensity compared their unobserved counterparts. Therefore, such selection should arguably bias our estimates against finding a positive relationship between firm size and IT intensity. We note that the fixed effects of size appear mostly monotonic in size in Figure 5, even for firms well above the threshold of 20 employees. Furthermore, our results are robust to restricting the data to firms with increasingly larger thresholds of size..$^{29}$

\section{Other Measures of Firm Scale}

In addition to measures of firm input and output, we further investigate the relationship between IT intensity and a number of other proxies for the firm's scale of operation. There are a number of different margins along which firms can expand their scales: they can sell more of the same products to the same markets, they can sell the same products to more markets, and they can sell more products. The BRN data does not provide us with a decomposition of firm sales along

\footnotetext{
${ }^{28}$ Note that these regressions will focus only on the variations across firms in the intensive margin of IT demand.

${ }^{29}$ Tables 16-25 in the online appendix replicate the regressions above for samples of firms with employment sizes above 10, 20, 50, 100, and 250 thresholds. As with our baseline sample, the vast majority of the resulting estimated coefficients in these selected samples remain positive and significant, suggesting that the likely selection in the sample does not drive the observed relationship between size and IT intensity. Note that limiting the sample to firms with more than 10 employees (Tables 16 and 17 in the online appendix) particularly improves our results. This evidence suggests that the sample of firms with fewer than 10 workers in the EAE and BRN data are potentially biased toward high performing firms with unusually high IT intensities.
} 
these margins. Instead, we rely on customs data that allows us to gain a partial picture of these different margins in the international markets in the sample of exporting firms.

Table 4 presents the results of regressions of log capital intensity replacing the size fixed effects in Equation (1) with two other measures of the scale of international sales: the number of international markets (destination countries) and the number of exported products. In both cases, there is a positive relationship between the IT intensity of the firm and these proxies of the scale of operations of the firm. On average, exporting to a new market is associated with an increase in IT intensity of around $2 \%(3 \%)$ and exporting a new product with an increase of around $0.6 \%$ $(0.8 \%)$.

As we will see in the next section, we attribute the relationship between firm scale and IT intensity on the organizational demands that stem from more complex patterns of production as firms expand their scale. We rely on DADS data to find suggestive evidence that simple measures of organizational complexity of firms indeed appear to be correlated with IT intensity. Table 4 also presents the results of regressions of log capital intensity on the firm's number of plants and the number of occupational layers. The latter measures are constructed from the DADS data following Caliendo et al. (2015a). On average, adding a new plant is associated with an increase in the software (hardware) intensity of firms by $0.15 \%(0.40 \%)$, while adding an occupational layer with an increase of more than $20 \%$ (around 10\%).

\subsection{Labor Share and Firm Scale}

To conclude our facts, let us examine the cross-sectional relationship between firm size and labor share in the French data, applying a similar strategy as that used above for the case of IT intensity. We run fixed effects regressions of the form

$$
\text { Labor Share }_{i t}=F E_{\text {Size }_{i t}}+F E_{k t}+F E_{a}+F E_{c}+v_{i t},
$$

where the fixed effects have the same interpretation as those of Equation (1), and where Labor Share ${ }_{i t}$ denotes the ratio of the wage bill including payroll taxes to firm value added or sales. This allows us to revisit the patterns that Autor et al. (2017b) have documented in the context of the US data. ${ }^{30}$ Figure 6 presents the resulting fixed effects for different size classes for regressions of labor share in value added and sales, relative to firms between 10-20 workers. ${ }^{31}$ We find a strong negative relationship between labor share and firm size. Given this result, it is straightforward

\footnotetext{
${ }^{30}$ In the case of US data, data on firm-level value added is not available outside the manufacturing sector. Here, we are able to compare the patterns for the labor share measured both relative to sales and value added.

${ }^{31}$ We limit our analysis to firms with more than 10 employees because many small firms have very small estimated values of labor share, and we believe that our proxy for labor payments of these small firms is likely to be downwardly biased, due to the fact that it may not include the bulk of labor payments of the firm's owner.
} 
to explain the cross-sectional relationship in Figure 4, in which we reported a negative relationship between our different measures of concentration and the industry-level labor share. Since larger firms have lower labor shares, when the market shares get reallocated toward larger firms the labor share falls.

\section{Theory}

In this section, we provide a theory that rationalizes the empirical facts that we uncovered in the previous section. The core of the model is the characterization of a production function that features the following property: as a firm grows, the returns to scale in production falls due to the ensuing organizational complexities, but the IT inputs help circumvent this fall in returns to scale. ${ }^{32}$ We first discuss this production function in Section 4.1, and then construct a model of industry equilibrium in which this production function characterizes the production at the firm level. The model's predictions will match the micro-level empirical regularities, and we will use it to examine the aggregate implications of these micro facts in Section 4.2.

\subsection{A Production Function with IT and Organizational Limits to Scale}

In this section, we construct a nonhomothetic production function that generates a systematic relationship between firm size and the intensity of IT inputs. We will then investigate the properties of this production function and, in particular, focus on its implications for variations in returns to scale and output elasticities in terms of firm size.

\subsubsection{Motivating the Production Function}

Consider a production function $Y=\left(Z X_{N}\right)^{1 / \gamma}$ where $Y$ is the output, $X_{N}$ is a bundle of nonIT inputs, including capital and labor, and $Z$ is the productivity of the firm in terms of non-IT inputs. The parameter $1 / \gamma$ controls the returns to scale of the production function in terms of non-IT inputs, if the productivity $Z$ of the firm were to remain constant. However, as we will describe below, we will assume that the productivity $Z$ of the firm in terms of the bundle of non-IT inputs is a function of the scale of the firm. Therefore, the returns to scale endogenously varies with the scale of production and in general does not equal the value of this parameter.

\footnotetext{
${ }^{32} \mathrm{~A}$ simple alternative model is one in which adopting IT involves a fixed cost, making IT only profitable for firms above a certain level of productivity and size. Such a model implies a strong relationship between IT intensity and firm scale when comparing small and large firms. However, the model also predicts that the relationship should vanish as we restrict attention only to large firms. Tables $16-25$ in the online appendix show that we find a strong positive relationship between size and IT intensity even in our sample of large firms. This result suggests that a model with a single fixed cost of adopting IT may not provide a reasonable account of the observed patterns in our data.
} 
The productivity $Z$ of non-IT inputs depends on the firm's technology and organizational structure. We characterize this productivity as a CES aggregate of the firm's technological ability $A_{\text {tech }}$ and the organizational productivity of the firm $Z_{\text {org }}$ as:

$$
Z\left(Y, \frac{X_{I}}{X_{N}}\right)=\left(A_{\text {tech }}^{\frac{\sigma-1}{\sigma}}+Z_{\text {org }}\left(Y, \frac{X_{I}}{X_{N}}\right)^{\frac{\sigma-1}{\sigma}}\right)^{\frac{\sigma}{\sigma-1}}
$$

The idea is that, to produce output, the firm uses organization to apply a given technology of production to its bundle of inputs. The technology of production is non-rival, in the sense that the firm can apply it costlessly over any range of inputs. In contrast, the organizational productivity of the firm may potentially depend on its scale of operation and, as we will see shortly, how heavily it relies on IT inputs.

Next, we characterize the relationship between the organizational productivity of the firm $Z_{\text {org }}$ and the scale of production and the IT inputs of the firm. We assume organizational productivity varies with the scale of production $Y$ with an elasticity $-\epsilon$. However, the firm can raise its organizational productivity $Z_{\text {org }}$ by raising its IT inputs used for each unit of the bundle of non-IT inputs. Finally, this productivity also grows with the firm's intrinsic organizational ability $A_{\text {org }}$, which will form a source of heterogeneity in the model. All in all, we consider the following definition for the productivity $Z_{\text {org }}$ of the firm:

$$
Z_{\text {org }}\left(Y, \frac{X_{I}}{X_{N}}\right) \equiv \frac{X_{I}}{X_{N}} \times Y^{-\epsilon} \times A_{\text {org }} .
$$

Substituting for the productivity terms from the expressions above, we can see that the combination of inputs, output, and productivities satisfy the constraint

$$
\left(\frac{A_{t e c h} X_{N}}{Y^{\gamma}}\right)^{\frac{\sigma-1}{\sigma}}+\left(\frac{A_{o r g} X_{I}}{Y^{\gamma+\epsilon}}\right)^{\frac{\sigma-1}{\sigma}}=1
$$

For reasons that will become evident shortly, let us define the term involving the IT inputs in the expression above to be the IT share of the firm

$$
\Omega \equiv\left(\frac{A_{\text {org }} X_{I}}{Y^{\gamma+\epsilon}}\right)^{\frac{\sigma-1}{\sigma}} \in(0,1) .
$$

As we will see below, this variable constitutes a key sufficient statistic that characterizes the behavior of firms in response to a shock to the relative price of IT in our model. 
Under the specification above, the output elasticity of the bundle of non-IT is given by

$$
\frac{X_{N} \partial Y}{Y \partial X_{N}}=\frac{1-\Omega}{\gamma+\epsilon \Omega}
$$

Equation (5) helps us illustrate some key intuitions about the properties of this production function. First, consider a firm with constant IT inputs $X_{I}$. First note that, due to the endogeneity of the productivity term $Z$, the scale elasticity of the production function in terms of the bundle of non-IT inputs is less than the value $1 / \gamma$. Examining Equation (5), we find two margins that explain why output $Y$ grows less than proportionally to $X_{N}^{1 / \gamma}$, as we scale up the inputs $X_{N}$. The term involving IT share $\Omega$ in the numerator accounts for the the dependence of productivity $Z$ on $X_{N}$. With constant IT inputs, raising non-IT inputs results in a reduction in the IT inputs used per unit of non-IT inputs, and lowers the productivity. The term in the denominator accounts for the dependence of productivity $Z$ on the output $Y$. With constant IT inputs, raising non-IT inputs also lowers the productivity since it results in a rise in the scale of production.

Equation (5) further captures the role of IT in shaping the returns to scale of the firm. Consider the following parametric restriction: $\sigma<1$ and $\epsilon>0$. This restriction corresponds to the case where technology and organizational productivity are complements and the organizational productivity falls in the scale of output. In this case, the production function has the following important property. As we substitute IT inputs $X_{I}$ for non-IT inputs $X_{N}$ along the same isoquant $Y, \Omega$ falls and the output elasticity of the bundle of non-IT inputs rises for all combinations of inputs and output. This setting for the model parameters therefore captures the intuition that adopting IT allows firms to fight organizational decreasing returns and to raise the output elasticity of all other inputs.

\subsubsection{Properties of the Production Function}

To better understand the properties of the production function derived in Section 4.1.1, let us for now abstract away from the productivity terms and define a function $Y=\mathcal{F}\left(X_{N}, X_{I}\right)$ implicitly through the constraint

$$
\left(\frac{X_{N}}{Y^{\gamma}}\right)^{\frac{\sigma-1}{\sigma}}+\left(\frac{X_{I}}{Y^{\gamma+\epsilon}}\right)^{\frac{\sigma-1}{\sigma}}=1
$$

We furthermore assume that parameters $(\gamma, \sigma)$ are positive valued and $\epsilon$ satisfies $\epsilon>-\gamma$ to ensure the production function is globally monotonically increasing in both inputs. This production function belongs to the class of nonhomothetic CES (nhCES) production functions (Sato, 1974, 
1977; Hanoch, 1975; Comin et al., 2015). ${ }^{33}$ As with standard homothetic CES aggregators, the nhCES production function features a globally constant elasticity of substitution between IT and non-IT inputs. In addition, as we will see below, the production function above has a constant elasticity of relative factor demand with respect to output.

We can see these properties of the production function by solving the cost minimization problem for firm $i$. We find that the relative factor demand is given by

$$
\frac{X_{I}}{X_{N}}=\left(\frac{W_{I}}{W_{N}}\right)^{-\sigma} Y^{(1-\sigma) \epsilon}
$$

Equation (7) shows that the demand for IT capital relative to non-IT inputs depends on the size of output $Y$ and the two parameters $(\sigma, \epsilon)$. In addition, as with the standard CES production function, the demand for IT capital relative to non-IT inputs rises when the relative price of IT capital falls. Firms in this case substitute IT capital for labor. If $\epsilon=0$, we find the CES production function, in which the relative price is only determinant of the relative demand. When $\epsilon \neq 0$, relative demand systematically varies with output $Y$. For this reason, we will refer to parameter $\epsilon$ as the nonhomotheticity parameter.

Equation (7) further shows the conditions that we need in order for the production function to capture the facts that we uncovered in the previous section, regarding the relationship between the IT intensity of firms and their size. To ensure that the output elasticity of IT capital exceeds that of non-IT inputs, we make the following assumption on parameters of the production function.

Assumption 1. The nonbomotheticity parameter satisfies $\epsilon>0$ if $\sigma<1$, and $\epsilon<0$ if $\sigma>1$.

Under our desired parametric restriction $\epsilon>0$ and $\sigma \in(0,1)$, the intensity of IT inputs rises in output, which is in line with the facts that we saw in the previous section. The alternative setting $\sigma>1$ and $\epsilon<0$ is also in line with the facts. However, as we saw above, this case leads to the counterintuitive result that raising the IT inputs of the firm potentially lowers the output elasticity of non-IT inputs. For now, we will take Assumption 1 to characterize the leading case in our model. However, in the next section we will estimate the parameters of the production function and find that the data in fact supports this assumption.

Solving the cost minimization problem, we can also find the cost function, which is given by

$$
\mathcal{C}\left(Y ; W_{N}, W_{I}\right) \equiv Y^{\gamma}\left[W_{N}^{1-\sigma}+\left(Y^{\epsilon} W_{I}\right)^{1-\sigma}\right]^{\frac{1}{1-\sigma}} .
$$

\footnotetext{
${ }^{33}$ The general class of nonhomothetic CES preferences may be defined as $\left(X_{N} / \mathcal{F}_{N}(Y)\right)^{1-\frac{1}{\sigma}}+\left(X_{I} / \mathcal{F}_{I}(Y)\right)^{1-\frac{1}{\sigma}}=1$ for two monotonically increasing functions $\mathcal{F}_{N}(\cdot)$ and $\mathcal{F}_{I}(\cdot)$ (see also Hanoch, 1975; Russell and Blackorby, 1981; Comin et al., 2015). To distinguish the more specific class defined by Equation (6), Sato (1977) refers to the class of preferences as almost-homothetic nonhomothetic CES preferences. Here, to simplify the exposition, we will follow Hanoch (1975) and Comin et al. (2015) and use the broad term nonhomothetic CES (nhCES) to refer to the particular class defined by Equation (6), which further imposes a constant output elasticity of relative factor demand.
} 
Additionally, we can derive the share of IT inputs in total costs of the firm

$$
\Omega\left(Y ; W_{N}, W_{I}\right) \equiv \frac{W_{I} X_{I}}{\mathcal{C}\left(Y ; W_{N}, W_{I}\right)}=\frac{\left(Y^{\epsilon} W_{I}\right)^{1-\sigma}}{W_{N}^{1-\sigma}+\left(Y^{\epsilon} W_{I}\right)^{1-\sigma}} .
$$

It is straightforward to show that, under cost minimization, the share of IT in total costs (in terms of factor prices and output) defined in Equation (9) is equal to the IT share that we defined (in terms of factor inputs and output) in Equation (4). Hence, we use the same notation for both and interchangeably refer to both objects as the IT share or IT cost share.

To investigate the returns to scale under nhCES production functions, we find it easier to compute the cost elasticity $\mathcal{E}$, i.e., the ratio of the marginal to average costs:

$$
\mathcal{E}\left(Y ; W_{N}, W_{I}\right) \equiv \frac{Y \mathcal{C}^{\prime}(Y)}{\mathcal{C}(Y)}=\gamma+\epsilon \Omega\left(Y ; W_{N}, W_{I}\right) .
$$

The cost elasticity is the reciprocal of the scale elasticity and depends on factor prices and the scale of operations $Y$. Equation (10) shows that the cost elasticity is a linear function of the IT share: firms with higher IT shares have higher cost elasticities and lower returns to scale. Note, however, that this result holds under cost minimization. Relying on the motivation provided in the previous section, we can think of these firms as those that have adopted higher IT intensities as an optimal response to their lower levels of returns to scale.

Equation (10) helps illustrates an important consequence of Assumption 1 about parameters $(\sigma, \epsilon)$. As the IT share $\Omega$ of a firm rises, its cost elasticity rises (falls) if $\sigma<1(\sigma>1)$ and its scale elasticity falls (rises). As we saw in Equation (9), differences in the IT share of firms could stem either from differences in the relative factor prices $W_{I} / W_{N}$ that the they face or from differences in their scale of operation $Y$. The dependence on relative factor prices suggests that higher relative price of IT inputs results in lower (higher) returns to scale when $\sigma<1(\sigma>1)$. More interestingly, the dependence on size has the following important implication: larger firms operate with lower (Bigher) returns to scale when $\sigma<1(\sigma>1)$. We show in Appendix A that the latter insight generalizes beyond the nhCES production function, and extends to a wide set of production functions that satisfy nonhomothetic factor demand.

The next lemma characterizes the variations in cost elasticity, as captured by the scale elasticity of marginal costs.

Lemma 1. The output elasticity of the marginal costs is given by

$$
\frac{Y \mathcal{C}^{\prime \prime}(Y)}{\mathcal{C}^{\prime}(Y)}=\mathcal{E}(Y)\left(1+(1-\sigma) \frac{\mathcal{V}(Y)}{\mathcal{E}(Y)^{2}}\right)-1
$$


where we have suppressed the dependence on factor prices $\left(W_{N}, W_{I}\right)$ to simplify the expression and have defined $\mathcal{V}(\cdot)$ as the variance of the income elasticity parameters:

$$
\mathcal{V}(Y) \equiv \epsilon^{2} \Omega(Y)[1-\Omega(Y)]
$$

Proof. See Appendix B.

The lemma shows that the convexity of the cost function rises (falls) with the variance of the IT share $\Omega$ if $\sigma<1(1<\sigma)$. When $\sigma<1$, the conditions $\gamma>1$ and $\epsilon>0$ are sufficient to ensure that the marginal cost always exceeds average costs and the cost function is globally convex. Lemma 1 shows that the cost function may not be convex in general when $\sigma>1$, even if the scale elasticity parameter satisfies $\gamma>1$.

Below, we will frequently normalize the prices in terms of the price of non-IT inputs $W_{N}$, and therefore express the functions above in terms of the relative price of IT goods $W \equiv W_{I} / W_{N}$ as $\mathcal{C}(Y ; W) \equiv \mathcal{C}(Y ; 1, W), \Omega(Y ; W) \equiv \Omega(Y ; 1, W)$, and $\mathcal{E}(Y ; W) \equiv \mathcal{E}(Y ; 1, W)$.

\subsection{General Equilibrium Model}

We now construct a simple general equilibrium model of a monopolistically competitive industry. In the model, firms produce with the production function that we characterized in the previous section, featuring the nonhomotheticity of IT factor demand. We will use this model to examine the implications of the firm-level nonhomotheticity of the production function at the aggregate level.

\subsubsection{Economic Environment}

The economy is populated by a unit mass of identical, infinitely-lived consumers, who in each period inelastically supply a unit of labor in the market. The consumers choose their consumption to maximize

$$
\sum_{t} e^{t} \log U_{t}
$$

where the instantaneous utility $U_{t}=Y_{t}$ is defined over a continuum of goods $i \in \mathcal{J}_{t}$ according to a standard CES aggregator to be defined below. The value of the aggregator $Y$ when consumers choose the bundle $\left\{Y_{i}\right\}_{i \in \mathcal{I}}$ of goods is given by

$$
Y_{t}=\left(\int_{i \in \mathcal{J}_{t}} Y_{i t}^{\frac{\lambda-1}{\lambda}} d i\right)^{\frac{\lambda}{\lambda-1}} .
$$


Each firm produces a unique good $i$, with a production function given by

$$
Y_{i t}=\mathcal{F}\left(e^{\theta_{i t}} X_{N, i t}, e^{\theta_{i t}+\phi_{i t}} X_{I, i t}\right) \text {, }
$$

where $\mathcal{F}(\cdot, \cdot)$ is defined by Equation (6), and $\theta_{i t}$ and $\phi_{i t}$ are firm-specific factor-symmetric and ITbiased $(\log )$ productivity states of the firm. ${ }^{34}$ In addition, as before, $X_{N, i t}$ and $X_{I, i t}$ are constantreturns-to-scale (CRS) and Cobb-Douglas bundles of capital-labor, and software-hardware, respectively:

$$
\begin{aligned}
X_{N, i t} & =K_{i t}^{\alpha} L_{i t}^{1-\alpha}, \\
X_{I, i t} & =S_{i t}^{\beta} H_{i t}^{1-\beta},
\end{aligned}
$$

with $S_{i t}$ and $H_{i t}$ denoting the firm's stocks of software and hardware, respectively.

Each period, potential entrants can enter the industry subject to paying irreversible entry costs $\chi$ in units of the bundle of non-IT inputs. Once they enter, they draw their productivity pair $\left(\theta_{i t}, \phi_{i t}\right)$ from a distribution $F$ and start operating in that very period. We assume a Markov structure on the evolution of firm-level productivity, whereby the next-period productivity of an active firm $i$ is given by

$$
\left(\begin{array}{c}
\theta_{i t} \\
\phi_{i t}
\end{array}\right)=\left(\begin{array}{cc}
\rho_{\theta \theta} & \rho_{\theta \phi} \\
\rho_{\phi \theta} & \rho_{\phi \phi}
\end{array}\right)\left(\begin{array}{c}
\theta_{i t-1} \\
\phi_{i t-1}
\end{array}\right)+\left(\begin{array}{c}
\eta_{\theta} \\
\eta_{\phi}
\end{array}\right)+\left(\begin{array}{c}
u_{\theta, i t} \\
u_{\phi, i t}
\end{array}\right)
$$

where $\boldsymbol{u}_{i t} \equiv\left(u_{\theta, i t}, u_{\phi, i t}\right)^{\prime}$ is a vector of zero-mean and normally distributed innovations. In addition, we assume that the two productivity innovations $u_{\theta, i t}$ and $u_{\phi, i t}$ are uncorrelated and have variances $\chi_{\theta}^{2}$ and $\chi_{\phi}^{2}$, respectively. We consider the cases where all the eigenvalues of the matrix of persistence parameters lie within the unit circle, so that the process has a stationary long-run distribution. The parameters $\eta_{\theta}$ and $\eta_{\phi}$ control the long-run mean productivities of firms, as they mature.

We assume that firms have to expend a fixed cost $\psi$ in units of the bundle of non-IT inputs every period in which they operate. However, they can temporarily shut down operation in periods in which they do not find their operation to be profitable. In other words, if firms decide to endogenously exit the market, their decision to exit is reversible, and therefore does not corre-

\footnotetext{
${ }^{34}$ Note that $e^{\theta_{i t}}$ is not a Hicks-Neutral productivity. To see this, note that the production function defined here is almost-homogeneous in the terminology of Sato (1977), in the sense that it satisfies the following condition$$
\mathcal{F}\left(Z^{\epsilon_{N}} X_{N}, Z^{\epsilon_{I}} X_{I}\right)=Z \mathcal{F}\left(X_{N}, X_{I}\right),
$$

everywhere. Equation (15) shows that a Hicks-Neutral productivity term is not neutral with respect to IT and non-IT inputs.
} 
spond to an option value. ${ }^{35}$ Finally, we assume that in addition firms may receive an exogenous death shock with probability $\delta$ in each period, in which case they irreversibly exit the market.

We consider a very simple structure for factor markets, in which the supply of all factors are inelastic. As already mentioned, consumers inelastically supply one unit of (homogenous) labor in the market and earn wage $W_{L, t}$. Furthermore, in our theoretical analysis in this section, we assume all capital stocks, including the stocks of software and hardware, have constant and exogenously given total aggregate values $\bar{K}, \bar{S}_{t}$, and $\bar{H}_{t}$, where we allow the aggregate stocks of software and hardware to potentially vary over time. Finally, we normalize to unity the price of the bundle of non-IT inputs $1 \equiv\left(W_{L, t} /(1-\alpha)\right)^{1-\alpha}\left(W_{K, t} / \alpha\right)^{\alpha}$ and let $W_{t} \equiv\left(W_{H, t} /(1-\beta)\right)^{1-\beta}\left(W_{S, t} / \beta\right)^{\beta}$ denote the prevailing price of the bundle of IT inputs $X_{I, t}$ at time $t$.

Our analysis will focus on moving between two steady-states of the model, characterized by some initial stocks $\bar{S}$ and $\bar{H}$ and some final ones $\bar{S}^{\prime}$ and $\bar{H}^{\prime}$, and the corresponding relative prices of IT $W$ to $W^{\prime}$. Hence, we will focus on characterizing stationary equilibria where aggregate values do not vary over time. Therefore, we will drop the time indices to simplify the notation wherever it is clear from the context that the time dimension does not play a crucial role.

To characterize the equilibrium, we first consider the partial equilibrium cost minimization problem of the firm and solve for the allocations of inputs and outputs across firms (as functions of their productivity states). We will then aggregate the economy and enforce the factor input market clearing conditions to characterize the stationary general equilibrium of the economy.

\subsubsection{Problem of An Active Firm}

Let us first consider the problem of a firm with productivity state $\left(\theta_{i}, \phi_{i}\right)$ that decides to produce along a stationary equilibrium. It is straightforward to see that the optimal cost of this firm if it produces $Y_{i}$ satisfies $C_{i}=e^{-\theta_{i}} \mathcal{C}\left(Y_{i} ; e^{-\phi_{i}} W\right)$, where the cost function $\mathcal{C}(\cdot)$ is given by Equation (8) and, accordingly, factor cost shares follow Equation (9). The marginal cost for this firm is given by $M C_{i} \equiv e^{-\theta_{i}} \mathcal{C}^{\prime}\left(Y_{i} ; e^{-\phi_{i}} W_{I}\right)$, where the marginal cost function $\mathcal{C}^{\prime}(\cdot)$ is given by $\mathcal{C}^{\prime} \equiv \mathcal{E C} / Y$, and the cost elasticity $\mathcal{E}\left(Y_{i} ; e^{-\phi_{i}} W\right)$ in given by Equation (10).

Now consider the profit maximization problem of the firm. A firm with productivity $\left(\theta_{i}, \phi_{i}\right)$ chooses the price that solves the following problem

$$
\max _{Y_{i}} P\left(\frac{Y_{i}}{Y}\right)^{-\frac{1}{\lambda}} Y_{i}-\frac{1}{e^{\theta_{i}}} \mathcal{C}\left(Y_{i} ; \frac{W}{e^{\phi_{i}}}\right)-\psi
$$

\footnotetext{
${ }^{35}$ We have made this assumption merely to maintain the simplicity of our model while 1) preserving an active role for selection and 2) generating a stationary distribution of firm sales with levels of concentration that are in line with the observed data. We do not believe the option value of operation would play an important role in our setting.
} 
where, as usual, the aggregate CES price index for consumers is given by $P=\left(\int_{i \in \mathcal{J}} P_{i}^{1-\lambda} d i\right)^{\frac{1}{1-\lambda}}$, and we have used (8) as the definition of the firm cost function. Before providing the solution to the firm's problem, we consider the following assumption as a set of parametric restrictions on the model.

Assumption 2. Model parameters $(\gamma, \epsilon, \sigma, \lambda)$ satisfy the following constraints:

i. If $0<\sigma<1$, we have $\gamma>1-1 / \lambda$.

ii. If $1<\sigma$, we have $\gamma>1-1 / \lambda$, and

$$
\sigma<1+\frac{4}{\epsilon}\left(\gamma+\epsilon-1+\frac{1}{\lambda}\right)\left(1+\frac{\gamma}{\epsilon}\right)
$$

Assumption 2 provides an upper bound on the elasticity of substitution between IT and nonIT inputs that ensures the resulting firm-level cost function is everywhere convex. Under this assumption, the following lemma characterizes the firm's optimal choice of price and outputs.

Lemma 2. Consider relative factor prices $W$ and price index and aggregate output $(P, Y)$. Under Assumptions 1 and 2, the problem of a firm with productivity pair $\left(\theta_{i}, \phi_{i}\right)$ has a unique solution characterized by the optimal price

$$
\frac{P_{i}}{P}=\frac{\lambda}{\lambda-1} \frac{\mathcal{C}^{\prime}\left(Y\left(\frac{P_{i}}{P}\right)^{-\lambda} ; e^{-\phi_{i} W}\right)}{e^{\theta_{i} P}} .
$$

The optimal price $P_{i}$ and the corresponding optimal output $Y_{i}=Y\left(P_{i} / P\right)^{-\lambda}$ defined by Equation (19) are monotonically decreasing and increasing, respectively, in each of the two firm productivity states $\theta_{i}$ and $\phi_{i}$.

The lemma states that, under the conditions provided by Assumption 2, the solution to the firm problem has the same intuitive characteristics as those of the monopolistic competition models with a constant-returns to scale production function (Melitz, 2003). More productive firms charge lower prices, produce larger quantities, earn higher revenues, and hire more workers. It is also straightforward to show that the profit function defined in Equation (17) is increasing in $\theta_{i}$ and $\phi_{i}$.

\section{Allocations Across Active Firms}

Next, let us characterize the allocations of inputs and outputs across active firms along a stationary equilibrium. We note that Lemma 2 defines a decreasing pricing function $\widetilde{P}(\cdot, \cdot ; P, Y, W)$ in 
terms of the productivity pair

$$
\frac{P_{i}}{P} \equiv \widetilde{P}\left(\theta_{i}, \phi_{i} ; P, Y, W\right) .
$$

Correspondingly, the output for firm $i$ is given by $Y_{i}=Y\left(P_{i} / P\right)^{-\lambda}$ and we can define the following functions of the productivity pair $\left(\theta_{i}, \phi_{i}\right)$ to characterize the variations in costs, IT intensity, and cost elasticity across firms

$$
\begin{aligned}
C_{i} & =\widetilde{C}\left(\theta_{i}, \phi_{i} ; P, Y, W\right) \equiv e^{-\theta_{i}} \mathcal{C}\left(Y \widetilde{P}\left(\theta_{i}, \phi_{i}\right)^{-\lambda} ; e^{-\phi_{i}} W\right), \\
\Omega_{i} & =\widetilde{\Omega}\left(\theta_{i}, \phi_{i} ; P, Y, W\right) \equiv \Omega\left(Y \widetilde{P}\left(\theta_{i}, \phi_{i}\right)^{-\lambda} ; e^{-\phi_{i}} W\right), \\
\mathcal{E}_{i} & =\widetilde{\mathcal{E}}\left(\theta_{i}, \phi_{i} ; P, Y, W\right) \equiv \mathcal{E}\left(Y \widetilde{P}\left(\theta_{i}, \phi_{i}\right)^{-\lambda} ; e^{-\phi_{i}} W\right),
\end{aligned}
$$

where functions $\mathcal{C}, \Omega$, and $\mathcal{E}$ are defined by Equations (8), (9), and (10) in the previous section, and where we have suppressed the dependence of $\widetilde{P}(\cdot, \cdot ; P, Y, W)$ on the endogenous aggregates $(P, Y, W)$ to simplify the expressions. Finally, we can write the allocations of revenues and variable profits of firms as

$$
\begin{aligned}
& R_{i}=\widetilde{R}\left(\theta_{i t}, \phi_{i t}\right) \equiv \frac{\lambda}{\lambda-1} \tilde{\mathcal{E}}\left(\theta_{i}, \phi_{i}\right) \tilde{C}\left(\theta_{i}, \phi_{i}\right), \\
& \Pi_{i}=\widetilde{\Pi}\left(\theta_{i t}, \phi_{i t}\right) \equiv\left(\frac{\lambda}{\lambda-1} \widetilde{\mathcal{E}}\left(\theta_{i}, \phi_{i}\right)-1\right) \widetilde{C}\left(\theta_{i}, \phi_{i}\right),
\end{aligned}
$$

where, as before, we have suppressed the dependence of all functions on the endogenous aggregates (and will continue to do so henceforth for all allocation functions).

Inspecting these functions, we make a number of important observations. First, we find a linear relationship between the firm-level cost elasticity and the IT intensity of the firm, given by

$$
\tilde{\mathcal{E}}\left(\theta_{i}, \phi_{i}\right)=\gamma+\epsilon \widetilde{\Omega}\left(\theta_{i}, \phi_{i}\right) .
$$

This relation of course follows directly from Equation (10) and relies on cost minimization: larger firms that have higher cost elasticities also have higher IT intensities. Next, we note that Equation (21) provides us with another implication of the presence of nonhomotheticity across firms. Despite the fact that firms charge the same markups, the firm-level profit share $\frac{\lambda}{\lambda-1} \mathcal{E}_{i}-1$ still varies across firms, due to the variation in the returns to scale across firms. If we assume $\sigma<1$, larger firms that are more IT-intensive and therefore will also have higher cost elasticity $\mathcal{E}_{i}$, following Equation (22). Since they operate at a lower scale elasticity, the ratio of marginal-to-average cost, and therefore the profit share, is higher for them. As a result, the overall factor input share of their income, including the labor share, is lower. 


\section{Value Functions and the Stationary Distribution}

Since all firm decisions are static in the model, characterizing the dynamics and the value functions of firms Along a stationary equilibrium of this model, all the aggregate variables are constant and we can define the value function of the firm as one satisfying the following Bellman equation

$$
V\left(\theta_{i t}, \phi_{i t}\right)=\max \left\{\tilde{\Pi}\left(\theta_{i t}, \phi_{i t}\right)-\psi, 0\right\}+(1-\delta) \varrho \mathbb{E}\left[V\left(\theta_{i t+1}, \phi_{i t+1}\right) \mid \theta_{i t}, \phi_{i t}\right],
$$

where the conditional expected value operator is defined on random variables $\left(\theta_{i t+1}, \phi_{i t+1}\right)$ based on the Markov process in Equation (16). Note that due the stationarity of the equilibrium, the prevailing interest rate for the firm will be such that their effective discounting parallels those of the households, with a discount factor of $\varrho$.

We can now characterize the decision of firms to remain active to temporarily shut down in a given period as follows. With slight abuse of notation, we define a set $\mathcal{J}$ in the space of log productivity states

$$
\mathcal{J} \equiv\{(\theta, \phi) \mid \widetilde{\Pi}(\theta, \phi)-\psi \geq 0\} .
$$

Given the normal distributions that we have used in the characterization of the Markov structure, the support of the stationary distributions of the model in the space of productivities $(\theta, \phi)$ has unbounded support and corresponds to $\mathbb{R}_{+}^{2}$. However, the set of active firms are those that find it profitable to produce and therefore belong to the set $\mathcal{J}$.

Let us now define a distribution $G_{o}$ whose probability density function $g_{o}$ satisfies

$$
g_{o}(\theta, \phi)=\delta f(\theta, \phi)+(1-\delta) \iint \mathbb{P}(\theta, \phi \mid u, v) g_{o}(u, v) d u d v, \quad \forall(\theta, \phi)
$$

where the transition probability distribution function $\mathbb{P}(\cdot, \cdot \cdot, \cdot)$ is given by the following multivariate normal probability distribution function:

$$
\mathbb{P}(\theta, \phi \mid u, v) \equiv \mathcal{N}\left(\left(\begin{array}{cc}
\rho_{\theta \theta} & \rho_{\theta \phi} \\
\rho_{\phi \theta} & \rho_{\phi \phi}
\end{array}\right)\left(\begin{array}{c}
u \\
v
\end{array}\right)+\left(\begin{array}{c}
\eta_{\theta} \\
\eta_{\phi}
\end{array}\right),\left(\begin{array}{cc}
x_{\theta}^{2} & 0 \\
0 & x_{\phi}^{2}
\end{array}\right)\right) .
$$

The first condition in Equation (23) characterizes the endogenous stationary distribution of firm productivity states $(\theta, \phi)$ given the exogenous probability distribution function of entrants $f$ and the Markov structure of the evolution of productivity states given by $\mathbb{P}$. Along a stationary equilibrium, the rate of entry equates the exogenous rate of exit $\delta$, leading to the simple equation characterizing this stationary distribution. As a cohort of firms ages, the distribution of the productivity states of the surviving firms in the cohort converges to a stationary distribution given our assumptions on $\mathbb{P}$. The stationary distribution across the industry is distinct from this 
stationary distribution as it includes firms of all ages.

Distribution $G_{o}$ characterizes the distribution of log productivity states of all firms that exist in the economy along a stationary equilibrium, whether or not they are active in the product markets. Having defined this distribution, the stationary distribution $G$ of active firms is simply the conditional distribution of falling within the set $\mathcal{J}$, with a probability density function given by

$$
g(\theta, \phi) \equiv \begin{cases}\frac{g_{o}(\theta, \phi)}{\int_{\mathcal{J}} g_{o}(u, v) d u d v}, & (\theta, \phi) \in \mathcal{J} \\ 0, & \text { otherwise }\end{cases}
$$

\section{Cross Sectional Predictions}

We can now examine the cross-sectional relationship between firm size, IT intensity, and labor share and under the stationary distribution $G$ on productivity states $\left(\theta_{i}, \phi_{i}\right)$. First, let us consider the regression coefficient of $\log$ IT intensity on log firm size:

$$
\frac{\operatorname{Cov}\left(x_{I, i}-x_{N, i}, y_{i}\right)}{\operatorname{Var}\left(y_{i}\right)}=\frac{\operatorname{Cov}\left(\log \Omega_{i}, y_{i}\right)}{\operatorname{Var}\left(y_{i}\right)}=(1-\sigma) \epsilon+(\sigma-1) \frac{\operatorname{Cov}\left(\phi_{i}, y_{i}\right)}{\operatorname{Var}\left(y_{i}\right)},
$$

where the covariances and the variance are under the distribution $G$, and in the first equality we have used the fact that, in the cross section of firms, we have $x_{I, i}-x_{N, i}=\log \Omega_{i}+$ constant. This expression shows that the positive correlation between IT intensity and firm size that we documented in Section 3 can be driven by the condition $(1-\sigma) \epsilon>0$ that we imposed in Assumption (1). Alternatively, the expression shows that the positive correlations can be generated if there is a correlation between IT biased productivity $\phi_{i}$ and size $y_{i}$. In Section 5.1, we will use an identification strategy to separate these two components.

Next, we consider a regression of labor share on log size to find

$$
\operatorname{Cov}\left(\frac{W_{L} L_{i}}{P_{i} Y_{i}}, y_{i}\right)=(1-\alpha) \frac{1-\lambda}{\lambda} \operatorname{Cov}\left(\frac{1-\Omega_{i}}{\gamma+\epsilon \Omega_{i}}, y_{i}\right) \approx-\frac{1-\alpha}{\gamma} \frac{1-\lambda}{\lambda}\left(1+\frac{\epsilon}{\gamma}\right) \operatorname{Cov}\left(\Omega_{i}, y_{i}\right),
$$

where in the second equality we have used an approximation assuming $\Omega_{i} \ll 1$. Given we have seen that the IT share is correlated with size in the cross section, the expression above further predicts a negative relationship between labor share and firm size in the cross section. To the extent that this correlation is driven by nonhomotheticity $\epsilon \neq 0$, the relationship between labor share and size is also driven by our mechanism. To the extent that we have nonhomotheticity and $\epsilon / \gamma>0$, the expression above suggests that our mechanism further implies a tighter link between IT intensity and size, on the one hand, and labor share and size, on the other. 


\subsubsection{Stationary General Equilibrium}

To close the model, we need to determine the aggregate relative input price and price index $(W, P)$ as well as the output and the mass of varieties $(Y, N)$. Below, we provide a definition of a stationary general equilibrium of this model (see the derivations in Appendix B.1).

Definition 1. Tuple (W, $Y, P, N)$ and the stationary distribution $G$ together characterize the general equilibrium of the model if it satisfy the following conditions:

1. The probability density of function of the stationary distributions $G$ and $G_{o}$ satisfy Equations (23) and (24) for all $(\theta, \phi)$.

2. The CES aggregate the price index satisfies:

$$
1=N \iint \widetilde{P}(\theta, \phi ; P, Y, W)^{1-\lambda} g(\theta, \phi) d \theta d \phi
$$

3. Factor market clearing conditions for the bundles of non-IT and IT inputs hold:

$$
\begin{array}{r}
N\left[\psi+\iint(1-\widetilde{\Omega}(\theta, \phi ; P, Y, W)) \tilde{C}(\theta, \phi ; P, Y, W) g(\theta, \phi) d \theta d \phi\right]+N_{o} \delta \chi=\bar{X}_{N} \\
N \iint \widetilde{\Omega}(\theta, \phi ; P, Y, W) \widetilde{C}(\theta, \phi ; P, Y, W) g(\theta, \phi) d \theta d \phi=W \bar{X}_{I},
\end{array}
$$

where we have defined $\bar{X}_{N} \equiv \bar{K}^{\alpha} \bar{L}^{1-\alpha}$ and $\bar{X}_{I} \equiv \bar{S}^{\beta} \bar{H}^{1-\beta}$ and $N_{o} \equiv N / \int_{\mathcal{J}} g_{o}(u, v) d u d v$.

4. Free entry condition holds:

$$
\chi=\iint V(\theta, \phi ; P, Y, W) f(\theta, \phi) d \theta d \phi .
$$

We have already discussed the construction of the stationary distribution G. Equation (25) follows from the aggregation of the prices across a mass $N$ of firms with varying productivity states characterized by distribution $G$ and pins down the price index $P$.

The factor market clearing conditions pin down the total output $Y$ and the relative price of IT inputs $W$. The factor market clearing condition for non-IT inputs (26) ensures that the sum of non-IT variable inputs, fixed costs, and costs of entry paid by all active incumbents and entrants equates the total stock of non-IT inputs $\bar{X}_{N}$. The term outside the parentheses corresponds to the costs of entry, accounting for the fact that the mass of entrants is given by $\delta \times N_{o}$ where $N_{o}$ 
is the mass of all firms in the economy, satisfying $N=N_{o} \times \int_{\mathcal{J}} g_{o}(u, v) d u d v$. We can think of this market clearing condition as the resource constraint that determines the size of the economy and the total outputs $Y$. The IT factor market clearing condition (27) then pins down the relative price of IT inputs $W$. Factor market clearing conditions for the components of the two bundle of IT and non-IT inputs follow from the two upper level factor market clearing conditions. ${ }^{36}$

Finally, the free entry condition in Equation (28) ensures that the expected value of entry, given by the expression on the right hand side, equates with the costs of entry, paid in units of nonIt inputs. Note that even entrants that end up initially inactive still have non-zero expected net present value due to the fact that future shocks might make them active and therefore profitable.

Let us now derive the aggregate factor income shares under a stationary equilibrium. To this end, it will prove useful to define the share of a firm with productivity $(\theta, \phi)$ in the aggregate industry factor payments (costs) as

$$
S(\theta, \phi) \equiv \frac{\tilde{C}(\theta, \phi)}{\bar{C}} g(\theta, \phi),
$$

where we have defined the average factor expenditure (total costs) of firms as

$$
\bar{C} \equiv \iint \tilde{C}(\theta, \phi) g(\theta, \phi) d \theta d \phi
$$

We can now introduce two key aggregate variables that summarize the returns to scale properties of the aggregate economy. Define the factor-expenditure-weighted average of cost elasticity, henceforth average cost elasticity, $\tilde{\mathcal{E}}$, and the factor-expenditure-weighted average IT intensity $\bar{\Omega}$ as

$$
\begin{aligned}
& \bar{\Omega} \equiv \int \tilde{\Omega}(\theta, \phi) S(\theta, \phi) d \theta d \phi, \\
& \overline{\mathcal{E}} \equiv \int \tilde{\mathcal{E}}(\theta, \phi) S(\theta, \phi) d \theta d \phi=\gamma+\epsilon \bar{\Omega} .
\end{aligned}
$$

The last equality follows from the linearity of Equation (22), which implies that the aggregate values of the cost elasticity and IT intensity inheriting the same relationship.

Using the definitions above, we can now present the expressions for aggregate factor income shares. The share of each of the two main factors, IT and non-IT input bundles, are determined in two steps. First, aggregate income is split between owners of firms and all factors, with their respective shares determined endogenously based on aggregate cost (scale) elasticity. ${ }^{37}$ Next, the

\footnotetext{
${ }^{36}$ See Appendix B for the derivations.

${ }^{37}$ Note that in this analysis, to emphasize the key intuition for our results, we focus on the aggregate profit share
} 
total share of income accrued to the two factors gets split between IT and non-IT inputs, with their respective shares endogenously determined based on the aggregate IT intensity. Given the Cobb-Douglas aggregators of the bundle of IT and non-IT inputs, a constant share of each of the two bundles then gets split between each component, i.e., software and hardware in the case of IT and capital and labor in the case of non-IT. We can summarize these relations as follows: ${ }^{38}$

$$
\begin{aligned}
& \text { Aggregate Profit-to-Cost in Production }=\operatorname{Pt} C \equiv \frac{\bar{\Pi}}{\bar{C}}=\frac{\lambda}{\lambda-1} \overline{\mathcal{E}}-1, \\
& \text { Aggregate Labor Share in Production }=L S^{p r o d} \equiv \frac{W_{L} \bar{L}}{N \bar{R}}=(1-\alpha) \frac{\lambda-1}{\lambda} \frac{1-\bar{\Omega}}{\overline{\mathcal{E}}} .
\end{aligned}
$$

We can now use Equations (33) and (34) to draw intuitions about the drivers of aggregate profit and labor shares. Equation (33) shows that the aggregate profit shares only depend on the average cost elasticity $\overline{\mathcal{E}}$ across firms. When average cost elasticity rises, it implies that the returns to scale on average falls across firms and therefore the profit shares rise in the aggregate. As we can see in Equation (34), this also reduces the aggregate labor share, to the extent that the share of total firm income going to falls. In addition, the labor share of course positively depends on the average share of IT in total factor income $\bar{\Omega}$.

\subsubsection{Comparative Statics: Fall in the IT Price}

At this point, we are prepared to study what happens in the model when the price of IT inputs falls. Through the lens of the general equilibrium model, we can account for such a fall through a rise in the aggregate stock of IT inputs from $\bar{X}_{I}$ to $\bar{X}_{I}^{\prime}>\bar{X}_{I}$, which, all else equal, results in a fall in relative prices from $W$ to some $W^{\prime}<W$.

Under standard models, which focus on the substitution between IT and non-IT inputs, the impact of this shock manifests itself through a shift in the shares of of labor and IT capital. This will be reflected in the changes in the average share of IT in total factor income $\bar{\Omega}$. In our model, the change in IT prices further causes changes in the labor share through a shift in the shares of income between firm costs and profits. This new channel is captured in Equations (33) and (34) by the response in the average cost elasticity $\overline{\mathcal{E}}$. Due to the heterogeneity across firms in their cost elasticities $\mathcal{E}_{i}$, we can in turn decompose the change in the response of average cost

and labor share in the production sector. In addition, another component of the share of aggregate income of going to non-IT inputs in the model comes from the income paid by to these inputs through the fixed costs of incumbent active firms and through the entry costs paid in the entrepreneurship sector. However, we have made the assumption that all fixed and entry costs are paid in units of the bundle of non-IT inputs only for modeling convenience and therefore do not focus on the shifts of aggregate income share that stem from this channel.

${ }^{38}$ Note that the labor share in the model satisfies $W_{L} \bar{L}=(1-\alpha) \bar{X}_{N}$. Appendix B provides the derivations of Definition 1 and Equations (33) and (34). 
elasticity $\overline{\mathcal{E}}$ into the within and across-firms components. To make this decomposition more transparent, in the next section we apply a comparative statics exercise that provides us with firstorder approximations that illustrate the different channels shaping the response of the average cost elasticity $\overline{\mathcal{E}}$.

To better illustrate these forces, consider the effect of the small change $\Delta w \equiv \Delta \log W$ in the relative price of IT factor inputs, which in our model corresponds to rise in exogenous stocks $\bar{H}$, $\bar{S}$, or both. As we saw before, the behavior of aggregate profit and labor shares crucially depend on the response of the average cost elasticity $\overline{\mathcal{E}}$. We can decompose this response, to the first order of approximation, into the within-firm and the reallocation effects as

$$
\Delta \overline{\mathcal{E}} \approx \underbrace{\iint \Delta \widetilde{\mathcal{E}}(\theta, \phi) S(\theta, \phi) d \theta d \phi}_{\text {Within-firm Effect }}+\underbrace{\int(\theta, \phi) \Delta S(\theta, \phi) d \theta d \phi}_{\text {Reallocation Effect }},
$$

where $\Delta \mathcal{E}(\theta, \phi)$ captures the change in the cost elasticity of a firm with productivity $(\theta, \phi)$ in response to the change in the cost of IT inputs. Similarly, $\Delta S(\theta, \phi)$ stands for the change in the share of a firm with productivity $(\theta, \phi)$ in total factor-expenditure of all firms, which captures the shifts in market shares as the result of the change in the IT prices.

The within-firm change in the cost elasticity is given by (see Appendix B.1 for the derivation):

$$
\Delta \widetilde{\mathcal{E}}(\theta, \phi) \approx(1-\sigma) \epsilon \widetilde{\Omega}(\theta, \phi)(1-\widetilde{\Omega}(\theta, \phi))(\Delta w+\epsilon \Delta \tilde{y}(\theta, \phi)) .
$$

The first term on the right-hand-side captures the effect of IT/non-IT substitution on the cost elasticity of firms. With the falling price of IT, and as all firms substitute toward IT, the cost elasticity falls. Therefore, through this channel the rise of IT raises the returns to scale and therefore labor share within firms. The second term on the right-hand-side captures the indirect effect through the change in the output of the firm. The size of both these effects depends on the size of parameters $(1-\sigma) \epsilon$, the output elasticity of IT intensity, and the variance $\Omega_{i}\left(1-\Omega_{i}\right)$ of IT share for firm $i$.

We can compute the effect on cross-firm reallocation of total factor payments to find ${ }^{39}$

$$
\frac{\Delta S(\theta, \phi)}{S(\theta, \phi)} \approx(\gamma+\epsilon \widetilde{\Omega}(\theta, \phi)) \Delta \tilde{y}(\theta, \phi)+\widetilde{\Omega}(\theta, \phi) \Delta w-\Delta \bar{c} .
$$

The first term captures the effect of changes in output across firms, whereas the second term captures the direct effect of change in the price of IT on the costs of firms with productivity $(\theta, \phi)$.

\footnotetext{
${ }^{39}$ Appendix B presents the derivation of Equations (36) and (37).
} 
The key to understanding the reallocation effect response is understanding the heterogeneity in output response $\Delta \tilde{y}(\theta, \phi)$ of firms to the change in the IT prices. The following lemma characterizes the pass-through of the change in the IT prices into the output of firms.

Lemma 3. Change in the log price of firm $i$ in response to a small change $\Delta w$ in the log price of IT factor inputs is given by

$$
\Delta \tilde{y}(\theta, \phi) \approx \frac{1}{1+\lambda \frac{\partial m c}{\partial y}(\theta, \phi)}\left(-\lambda \frac{\partial m c}{\partial w}(\theta, \phi) \Delta w+\lambda \Delta p+\Delta y\right)
$$

where the IT price and output elasticities of marginal costs for firms with productivity $(\theta, \phi)$ are given by

$$
\begin{aligned}
& \frac{\partial m c}{\partial w}(\theta, \phi) \equiv \frac{\partial \log \mathcal{C}^{\prime}}{\partial \log W}=\widetilde{\Omega}(\theta, \phi)\left[1+(1-\sigma) \epsilon\left(\frac{1-\widetilde{\Omega}(\theta, \phi)}{\gamma+\epsilon \widetilde{\Omega}(\theta, \phi)}\right)\right], \\
& \frac{\partial m c}{\partial y}(\theta, \phi) \equiv \frac{\partial \log \mathcal{C}^{\prime}}{\partial \log Y}=\gamma-1+\epsilon \widetilde{\Omega}(\theta, \phi)\left[1+(1-\sigma) \epsilon\left(\frac{1-\widetilde{\Omega}(\theta, \phi)}{\gamma+\epsilon \widetilde{\Omega}(\theta, \phi)}\right)\right] .
\end{aligned}
$$

The first term in Equation (38) captures the key intuition behind the reallocation effect: when the price of IT falls, the direct effect on the marginal cost of firms, i.e., the elasticity of their marginal cost with respect to IT prices, varies across firms. In particular, Equation (39) shows how firms with a higher IT intensity may have a higher pass-through of the change in IT prices into the price of their final outputs. Note that the second equation above gives the output elasticity of marginal costs, defined in Equation (11).

All in all, the results of this section show that there are multiple different channels for the IT price to affect the average cost elasticity $\overline{\mathcal{E}}$. The within-firm effect and the reallocation effect may in general each go in the opposite directions. In the next section, we perform a quantitative exercise to gauge the direction and magnitude of these effects for the set of model parameters that match the broad moments of the data.

\section{Estimation and Calibration}

In this section, we bring the model developed in Section 4 to data and use it to explain the evolution of market concentration and labor share in response to the rise of IT. We follow the structure of the previous section and organize our approach in two stages. We first identify the production function of Section 4.1 in the micro data and provide evidence for the presence of nonhomotheticity. We then use the resulting estimates to calibrate the general equilibrium model of Section 
4.2 to show that the model can fit the broad patterns of changes in the labor share documented in Section 3.

\subsection{Estimating Production Function with Nonhomothetic IT Demand}

Let us set up an empirical counterpart to the economic environment that we defined in the previous section. As before, we define the production function as a function of labor, capital, software, and hardware as

$$
Y_{i t}=\mathcal{F}\left(e^{\theta_{i t}} K_{i t}^{\alpha} L_{i t}^{1-\alpha}, e^{\theta_{i t}+\phi_{i t}} S_{i t}^{\beta} H_{i t}^{1-\beta}\right),
$$

where function $\mathcal{F}(\cdot, \cdot)$ is the nonhomothetic CES function defined as before. Aside from the productivity terms, the production function is fully characterized with the tuple of parameters $\varsigma \equiv(\alpha, \beta, \gamma, \epsilon, \sigma)$. Henceforth, we will use the small cap letters to denote the logarithm of each corresponding variable, e.g., $y_{i t} \equiv \log Y_{i t}$.

We follow the literature on production function estimation and impose constraints on the timing and nature of firm decision making in order to identify the production function. Let us first start with the timing assumptions and define the information set of the firm in each period $t$ as follows.

Assumption 3. Let $\mathcal{I}_{t}$ denote the information set of the firm at time $t$, which includes the paths of all observables up to time $t$. We assume that $\theta_{i t}, \phi_{i t} \in \mathcal{I}_{i t}$ and all choices of the firm at time $t$, including capital, may depend on its information set $\mathcal{I}_{t}{ }^{40}$

Next, recall that we imposed a Markov structure on the evolution of productivities in Equation (16). We slightly generalize that process by allowing for a time-trend in the long-run averages of each of the two productivities, and define the vector of productivity state innovations as

$$
\boldsymbol{u}_{i t} \equiv\left(\begin{array}{c}
u_{\theta, i t} \\
u_{\phi, i t}
\end{array}\right)=\left(\begin{array}{c}
\theta_{i t} \\
\phi_{i t}
\end{array}\right)-\left(\begin{array}{cc}
\rho_{\theta \theta} & \rho_{\theta \phi} \\
\rho_{\phi \theta} & \rho_{\phi \phi}
\end{array}\right)\left(\begin{array}{c}
\theta_{i t-1} \\
\phi_{i t-1}
\end{array}\right)-\left(\begin{array}{c}
\eta_{\theta}+\mu_{\theta} t \\
\eta_{\phi}+\mu_{\phi} t
\end{array}\right) .
$$

We further allow for these innovations to have a general distribution but maintain that they are orthogonal to the information set of the firm at time $t$. Following the literature on dynamic panel data methods, this structure allows us to use the lagged choices of firms as instruments for current inputs, subject to controlling for current productivities. The next assumption summarizes our assumptions about the evolution of productivity states and will be crucial for deriving our moment conditions.

\footnotetext{
${ }^{40}$ Note that based on the accumulation equation that we have used to construct the stocks of capital (Equation 70 in the appendix), the firm's choices at time $t$ include its investment choices within that period, which is in turn within the information set of the firm at time $t$.
} 
Assumption 4. The evolution of the productivity states satisfies Markov structure in Equations (42) where $\mathbb{E}\left[\boldsymbol{u}_{i t} \mid \mathcal{I}_{t-1}\right]=(0,0)^{\prime}$.

Next, we characterize the potential frictions in firm decision making. Here, we relax our assumptions in the previous section on the frictionless nature of all factor input markets. In particular, we will allow for potential adjustment costs or other frictions in non-IT capital and hardware, but continue to rule out such adjustment costs for labor and software inputs. The resulting setup, summarized by Assumption 5 below, allows us to provide some generality to our account of input market frictions while maintaining one static first order condition in each of the two bundles of IT and non-IT inputs. This will allow us to derive one moment condition based on static cost minimization.

Assumption 5. Labor and software inputs are flexible and costlessly adjustable.

We rely on Assumptions 4 and 5 to derive moment conditions that allow us to identify the production function in the presence of two sources of unobserved heterogeneity. Our strategy combines two sets of moment conditions. The first set of moments, which come from the functional form of the production function, corresponds to the assumptions made on the factor-symmetric unobserved productivity state $\theta_{i t}$ and resembles the moment conditions used in standard production function estimation. The second set comes from cost minimization and corresponds to the assumptions made on the IT-biased productivity. The strategy closely parallels those employed recently by Oberfield and Raval (2014) and Doraszelski and Jaumandreu (2018) for estimating a homothetic CES production function, which is nested in our functional form if we restrict the model to $\epsilon=0$.

Let us next derive expressions that allow us to characterize the two unobserved productivity terms, IT-biased and factor-symmetric, as functions of observed data and the parameters of the production function.

\section{Cost Minimization and IT-biased Productivity}

Appendix D sets up the dynamic program of the firm under general forms of adjustment costs for non-IT capital and hardware, and uses Assumption 5 to derive the following result.

Lemma 4. Under Assumption 5, the firm's choices of inputs in each period satisfies

$$
s_{i t}-l_{i t}=\sigma\left(w_{L, t}-w_{S, t}\right)+(\sigma-1)\left[\phi_{i t}-\epsilon y_{i t}-\alpha\left(k_{i t}-l_{i t}\right)+(1-\beta)\left(b_{i t}-s_{i t}\right)\right] .
$$

The lemma generalizes the static cost minimization result we used in the previous section to accommodate potential adjustment costs for non-IT capital and hardware. First, note that if 
these two inputs are flexible, then the Cobb-Douglas aggregation of the two bundles of IT and non-IT pins down log factor input ratios $k_{i t}-l_{i t}$ and $h_{i t}-s_{i t}$ by the intensity parameters $\alpha$ and $\beta$, respectively. These two terms are therefore constant under flexible inputs, and we recover the standard cost minimization that we employed in the previous section.

In the presence of adjustment costs, the (log) capital to labor ratio $k_{i t}-l_{i t}$ and hardware to software ratio $h_{i t}-s_{i t}$ both vary over time and across firms (even within an industry). Therefore, the optimal choices of software to labor ratio $s_{i t}-l_{i t}$ depend, not only on relative prices $w_{L, t}-$ $w_{S, t}$, output $y_{i t}$, and IT-biased productivity $\phi_{i t}$, but also on the capital-to-labor and hardware-tosoftware ratios. ${ }^{41}$

This result allows us to derive a key moment condition that we will use to identify our core parameter $\epsilon$. Let $\boldsymbol{D}_{i t} \equiv\left(\widehat{w}_{i t}, l_{i t}, k_{i t}, s_{i t}, h_{i t}, y_{i t}\right)$ denote the vector of all relevant observations for firm $i$ at time $t$, where we have let $\widehat{w}_{i t} \equiv w_{S, t}-w_{L i, t}$ be the firm-specific relative price of software. ${ }^{42}$ Accordingly, we define a function $\Phi(\cdot ; \cdot)$ of observables and model parameters as

$$
\Phi\left(\boldsymbol{D}_{i t} ; \boldsymbol{\varsigma}\right)=\frac{1}{\sigma-1}\left(\sigma \widehat{w}_{i t}+s_{i t}-l_{i t}\right)+\epsilon y_{i t}+\alpha\left(k_{i t}-l_{i t}\right)-(1-\beta)\left(b_{i t}-s_{i t}\right) .
$$

Comparing Equation (44) and the expression in Equation (43) shows that function $\Phi$ indeed equates with the value of IT-biased productivity $\phi_{i t}$, conditional on the observed data for a given set of model parameters. As we will see below, when combined with our assumptions about timing of firm decisions, this result will provide us with one of the two sets of moment conditions.

\section{Production Function and Factor-symmetric Productivity}

Let us rewrite the expression for the production function (41) in terms of the logarithms of firm inputs and outputs as follows

$$
y_{i t}=\frac{1}{\gamma}\left\{\frac{\sigma-1}{\sigma} \log \left[e^{\frac{\sigma-1}{\sigma}\left(\alpha k_{i t}+(1-\alpha) l_{i t}\right)}+e^{\frac{\sigma-1}{\sigma}\left(\beta s_{i t}+(1-\beta) b_{i t}+\phi_{i t}-\epsilon y_{i t}\right)}\right]+\theta_{i t}\right\} .
$$

This expression implies that we can define a function $\Theta(\cdot ; \cdot)$ of observables and model parameters

$$
\Theta\left(\boldsymbol{D}_{i t} ; \varsigma\right) \equiv \gamma y_{i t}+\frac{\sigma}{1-\sigma} \log \left[e^{\frac{\sigma-1}{\sigma}\left(\alpha k_{i t}+(1-\alpha) l_{i t}\right)}+e^{\frac{\sigma-1}{\sigma}\left(\beta s_{i t}+(1-\beta) b_{i t}-\epsilon y_{i t}+\Phi\left(\widehat{w}_{i t}, l_{i t}, k_{i t}, s_{i t}, b_{i t}, y_{i t} ; \varsigma\right)\right)}\right],
$$

that equates with the value of factor-symmetric productivity $\theta_{i t}$.

\footnotetext{
${ }^{41}$ Note that this result also poses a challenge for alternative reduced-form identification strategies relying solely on demand shocks as potential instruments for output $y_{i t}$. Since output $y_{i t}$ may have an impact on capital-to-labor and hardware-to-software ratios, due potentially to adjustment costs or financial constraints, Equation (43) shows that we additionally needs instruments for the latter two ratios to identify $\epsilon$.

${ }^{42}$ As we will discuss below, we will use local wages $w_{L i, t}$ to compute the relative price of for firm $i$ at any point in time, as part of our strategy for the identification of $\sigma$.
} 


\section{Moment Conditions Based on Timing Assumptions}

Having expressed the unobserved productivity states $\left(\theta_{i t}, \phi_{i t}\right)$ in terms of observed data and model parameters as $(\Theta, \Phi)$, we can now substitute them in Equation (42) and use Assumption 5 to derive the following moment conditions:

$$
\mathbb{E}\left[\left(\begin{array}{c}
\Theta\left(\boldsymbol{D}_{i t} ; \varsigma\right) \\
\Phi\left(\boldsymbol{D}_{i t} ; \varsigma\right)
\end{array}\right)-\left(\begin{array}{cc}
\rho_{\theta \theta} & \rho_{\theta \phi} \\
\rho_{\phi \theta} & \rho_{\phi \phi}
\end{array}\right)\left(\begin{array}{c}
\Theta\left(\boldsymbol{D}_{i t-1} ; \varsigma\right) \\
\Phi\left(\boldsymbol{D}_{i t-1} ; \varsigma\right)
\end{array}\right)-\left(\begin{array}{c}
\eta_{\theta}+\mu_{\theta} t \\
\eta_{\phi}+\mu_{\phi} t
\end{array}\right) \mid \mathcal{I}_{t-1}\right]=\left(\begin{array}{l}
0 \\
0
\end{array}\right) .
$$

These moment condition can in principle identify all of the parameters of the production function. However, the identification of the elasticity of substitution $\sigma$ in this case does not rely on the variations in the relative price of software $\widehat{w}_{i t}$ as we do not have any corresponding instrument. ${ }^{43}$ Therefore, we amend our strategy with additional instruments for the relative price of software, as we will describe below.

\section{Moment Conditions Based on Relative Factor Price Instruments}

We include a final moment condition in our estimation to instrument for variations in relative price of software $\widehat{w}_{i t}$ at the regional level. For this purpose, we borrow from Oberfield and Raval (2014) and construct shift-share instruments $z_{i t}$ for local wages for each firm, using the initial local industrial composition and the change in each industry's wage bill at the national level. ${ }^{44}$ These instruments are correlated with current and past relative wages $w_{L, i t}$ and $w_{L, i t-1}$ and hence with relative prices of software $\widehat{w}_{i t}$ and their lagged values $\widehat{w}_{i t-1}$. We integrate these instruments in the same estimation framework by writing the following moment condition

$$
\mathbb{E}\left[\Phi\left(\boldsymbol{D}_{i t} ; \varsigma\right)-\left(\begin{array}{cc}
\rho_{\phi \theta} & \rho_{\phi \phi}
\end{array}\right)\left(\begin{array}{c}
\Theta\left(\boldsymbol{D}_{i t-1} ; \varsigma\right) \\
\Phi\left(\boldsymbol{D}_{i t-1} ; \varsigma\right)
\end{array}\right)-\left(\eta_{\phi}+\mu_{\phi} t\right) \mid z_{i t}\right]=0
$$

assuming that the shift-share instruments are orthogonal to innovations in contemporaneous ITbiased productivity. This is a weaker assumption than the typical assumption in the literature, which posits that the instruments are orthogonal to contemporaneous productivity rather than just productivity innovations (see, e.g., Oberfield and Raval, 2014).

We can use these system of moment conditions (46) and (47) to estimate the production function in a nonlinear 2SLS framework, using as instruments the shift-share instruments, the lagged values of labor, capital, software, hardware, as well as lagged productivities $\Theta\left(\boldsymbol{D}_{i t-1} ; \varsigma\right)$

\footnotetext{
${ }^{43}$ Instead, the identification of $\sigma$ based on Equation (43) would merely rely on variations in software-to-hardware $s_{i t}-h_{i t}$ and capital-to-labor ratios $k_{i t}-l_{i t}$, instrumented by their corresponding lagged values. Variations in these ratios across firms are driven by likely variations in distortions to the optimal choices of relative software-to-hardware and capital-to-labor ratios due to adjustment costs.

${ }^{44}$ See more detail about the construction of the instrument in Section 2 of the online appendix.
} 
and $\Phi\left(\boldsymbol{D}_{i t-1} ; \varsigma\right)$.

\section{Estimation Results}

Table 7 presents the estimated parameters of the production function for the sample of all firms and for the sample of manufacturing firms. For comparison, it also presents the estimated values of parameters under two standard production functions nested in our model: a homothetic CES production function, when we restrict the nonhomotheticity parameter to $\epsilon=0$, and a CobbDouglas production function, when we additionally assume $\sigma=1$. In the second case, the cost minimization equation does not deliver any information for the estimation and we drop it from the framework, leading to a standard dynamic-panel estimation of the Cobb-Douglas production function with four inputs: non-IT capital, labor, software, and hardware. ${ }^{45}$

Focusing first on our core parameter of interest $\epsilon$, we find precise, significant, and sizable positive estimates for this parameter in both samples $(\epsilon=0.39$ for all industries and $\epsilon=0.48$ in manufacturing). These estimated values reject the homotheticity of the production function. Importantly, the estimated elasticities of substitution in both samples are below unity $(\sigma=0.23$ for all industries and $\sigma=0.17$ in manufacturing). ${ }^{46}$ The combination of these two parameters indeed satisfy the condition proposed in Assumption 1, suggesting that the positive correlations between IT intensity and size that we uncovered are at least partially explained by the presence of nonhomotheticity. Importantly, the estimated elasticities of substitution also imply gross complementarity between IT and non-IT inputs. Despite the fact that we reject the homothetic CES, we still find that the estimated elasticity of substitution under a CES production function is also below 1 , although it appears biased downward in both samples.

We find similar estimates for the cost elasticity parameter $\gamma$ in both samples $(\gamma \approx 0.95)$ that imply increasing returns to scale for the firms as their size goes to zero. Importantly, the implication of these estimates for our production function is a systematic relationship between firm size and returns to scale. Recall that cost elasticity is the reciprocal of the scale elasticity. Therefore, the combination of point estimates for $\gamma$ and $\epsilon$ in the sample of all industries imply scale elasticities that range from 0.75 to 1.06 as we move from the largest to the smallest firms (the corresponding values are 0.70 and 1.05 for the sample of manufacturing firms). In contrast, under both CES and Cobb-Douglas production functions, the scale elasticity is constant across all firms. As we would

\footnotetext{
${ }^{45}$ See Appendix $\mathrm{D}$ for further details on the algorithm used for the estimation and for the schemes used for the estimation of the Cobb-Douglas and CES production functions.

${ }^{46}$ Oberfield and Raval (2014) and Doraszelski and Jaumandreu (2018) estimate the micro-level elasticity of substitution between capital and labor using identification strategies that account for potential factor-augmenting productivity shocks, and find values between 0.4 and 0.7 . An earlier set of macroeconomic estimates find values slightly higher but still below unity (e.g., Antràs, 2004; Klump et al., 2007; Chirinko, 2008). We also note that Karabarbounis and Neiman (2014) use an estimation strategy that relies on the cross-sectional variations in the industry-level data that finds a value above 1 .
} 
expect, the estimated values of the cost elasticity parameter $\gamma$ under these restricted models imply scale elasticities within the same range but fairly close to constant return to scale (e.g., in the sample of all industries, 1.01 under CES and 1.00 under Cobb-Douglas). These numbers are in line with most prior micro estimates of the returns to scale, but suggest a potential heterogeneity bias in those standard estimates.

Moving on to the other parameters, the values of the elasticity of non-IT capital and software are precisely estimated and imply lower output elasticities compared to labor and hardware, respectively. While the estimates for the elasticity of non-IT capital $\alpha$ appear fairly robust to misspecification (similar across the three production functions), the estimates for the software elasticity appear more sensitive to the specification. In particular, the Cobb-Douglas estimates are much larger (smaller) than those under the two CES specifications in the sample of all industries (manufacturing). We find fairly sizable autocorrelations $\left(\rho_{\theta \theta}, \rho_{\phi \phi}\right)$ in the dynamics of the two productivity states implying a high degree of persistence. However, we find very small, and precisely estimated, cross terms in the persistence coefficients $\left(\rho_{\theta \phi}, \rho_{\phi \phi}\right)$. The last set of results appear fairly robust under all specifications.

Figures 7, 8 and 9 provide the estimated parameters $\epsilon, \sigma$ and $\gamma$ across 17 industries at the A38 level of the aggregated NAF classification. ${ }^{47}$ These industries span most of the French market economy excluding real estate, finance and agriculture. Table 8 presents the results for the five main estimated parameters. First, note that the estimated values of the parameter $\epsilon$ are positive and significant for most of the industries. The mean and the median estimate across the industries are 0.86 and 0.57 , respectively. Second, estimated values of the parameter $\sigma$ are never significantly above 1 . The mean and the median estimate across the industries are 0.18 and 0.14 , respectively. Interestingly enough, our estimated values of the cost elasticity parameter $\gamma$ are generally close to 1 across industries (the mean and medians across industries are 0.94 and 0.97 , respectively). This is in line with most available estimates of the cost elasticity that are interpreted as evidence for constant returns to scale at the firm level. In our setting, these very estimates only imply (approximate) constant returns to scale for the lowest IT share firms.

\footnotetext{
${ }^{47}$ With 38 industries, the A38 level is more detailed than the 1-digit NAF level (10 industries) but more aggregated than the 2-digits NAF level (88 industries). Excluding agriculture, finance, real estate and nonmarket industries, our sample is comprised of 27 industries. Because some of those industries contain fewer than $\mathbf{5 0}$ observations in a given year, we construct three pooled industries (ICT, Research and Energy, mining and utilities), for a new total of 22 industries. For five of those industries, our estimation procedure failed to provide reasonable estimates: linear estimations for the accommodation and food services failed to converge, and nonlinear estimations for chemicals and "other manufacturing" industries also failed to converge. Estimations for the construction and ICT industries yield very large point estimates and standard errors for $\epsilon$ so we exclude those two industries from our main tables and figures. We are left with 17 industries, 13 of which are included in the manufacturing sector. Tables 26 and 27 and Figures 4-8 in the online appendix display results for some excluded industries except accomodation and food services.
} 


\subsection{Calibration}

In this section, we present the results of a simple calibration of the general equilibrium model of Section 4.2 to investigate its response to the fall in the relative price of IT inputs observed in Figure 1. We will first discuss our strategy for calibrating the model and will then examine the properties of the equilibrium in the two steady states corresponding to the initial (high) and final (low) relative prices of IT.

\section{Calibration Strategy}

There are two sets of parameters in the model: those that characterize the production function and the heterogeneity across firms in the corresponding productivity state variables, and those that characterize the other components of the economic environment, including preferences and the processes of entry and exit. To calibrate the first set of parameters, we mostly rely on the estimation results, based on the identification strategy in Section 5.1. In particular, we use the estimates reported in Table 7 for the parameters of the production function and for the Markov process governing the evolution of productivities in the sample of all industries. For the remainder of the parameters, we choose them aiming to closely match a number of relevant aggregate data moments.

The first and second sets of rows in Table 9 revisit the values of the parameters of the production function and the productivity process used in the calibration. There are only two parameters here that we do not directly estimate. The last row in the parameters of the production function corresponds to the fixed cost of operation $\psi$, which we have not estimated and therefore have to calibrate, as discussed below. The last row in the parameters of the productivity process corresponds to the variances $\left(\varkappa_{\theta}^{2}, \varkappa_{\phi}^{2}\right)$ of the two productivity innovations $\left(u_{\theta, i t}, u_{\phi, i t}\right)$, which we have not directly estimated but can still calculate based on the residuals found in our estimation results.

To fully characterize the model, we need to specify a functional form for the distribution $F$ of the productivities of entrants. Guided by the results of the estimation, we assume the following joint distribution for the productivities of entrants ${ }^{48}$

$$
F(\theta, \phi) \equiv \operatorname{TrunPareto}\left(e^{\theta} ; \xi_{o}, \underline{\theta}_{o}, \bar{\theta}_{o}\right) \times \mathcal{N}\left(\phi ; \bar{\phi}_{o}, \varkappa_{o}^{2}\right)
$$

\footnotetext{
${ }^{48}$ Figures $11-14$ in the online appendix display the distributions of $\theta$ and $\phi$ for entrants implied by the results of our estimation in the previous section. In particular, we provide evidence that the distribution of the factorsymmetric productivity $\theta$ among entrants has a Pareto tail. In contrast, the distribution for $\phi$ appears best described by a log-normal distribution.
} 
where the cumulative distribution function of the truncated Pareto distribution is given by

$$
F(\theta)=\frac{e^{-\xi_{o} \underline{\theta}_{o}}-e^{-\xi_{o} \theta}}{e^{-\xi_{0} \theta_{o}}-e^{-\xi_{o} \bar{\theta}_{o}}}
$$

and IT biased productivity state $\phi$ has a normal distribution with mean $\bar{\phi}_{o}$ and variance $\chi_{o}^{2}$. To calibrate the parameters $\left(\xi_{0}, \bar{\theta}_{0}\right)$, we rely on the productivity estimates that we uncovered in the previous section. Given the Pareto assumption and the independence between the distributions of $\theta$ and $\phi$, the right tail of the distribution of factor-symmetric productivity must correspond to the largest firms in the sample. Therefore, despite heavy selection in our sample toward larger entrants, we can still infer the behavior of the tail of the distribution based on the estimated $\theta \mathrm{s}$ among entrants (firms younger than one year). Similarly, we calibrate the variance $\chi_{0}^{2}$ of the distribution of IT biased productivity among entrants from data. We will come back to the calibration of the remaining two parameters $\underline{\theta}_{o}$ and $\bar{\phi}_{o}$ below.

Several of the model parameters can be directly matched to observable moments in the data, or values reported in prior work. For the exogenous probability of exit, we calibrate its value to the average rate of exit of large firms in our sample of around $\delta=0.04$. We calibrate the cost of entry $\chi$ to fit the number of firms per worker in our data $(N \approx 0.08)$, given all other parameters of the model. These two parameters appear in the last two rows of the parameters of the process of entry and exit. The last set of rows in Table 9 reports the parameters of the demand: we set the discount rate to be the value 0.95 , commonly assumed in the literature and, as discussed below, calibrate the elasticity of substitution among different firm products $\lambda$ along with the remaining model parameters.

To calibrate the set of four parameters $\left(\lambda, \psi, \underline{\theta}_{o}, \bar{\phi}_{o}\right)$, we perform a search in the set of model parameters to find those under which the model best fits the following four moments from the data in year 1990: ${ }^{49}$ two moments on market concentration (the share of top $1 \%$ and $5 \%$ of firms in total sales), in addition to aggregate labor share and aggregate IT intensity $(\bar{\Omega})$. For the first three moments, we use our micro data and compute them based on the pooled sample of BRN and RSI firms. For the last moment, since our sample of EAE firms where we observed IT intensities is not representative, we rely on the macro data series to find the aggregate IT intensity corresponding to $\bar{\Omega}$ in the model.

Table 10 shows the values of the targeted moments as observed in the data and as calculated in our calibrated model. For each moment, we have also indicated the corresponding model parameters that have been calibrated based on that moment. The calibrated distribution of factorsymmetric productivity states among entrants closely fits that found based on estimated values in

\footnotetext{
${ }^{49}$ We start the search with the following values for the model parameters: we use $\psi=0, \lambda=5$, for $\left(\underline{\theta}_{o}, \bar{\phi}_{o}\right)$ we start with the corresponding values based on the estimates in our sample of entrants.
} 
the data (the first three rows). By construction, the model also exactly fits the total mass of firms and the rate of exit among large firms (the last two rows). Among the four moments used for the parameter search, the model closely fits three: those corresponding to market concentration and IT intensity, while producing a value for the aggregate share of around $75 \%$, which is above the value observed in the data by around 4 percentage points.

The table further provides a number of untargeted moments, including the unweighted means of the distribution of labor share and IT intensity, and alternative measures of concentration, specifically, the standard deviations of the distributions of log sales and employment. Once again, the model closely fits the values for those corresponding to market concentration and IT intensity, while producing a value for the mean of the distribution of labor share that is somewhat larger than that observed in the data.

\section{Calibration Results}

We consider the response of the model to the fall in the price of IT that we observe in the data, in line with the patterns corresponding to the price of IT investment presented in Figure 1. In particular, the data suggests a fall in the relative price of the bundle of IT inputs from an initial level of $W=0.0203$ in the beginning of the 1990 s to around $W^{\prime}=0.0075$ by 2007 . The relative price of IT is constructed as the ratio of the price of the bundle of IT inputs to the price of the bundle of non-IT inputs, using $(\alpha, \beta)$ estimates from Table 7 and macro data for the user cost of software, hardware and average wage per worker in thousand euros. ${ }^{50}$ Since our estimates for the trend in $\phi$ are negligible, we take this to be the only shock to our model, and compute the new stationary general equilibrium of the model moving from $W$ to a new level of the relative price of IT corresponding to $W^{\prime}$.

Figure 10 shows how the responses of output, sales, share of firm in industry factor payments, and cost elasticity varies across firms, as a function of the firm's initial IT share $\Omega_{i}$. As we saw in the previous section, despite there being two productivity variables, the IT share $\Omega_{i}$ is a sufficient statistic for the responses of firms to this shock. From cost minimization, we know that the variations in $\Omega_{i}$, in turn, can be driven by variations in the IT-bias of productivity $\phi_{i}$. and variations in output $y_{i}$ (resulting from differences in both productivity states).

Figure 10 (A) shows the variations in the response of output across firms (corresponding to the result of Lemma 3). We find that the output (price) of high-IT share firms, which are typically

\footnotetext{
${ }^{50}$ See Section 2 of the online appendix for a discussion of the construction of the relative price of IT based on the series reported in the French national accounts. We note that the size of the fall in the IT prices that we used here is substantially lower than the values reported in recent work attempting to measure IT price indices focusing on proper adjustments of quality improvements (see, e.g., Byrne and Corrado, 2017). Since we partially rely on other macro values reported by INSEE, we choose to also rely on their series for the prices of IT inputs for consistency. We believe the resulting numbers are for this reason conservative predictions for the impacts of the rise of IT for factor shares of income.
} 
larger and more productive, rises (falls) considerably more than the output (price) of smaller and less productive firms. Figures 10 (B) and (C) show the changes in the sales and shares of firms in total production-sector factor payments. We find that the fall in the price of IT results in a large shift of market activity from low IT-share firms (typically smaller and less productive) to high IT-share firms (typically larger and more productive). This sets in motion the reallocation patterns that result in the shifts of the total factor shares toward those of these high IT-share firms: they have higher profit shares and pay a lower share of their generated income to labor and other factors.

Figure 10 (D) shows the within-firm effect on firms' cost elasticities (corresponding to Equation 36). We find that the cost elasticity of firms generally falls. Firms in the medium range of IT shares respond most strongly to this fall. This means that the scale elasticity of firms rises and their profit share, a pattern that diverges compared to that generated by the reallocations above.

Table 11 presents the response of the aggregate variables in the model to a fall in the price of IT inputs. As one would expect, in response to the fall in costs of using IT inputs, aggregate output mildly rises and the price index falls. The latter effect implies a rise in competition for all firms including entrants that are typically smaller than the average firms. As a result, the rate of entry falls.

More importantly, we find that despite the change in prices the average cost elasticity in the aggregate does not show a sizable response. This lack of response masks substantial compositional changes within the economy: a negative contribution from the within effect is accompanied by a positive contribution from the reallocation effect. Whereas firms leverage IT to raise their scale elasticities and reduce their cost elasticities, the reallocation toward low scale elasticity firms shifts the average cost elasticity upward. We find that the reallocation effect overall cancels out the withinfirm effect in the aggregate.

These patterns then reflect themselves in the response of the aggregate labor share (in the production sector). In particular, we find that the aggregate lack of response in labor share masks sizable changes in the within and across contributions: while within-firm labor share rises by around 2 percentage points, the reallocations contribute negatively by around the same amount. The corresponding values in the data, based on Figure 3, is around 4 percentage points.

As should by now be clear, these changes are accompanied by a rise in concentration in the industry. In particular, the shares of top $1 \%$ and $5 \%$ of firms in total sales rise by around 6 and 3 percentage points, while the corresponding values in the data (see Figure 2) are around 8 and 6 percentage points, respectively.

Therefore, we conclude that the model can explain around half of the changes in the industry concentration and the compositional changes in the aggregate labor share starting from 1990s, as the response to the fall in the relative price of IT inputs. 


\section{Conclusion}

In this paper, we presented novel data on the investment and capital stocks of firms in software and hardware in the universe of French firms. In our data, we found that the intensity of IT demand strongly and robustly correlates with firm size, using a broad set of different measures of IT intensity and firm size. Moreover, we argued that a production function featuring nonhomotheticity of IT factor demand fits this this empirical regularity, as well as an observed negative correlation between firm size and labor share. The latter holds assuming an elasticity of substitution between IT and non-IT inputs that falls below unity, and stems from lower returns-to-scale predicted by the model for larger firms.

We applied an identification strategy to estimate the production function and find that IT demand is indeed nonhomothetic and that the elasticity of substitution between IT and non-IT is indeed below one. These results imply that the marginal product of IT, relative to the marginal product of non-IT inputs, grows in firm size. We further provided a simple theoretical general equilibrium model of industry dynamics to study the aggregate implications of the firm-level nonhomotheticity of the production function. In particular, we showed that the resulting model predicts, just as we find in the data, that the observed fall in the price of IT results in a reallocation of market shares across firms toward those firms with higher IT intensity and typically larger size and market shares.

In this paper, we do not take a stance on the underlying forces that may give rise to nonhomothetic IT demand at the firm-level. However, we note that our results hold across a broad set of both IT producing and IT using industries. Therefore, we believe that these forces should involve the effects of IT on the operations of the firm, rather than the technological content of the produced product or service. For instance, the expenditures of firms on software observed in our data mainly correspond to the software products used in human resource management, consumer management, or supply chain and inventory management. On an intuitive level, it appears that these software solutions aim to address the complexity arising from managing large numbers of workers, customers, suppliers, products, and intermediate inputs. We hope to investigate the internal links between IT adoption and the organizational aspects of firm-level production in future research.

\section{References}

Acemoglu, Daron and David Autor, "Skills, Tasks and Technologies: Implications for Employment and Earnings," in “Handbook of Labor Economics, Volume 4B,” Vol. 4, Elsevier B.V., 2011, pp. 1043-1171. 2 
Aghion, Philippe, Antonin Bergeaud, Timo Boppart, Peter J. Klenow, and Huiyu Li, "A Theory of Falling Growth and Rising Rents," Federal Reserve Bank of San Francisco, Working Paper Series, 2019, (March), 01-43. 8

Akcigit, Ufuk and Sina T Ates, "What happened to US business dynamism?," 2019. 7

Akerman, Anders, Ingvil Gaarder, and Magne Mogstad, "The skill complementarity of broadband internet," Quarterly Journal of Economics, 2015, 130 (4), 1781-1824. 2, 6

Andrews, Dan, Chiara Criscuolo, and Peter N Gal, “The Best versus the Rest: The Global Productivity Slowdown, Divergence across Firms and the Role of Public Policy,” 2016. 4, 7, 13

Antràs, Pol, "Is the U.S. Aggregate Production Function Cobb-Douglas? New Estimates of the Elasticity of Substitution," Contributions in Macroeconomics, 2004, 4 (1). 39

Aral, Sinan, Erik Brynjolfsson, and D J Wu, "What came first, IT or productivity? The virtuous cycle of investment and use in enterprise systems," in "27th International Conference on Information Systems," Vol. 29 2006, pp. 9-33. 6

Autor, David, David Dorn, Lawrence F Katz, Christina Patterson, and John Van Reenen, "Concentrating on the Fall of the Labor Share," American Economic Review: Papers E Proceedings, 2017, 107 (5), 180-185. 2, 4, 7

_ , _ , , _ , and _ , "The Fall of the Labor Share and the Rise of Superstar Firms," MIT Working Paper, 2017. $2,4,7,8,13,17,56,57$

Autor, David H, Frank Levy, and Richard J Murnane, “The Skill Content of Recent Technological Change: An empirical Investigation,” Quarterly Journal of Economics, 2003, 118 (4), 1279-1333. 2

_ , Lawrence F Katz, and Alan B Krueger, "Computing Inequality: Have Computers Changed the Labor Market?,” The Quarterly Journal of Economics, 1998, 113 (4), 1169-1213. 2

Baqaee, David Rezza and Emmanuel Farhi, "Productivity and Misallocation in General Equilibrium.," 2017. 8

Barbesol, Yoann, Thomas Heckel, and Simon Quantin, "Élasticité de la production au capital informatique: estimations à l'aide de données d'entreprises," Économie et Statistique, 2008, 419 (1), 55-71. 10

Barkai, Simcha, "Declining Labor and Capital Shares,” 2016. 7, 8

Bartik, Timothy J, "Who Benefits from State and Local Economic Development Policies?," 1991. 11

Basco, Sergio and Martí Mestieri, "Mergers along the Global Supply Chain: Information Technologies and Routineness," Oxford Bulletin of Economics and Statistics, 2018, 80 (2), 406-433. 7 
Basu, Susanto and John G Fernald, "Returns to Scale in U. S. Production: Estimates and Implications," Journal of Political Economy, 1997, 105 (2), 249-283. 3

_, _, Nicholas Oulton, and Sylaja Srinivasan, "The Case of the Missing Productivity Growth, or Does Information Technology Explain Why Productivity Accelerated in the United States but Not in the United Kingdom?,” in “NBER Macroeconomics Annual,” Vol. 18 2003, pp. 9-63. 2

Berlingieri, G., P. Blanchenay, and C. Criscuolo, “The great divergences,” 2017. 7, 13

Bloom, Nicholas, Luis Garicano, Raffaella Sadun, and John Van Reenen, "The distinct effects of Information Technology and Communication Technology on firm organization," Management Science, 2014, 10 (12), 2859-2885. 7

_, Raffaella Sadun, and John Van Reenen, "Americans do IT better: US multinationals and the productivity miracle," American Economic Review, 2012, 102 (1), 167-201. 2, 10

Brynjolfsson, Erik and Shinkyu Yang, "Information Technology and Productivity: A Review of the Literature," Advances in Computers, 1996, 43, 179-214. 6

Byrne, David and Carol Corrado, "ICT Prices and ICT Services: What do they tell us about Productivity and Technology?," Finance and Economics Discussion Series, 2017, 2017 (015). 2, 43

Caliendo, Lorenzo and Esteban Rossi-Hansberg, "The Impact of Trade on Organization and Productivity," Quarterly Journal of Economics, 2012, 127 (3), 1393-1467. 7

_ , Ferdinando Monte, and Esteban Alejandro Rossi-Hansberg, "The Anatomy of French Production Hierarchies," Journal of Political Economy, 2015, 123 (4), 1-75. 7, 17

_ , Giordano Mion, Luca D Opromolla, and Esteban Rossi-hansberg, "Productivity and Organization in Portuguese Firms,” 2015. 7

CEA, "Benefits of competition and indicators of market power," Technical Report, Council of Economic Advisers Issue Brief 2016. 7

Chevalier, Charles Marie and Antoine Luciani, "ICT, Productivity and Employment in French Manufacturing Industries,” Technical Report, AFSE 2017. 10

Chirinko, Robert S., "Sigma: The long and short of it," Journal of Macroeconomics, 2008, 30 (2), 671-686. 39

Comin, Diego, Danial Lashkari, and Marti Mestieri, "Structural change with long-run income and price effects,” 2015. 5, 21

Crouzet, Nicolas and Janice Eberly, "Intangibles, Investment, and Efficiency," American Economic Review: Papers E Proceedings, 2017. 7 
_ and _ , "Understanding Weak Capital Investment : the Role of Market Concentration and Intangibles," 2018. 7

De Loecker, Jan and Jan Eeckhout, "The rise of market power and the macroeconomic implications," 2017. 8

Deaton, Angus S, The Analysis of Household Surveys: A Microeconometric Approach for Development Policy, World Bank Group, 2018. 15

Decker, Ryan A, John C Haltiwanger, Ron S Jarmin, and Javier Miranda, "Where has the skewness gone? The decline in high-growth (young) firms in the US," 2015. 7

_ , John Haltiwanger, Ron S Jarmin, and Javier Miranda, "Declining Business Dynamism: Implications for Productivity?," 2016. 7

Decker, Ryan and John Haltiwanger, "The Secular Decline in Business Dynamism in the U. S.," Manuscript, ..., 2013, (June), 1-58. 7

DeStefano, Timothy, Richard Kneller, and Jonathan Timmis, "The (Fuzzy) Digital Divide: Universal Broadband Access and Firm Performance Universal Broadband Access and Firm Performance,” 2014. 6

_ , _ , and _ , "Information Communication Technologies and Firm Performance: Evidence for UK Firms," 2016. 6

Doraszelski, Ulrich and Jordi Jaumandreu, "Measuring the Bias of Technological Change," Journal of Political Economy, 2018, 126 (3), 1027-1084. 2, 5, 36, 39

Draca, Mirko, Raffaella Sadun, and John Van Reenen, Productivity and ICTs: A Review of the Evidence 2009. 6

Eden, Maya and Paul Gaggl, "On the welfare implications of automation," Review of Economic Dynamics, 2018, 29 (November), 15-43. 2

Elsby, Michael W L, Bart Hobijn, and Ayşegül Sahin, “The decline of the US labor share,” Brookings Papers on Economic Activity, 2013, (2), 1-63. 2, 7

Erik Brynjolfsson, Lorin M. Hitt, “Computing productivity: Firm-level evidence," The Review of Economics and Statistics, 2003, 85 (4), 793-808. 6

Fort, Teresa C, “Technology and Production Fragmentation: Domestic versus Foreign Sourcing,” 2014. 7

Frouté, Olivier, "Estimates of GFCF in Software in France: Sources, Results and Outlook," Technical Report STD/NA(2001)26, OECD 2001. 10 
Gaggl, Paul and Greg C. Wright, "A short-run view of what computers do: Evidence from a UK tax incentive," American Economic Journal: Applied Economics, 2017, 9 (3), 262-294. 7

Garicano, Luis, "Hierarchies and the Organization of Knowledge in Production," Journal of Political Economy, 2000, 108 (5), 874-904. 6

- and Esteban Rossi-Hansberg, "Organization and Inequality in a Knowledge Economy," Quarterly Journal of Economics, 2006, 121 (4), 1383-1435. 6

Gouin-Bonenfant, Emilien, "Productivity Dispersion, Between-Firm Competition, and the Labor Share," 2018. 7

Grossman, Gene M, Elhanan Helpman, Ezra Oberfield, and Thomas Sampson, "The Productivity Slowdown and the Declining Labor Share : A Neoclassical Exploration ,” 2017. 7

Gutiérrez, Germán and Thomas Philippon, "Declining Competition and Investment in the U.S.," 2017. 7

Haltiwanger, John C, “Top ten signs of declining business dynamism and entrepreneurship in the US," 2015. 7

Hanoch, Giora, "Production and Demand Models with Direct or Indirect Implicit Additivity," Econometrica, 1975, 43 (3), 395-419. 21

Harrigan, James, Ariell Reshef, and Farid Toubal, "The march of the techies: technology, trade, and job polarization in France, 1994-2007,” 2016. 6

_ , _ , and _ , “Techies, trade, and skill-biased productivity,” 2018. 6

Hopenhayn, Hugo A., Julian Neira, and Rish Singhania, "From population prowth to firm demographics: implications for concentration, entrepreneurship and the labor share," 2018. 7

Jäger, Kirsten, "EU KLEMS Growth and Productivity Accounts 2017 Release - Description of Methodology and General Notes,” Technical Report, The Conference Board 2017. 8, 10

Jorgenson, Dale W, "Information Technology and the U.S. Economy," American Economic Review, 2001, $91(1), 1-32.2$

_ , Mun S Ho, and Kevin J Stiroh, "Growth of U. S. Industries and Investments in Information," in Carol A Corrado, John C Haltiwanger, and Daniel E Sichel, eds., Measuring Capital in the New Economy, University of Chicago Press, 2005, pp. 403-478. 2

Karabarbounis, Loukas and Brent Neiman, “The global decline of the labor share," Quarterly Journal of Economics, 2014, 129 (1), 61-103. 2, 7, 39 
Karahan, Fatih and Benjamin Pugsley, “Demographic Origins of the Startup Deficit,” 2016. 7

Kehrig, Matthias and Nicolas Vincent, "Growing productivity without growing wages: the micro-level anatomy of the aggregate labor share decline," 2017. 2, 4, 7, 13, 83

Klump, Rainer, Peter McAdam, and Alpo Willman, "Factor Substitution and Factor-Augmenting Technical Progress in the United States: A Normalized Supply-Side System Approach," Review of Economics and Statistics, 2007, 89 (1), 183-192. 39

Koh, Dongya, Raül Santaeulàlia-Llopis, and Yu Zheng, "Labor share decline and intellectual property products capital," 2015. 2, 7

Krusell, Per, Lee E Ohanian, Jose-Victor Ríos-Rull, and Giovanni L Violante, "Capital-Skill Complementarity and Inequality: a Macroeconomic Analysis,” 2000, 68 (5), 1029-1053. 2

Lawrence, Robert Z, "Recent declines in labor's share in US income: a preliminary neoclassical account," 2015. 7

Liu, Ernest, Atif R Mian, and Amir Sufi, “Low interest rates, market power, and productivity growth," 2019. 7

Mariscal, Asier, "Firm Organization and Information Technology : Micro and Macro Implications," 2018, pp. 1-37. 8

Martinez, Joseba, “Automation, Growth, and Factor Shares,” 2018. 7

Melitz, Marc J, “The Impact of Trade on Intra-Industry Reallocations and Aggregate Industry Productivity," Econometrica, 2003, 71 (6), 1695-1725. 26

Oberfield, Ezra and Devesh Raval, "Micro Data and Macro Technology,” 2014. 2, 5, 36, 38, 39

Oliner, Stephen D and Daniel E Sichel, “The Resurgence of Growth in the Late 1990s: Is Information Technology the Story?," Journal of Economic Perspectives, 2000, 14 (4), 3-22. 2

Russell, R Robert and Charles Blackorby, "The Morishima Elasticity Substitution; Symmetry, Constancy, Separability, and Its Relationship to the Hicks and Allen Elasticities," Review of Economic Studies, 1981, 48 (1), 147-158. 21

Sato, Ryuzo, "On the class of separable non-homothetic CES functions," Economic Studies Quarterly, 1974, 15, 42-55. 5, 20

_ , "Homothetic and Non-Homothetic CES Production Functions," American Economic Review, 1977, 67 (4), 559-569. 5, 21, 24 
Stiroh, Kevin, "Information technology and productivity: Old answers and new questions," CESifo Economic Studies, 2008, 54 (3), 358-385. 6

Stiroh, Kevin J, "Information Technology and the U.S. Productivity Revival: What Do the Industry Data Say?," American Economic Review, 2002, 92 (5), 1559-1576. 2

van Ark, Bart, Mary O’Mahony, and Marcel P Timmer, "The Productivity Gap between Europe and the United States: Trends and Causes," Journal of Economic Perspectives, 2008, 22 (1), 25-44. 2 


\section{Tables}

Table 1: Summary Statistics

\begin{tabular}{lcccccccc}
\hline & \multicolumn{3}{c}{ All firms } & \multicolumn{5}{c}{ Manufacturing firms } \\
& Obs. & Mean & Median & Sd & Obs. & Mean & Median & Sd \\
& $(\mathrm{Nb})$ & & & & $(\mathrm{Nb})$ & & & \\
\hline Sales & $6,610,529$ & $3,591.704$ & 585.557 & $79,833.412$ & 987,652 & $6,540.114$ & 830.390 & $70,468.868$ \\
Value-Added & $6,610,529$ & $1,043.134$ & 214.000 & $41,023.411$ & 987,652 & $1,985.866$ & 349.000 & $34,921.849$ \\
Number of Employees & $6,610,529$ & 20.928 & 5.000 & 609.978 & 987,652 & 35.644 & 9.000 & 206.175 \\
Labor Share & $6,539,620$ & 0.808 & 0.791 & 0.340 & 979,598 & 0.818 & 0.795 & 0.313 \\
Total Investment & $5,886,407$ & 155.822 & 7.000 & $10,127.683$ & 901,246 & 301.017 & 16.464 & $4,299.071$ \\
Total Capital & $6,610,529$ & $1,160.841$ & 87.298 & $89,164.311$ & 987,652 & $2,597.479$ & 217.710 & $30,583.961$ \\
Software Investment & $1,338,935$ & 10.755 & 0.000 & 712.345 & 277,733 & 20.268 & 0.000 & 340.489 \\
Software Capital & $2,495,553$ & 15.456 & 0.000 & $1,201.477$ & 380,957 & 40.940 & 0.708 & 721.715 \\
Hardware Investment & $5,886,407$ & 6.607 & 0.000 & 414.991 & 901,246 & 10.202 & 0.000 & 181.082 \\
Hardware Capital & $6,610,529$ & 23.338 & 0.000 & $1,794.069$ & 987,652 & 45.739 & 0.000 & 665.723 \\
\hline IT Per Worker & & & & & & & & \\
Software Investment & $1,338,935$ & 0.050 & 0.000 & 0.223 & 277,733 & 0.092 & 0.000 & 0.263 \\
Software Capital & $2,495,553$ & 0.080 & 0.000 & 3.176 & 380,957 & 0.220 & 0.021 & 7.824 \\
Hardware Investment & $5,886,407$ & 0.200 & 0.000 & 0.801 & 901,246 & 0.126 & 0.000 & 0.481 \\
Hardware Capital & $6,610,529$ & 0.469 & 0.000 & 2.395 & 987,652 & 0.399 & 0.000 & 1.239 \\
\hline IT Relative Intensity & & & & & & & & \\
Software Investment & $1,163,277$ & 0.038 & 0.000 & 1.513 & 266,704 & 0.040 & 0.000 & 0.687 \\
Software Capital & $2,338,353$ & 0.004 & 0.000 & 0.022 & 371,891 & 0.006 & 0.001 & 0.019 \\
Hardware Investment & $4,672,543$ & 0.114 & 0.000 & 1.554 & 771,381 & 0.071 & 0.000 & 1.403 \\
Hardware Capital & $5,941,640$ & 0.039 & 0.000 & 0.129 & 917,040 & 0.019 & 0.000 & 0.072 \\
\hline
\end{tabular}

Note: All amounts are $\mathrm{K} €$. Labor share is defined as the sum of wage bill and payroll taxes divided by values-added. Software investment is observed on the EAE sample, and hardware and total investment on the BRN sample. Capital measures are built using the Perpetual Inventory Method (PIM), imputing zero investment for missing data. IT capital is reported for all firms that are appeared at least once in EAE or BRN. Data Appendix E describes the sources for each variable. 
Table 2: Software Investment Summary Statistics (1996)

\begin{tabular}{|c|c|c|c|c|c|c|c|}
\hline \multirow[t]{2}{*}{1996} & \multicolumn{4}{|c|}{ Number of Firms } & \multicolumn{2}{|c|}{ Average values } & \multirow{2}{*}{ 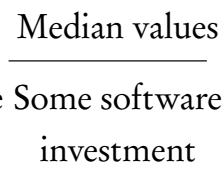 } \\
\hline & All & EAE & $\begin{array}{l}\text { No software } \\
\text { investment }\end{array}$ & $\begin{array}{c}\text { Some software } \\
\text { investment }\end{array}$ & EAE & $\begin{array}{c}\text { Some software } \\
\text { investment }\end{array}$ & \\
\hline $0-5$ & 206,385 & 10,551 & 10,517 & 34 & 0.01 & 2.58 & 2.21 \\
\hline $5-10$ & 131,300 & 13,538 & 13,266 & 272 & 0.08 & 4.17 & 1.83 \\
\hline $10-20$ & 56,554 & 11,658 & 10,788 & 870 & 0.51 & 6.81 & 2.90 \\
\hline $20-50$ & 47,232 & 32,496 & 26,155 & 6,341 & 1.64 & 8.38 & 3.51 \\
\hline $50-100$ & 10,991 & 9,406 & 6,404 & 3,002 & 4.71 & 14.77 & 6.10 \\
\hline $100-250$ & 6,956 & 6,158 & 3,602 & 2,556 & 11.95 & 28.80 & 10.98 \\
\hline $250-500$ & 2,111 & 1,960 & 966 & 994 & 31.71 & 62.53 & 31.86 \\
\hline $500-1000$ & 916 & 880 & 362 & 518 & 91.07 & 154.71 & 70.51 \\
\hline $1000-2500$ & 445 & 427 & 161 & 266 & 237.96 & 381.98 & 158.01 \\
\hline $2500-5000$ & 119 & 112 & 42 & 70 & 517.22 & 827.55 & 401.09 \\
\hline+5000 & 55 & 51 & 18 & 33 & 5741.85 & 8873.76 & 759.20 \\
\hline
\end{tabular}

Note: The first column denote the class size in terms of BRN employment. Columns (2)-(5) count the number of firms for each of the four samples, in each class size : all firms in 1996, firms sampled in EAE in 1996, of which firms that declared zero or missing software investment, and firms that declared positive software investment. Columns (6)-(7) display average software investment for all firms in EAE in 1996 and those that declared positive investment. Column (8) displays median software investment for firms that declared positive software investment. 
Table 3: Regressions of IT Intensity on Log Firm Size

\begin{tabular}{|c|c|c|c|c|c|c|c|c|}
\hline & \multicolumn{4}{|c|}{ Investment } & \multicolumn{4}{|c|}{ Log Capital } \\
\hline & Workers & Workers & Wage Bill & Wage Bill & Workers & Workers & Wage Bill & Wage Bill \\
\hline \multicolumn{9}{|c|}{ Panel 1 : Software Intensity } \\
\hline \multirow[t]{2}{*}{ Size (proxied by sales) } & 0.0205 & & 0.5034 & & 0.3650 & & 0.3115 & \\
\hline & $(0.0001)$ & & $(0.0029)$ & & $(0.0031)$ & & $(0.0031)$ & \\
\hline \multirow[t]{2}{*}{ Size (proxied by VA) } & & 0.0211 & & 0.5191 & & 0.3458 & & 0.2933 \\
\hline & & $(0.0001)$ & & $(0.0030)$ & & $(0.0033)$ & & $(0.0033)$ \\
\hline Observations & $1,145,874$ & $+1,146,068$ & $1,145,917$ & $1,146,115$ & 575,594 & 575,686 & 575,579 & 575,676 \\
\hline $\mathrm{R} 2$ & 0.0911 & 0.0896 & 0.0840 & 0.0829 & 0.2396 & 0.2356 & 0.2281 & 0.2249 \\
\hline \multicolumn{9}{|c|}{ Panel 2: Hardware Intensity } \\
\hline \multirow[t]{2}{*}{ Size (proxied by sales) } & 0.0412 & & 0.8812 & & 0.2630 & & 0.2031 & \\
\hline & $(0.0002)$ & & $(0.0052)$ & & $(0.0007)$ & & $(0.0007)$ & \\
\hline \multirow[t]{2}{*}{ Size (proxied by VA) } & & 0.0323 & & 0.5930 & & 0.1991 & & 0.1289 \\
\hline & & $(0.0002)$ & & $(0.0054)$ & & $(0.0008)$ & & $(0.0008)$ \\
\hline Observations & $4,340,454$ & $4,341,159$ & $4,340,014$ & $4,340,853$ & $2,839,365$ & $2,839,569$ & $2,839,373$ & $2,839,754$ \\
\hline \multirow[t]{2}{*}{ R2 } & 0.1647 & 0.1607 & 0.1386 & 0.1353 & 0.4188 & 0.4068 & 0.3823 & 0.3718 \\
\hline & Total & Total & Tangible & Tangible & Total & Total & Tangible & Tangible \\
\hline \multicolumn{9}{|c|}{ Panel 3 : Software Rel. Intensity } \\
\hline \multirow[t]{2}{*}{ Size (proxied by sales) } & 0.0044 & & 0.0053 & & 0.2779 & & 0.2842 & \\
\hline & $(0.0000)$ & & $(0.0000)$ & & $(0.0032)$ & & $(0.0032)$ & \\
\hline \multirow[t]{2}{*}{ Size (proxied by VA) } & & 0.0047 & & 0.0056 & & 0.2899 & & 0.2980 \\
\hline & & $(0.0000)$ & & $(0.0000)$ & & $(0.0034)$ & & $(0.0035)$ \\
\hline Observations & $1,127,629$ & $1,127,816$ & $1,117,482$ & $1,117,639$ & 530,334 & 530,395 & 529,045 & 529,104 \\
\hline $\mathrm{R} 2$ & 0.0820 & 0.0826 & 0.0756 & 0.0762 & 0.2346 & 0.2341 & 0.2350 & 0.2346 \\
\hline \multicolumn{9}{|c|}{ Panel 4: Hardware Rel. Intensity } \\
\hline \multirow[t]{2}{*}{ Size (proxied by sales) } & 0.0172 & & 0.0198 & & 0.2134 & & 0.2279 & \\
\hline & $(0.0001)$ & & $(0.0001)$ & & $(0.0008)$ & & $(0.0008)$ & \\
\hline \multirow[t]{2}{*}{ Size (proxied by VA) } & & 0.0157 & & 0.0182 & & 0.1705 & & 0.1884 \\
\hline & & $(0.0001)$ & & $(0.0001)$ & & $(0.0009)$ & & $(0.0009)$ \\
\hline Observations & $4,366,163$ & $4,366,860$ & $4,302,290$ & $4,302,802$ & $2,755,218$ & $2,755,436$ & $2,756,088$ & $2,756,211$ \\
\hline $\mathrm{R} 2$ & 0.1860 & 0.1826 & 0.2409 & 0.2384 & 0.4163 & 0.4104 & 0.4491 & 0.4435 \\
\hline
\end{tabular}

Note: In columns (1)-(4), the dependent variable is IT investment intensity and in columns (5)-(8) it is log IT capital intensity. In panels 1 and 2, IT intensity is proxied by software and hardware investment (capital) per worker or over wage bill, and in panels 3 and 4 by software and hardware investment (capital) over total or tangible capital. The independent variable is the logarithm of firm size either proxied by sales or value added. The time period is 1995-2007. In panels 1 and 3 the sample is all firms sampled by EAE, and in panels 2 and 4, the sample is BRN firms. All columns include a full set of 3-digit industry classification fixed effects interacted with year fixed effects and a full set of cohorts fixed effect (pre 1980, 1980-1993, 1993-1995 ... 2005-2007) and normalised age fixed effects. A semi-elasticity of 0.0205 of software investment per worker to sales means that raising sales by a factor of 2 raises software per worker by $0.0205 \ln 2=\mathrm{K} € 0.014$. An elasticity of 0.365 of capital per worker to sales means that raising sales by a factor of 2 raises capital per worker by $36.5 \%$. 


\section{Table 4: Regressions of Log IT Intensity of Capital On Measures of Firm Scale}

\begin{tabular}{|c|c|c|c|c|c|c|c|c|}
\hline & \multicolumn{4}{|c|}{ IT Intensity } & \multicolumn{4}{|c|}{ IT Rel. Intensity } \\
\hline & Workers & Workers & Wage Bill & Wage Bill & Total & Total & Tangible & Tangible \\
\hline \multicolumn{9}{|l|}{ Panel 1 : Software } \\
\hline \multirow[t]{2}{*}{ Number of plants } & 0.0015 & & 0.0014 & & 0.0014 & & 0.0015 & \\
\hline & $(0.0002)$ & & $(0.0002)$ & & $(0.0002)$ & & $(0.0002)$ & \\
\hline \multirow[t]{2}{*}{ Number of occupational layers } & & 0.2657 & & 0.2260 & & 0.2594 & & 0.2640 \\
\hline & & $(0.0048)$ & & $(0.0047)$ & & $(0.0050)$ & & $(0.0050)$ \\
\hline Observations & 563,244 & 563,244 & 563,383 & 563,383 & 519,078 & 519,078 & 517,835 & 517,835 \\
\hline $\mathrm{R} 2$ & 0.2218 & 0.2260 & 0.2147 & 0.2178 & 0.2241 & 0.2281 & 0.2242 & 0.2282 \\
\hline \multirow[t]{2}{*}{ Number of destination countries } & 0.0276 & & 0.0243 & & 0.0225 & & 0.0232 & \\
\hline & $(0.0004)$ & & $(0.0004)$ & & $(0.0004)$ & & $(0.0004)$ & \\
\hline \multirow[t]{2}{*}{ Number of products } & & 0.0065 & & 0.0059 & & 0.0054 & & 0.0056 \\
\hline & & $(0.0002)$ & & $(0.0002)$ & & $(0.0002)$ & & $(0.0002)$ \\
\hline Observations & 278,803 & 278,803 & 279,590 & 279,590 & 261,609 & 261,609 & 261,144 & 261,144 \\
\hline R2 & 0.1958 & 0.1871 & 0.1887 & 0.1817 & 0.1867 & 0.1806 & 0.1875 & 0.1811 \\
\hline \multicolumn{9}{|l|}{ Panel 2: Hardware } \\
\hline \multirow[t]{2}{*}{ Number of plants } & 0.0040 & & 0.0040 & & 0.0035 & & 0.0040 & \\
\hline & $(0.0001)$ & & $(0.0001)$ & & $(0.0001)$ & & $(0.0001)$ & \\
\hline \multirow[t]{2}{*}{ Number of occupational layers } & & 0.0993 & & 0.0704 & & 0.1128 & & 0.1255 \\
\hline & & $(0.0009)$ & & $(0.0009)$ & & $(0.0010)$ & & $(0.0010)$ \\
\hline Observations & $2,727,495$ & $2,727,495$ & $2,729,106$ & $2,729,106$ & $2,651,460$ & $2,651,460$ & $2,652,628$ & $2,652,628$ \\
\hline $\mathrm{R} 2$ & 0.3917 & 0.3938 & 0.3638 & 0.3647 & 0.4005 & 0.4030 & 0.4321 & 0.4350 \\
\hline \multirow[t]{2}{*}{ Number of destination countries } & 0.0337 & & 0.0299 & & 0.0258 & & 0.0272 & \\
\hline & $(0.0002)$ & & $(0.0002)$ & & $(0.0002)$ & & $(0.0002)$ & \\
\hline \multirow[t]{2}{*}{ Number of products } & & 0.0084 & & 0.0078 & & 0.0068 & & 0.0071 \\
\hline & & $(0.0001)$ & & $(0.0001)$ & & $(0.0001)$ & & $(0.0001)$ \\
\hline Observations & 553,427 & 553,427 & 555,879 & 555,879 & 546,058 & 546,058 & 546,478 & 546,478 \\
\hline $\mathrm{R} 2$ & 0.2831 & 0.2628 & 0.2533 & 0.2366 & 0.3129 & 0.3033 & 0.3339 & 0.3237 \\
\hline
\end{tabular}

Note: In columns (1)-(4), the dependent variable is log IT capital intensity and in columns (5)-(8) it is log IT capital relative intensity. In panel 1 IT is proxied by software, and in panel 2 by hardware. The time period is 1995-2007. In panels 1 sample is all firms sampled by EAE, and in panel 2 the sample is BRN firms. All columns include a full set of 3-digit industry classification fixed effects interacted with year fixed effects and a full set of cohorts fixed effect (pre 1980, 1980-1993, 1993-1995 ... 2005-2007) and normalised age fixed effects. A semi-elasticity of 0.0276 of capital per worker to the number of destination countries means that exporting to one new country raises capital per worker by $2.76 \%$. 
Table 5: Regressions of Change in the Industry-level Labor Share on Change in the Measure of Concentration

\begin{tabular}{|c|c|c|c|c|c|c|c|}
\hline \multirow[b]{2}{*}{ Top 1\% Share } & \multicolumn{7}{|c|}{5 Year Change } \\
\hline & $\begin{array}{c}-0.1785 \\
(0.0507)\end{array}$ & & & & & & \\
\hline Top 5\% Share & & $\begin{array}{l}-0.3226 \\
(0.0711)\end{array}$ & & & & & \\
\hline Largest Firm Share & & & $\begin{array}{l}-0.1192 \\
(0.0339)\end{array}$ & & & & \\
\hline 4 Largest Firms Share & & & & $\begin{array}{l}-0.1601 \\
(0.0254)\end{array}$ & & & \\
\hline 10 Largest Firms Share & & & & & $\begin{array}{c}-0.1422 \\
(0.0238)\end{array}$ & & \\
\hline 20 Largest Firms Share & & & & & & $\begin{array}{c}-0.1411 \\
(0.0245)\end{array}$ & \\
\hline Herfindahl-Hirschmann Index & & & & & & & $\begin{array}{l}-0.1480 \\
(0.0483)\end{array}$ \\
\hline Observations & 2,731 & 2,731 & 2,731 & 2,731 & 2,731 & 2,731 & 2,731 \\
\hline R2 & 0.0876 & 0.1131 & 0.0616 & 0.0696 & 0.0631 & 0.0610 & 0.0631 \\
\hline
\end{tabular}

Note: This table replicates for France the results obtained by Autor et al. (2017b) based on US micro data. Each estimate is the result of a regression. Regressions are carried at the 3-digit sector classification level. The dependent variable is the change in labor share in value added of a given sector. Labor shares are defined as the ratio of the sum of workers' compensation and taxes paid on labor in a given sector over respectively total value added of this sector. The independent variable reports changes of different measures of concentration, based on firms share of sales. The estimation method in all columns is OLS, with time fixed effect. 
Table 6: Regressions of Change in the Industry-level Labor Share on Change in the Measure of Concentration

\begin{tabular}{|c|c|c|c|c|c|c|c|}
\hline \multirow[b]{2}{*}{ Top 1\% Share } & \multicolumn{7}{|c|}{10 Year Change } \\
\hline & $\begin{array}{c}-0.1367 \\
(0.0526)\end{array}$ & & & & & & \\
\hline Top 5\% Share & & $\begin{array}{l}-0.2642 \\
(0.0827)\end{array}$ & & & & & \\
\hline Largest Firm Share & & & $\begin{array}{c}-0.0502 \\
(0.0440)\end{array}$ & & & & \\
\hline 4 Largest Firms Share & & & & $\begin{array}{l}-0.1758 \\
(0.0265)\end{array}$ & & & \\
\hline 10 Largest Firms Share & & & & & $\begin{array}{c}-0.1940 \\
(0.0231)\end{array}$ & & \\
\hline 20 Largest Firms Share & & & & & & $\begin{array}{l}-0.2000 \\
(0.0229)\end{array}$ & \\
\hline Herfindahl-Hirschmann Index & & & & & & & $\begin{array}{l}-0.0410 \\
(0.0594)\end{array}$ \\
\hline Observations & 1,680 & 1,680 & 1,680 & 1,680 & 1,680 & 1,680 & 1,680 \\
\hline R2 & 0.0289 & 0.0477 & 0.0053 & 0.0385 & 0.0449 & 0.0437 & 0.0035 \\
\hline
\end{tabular}

Note: This table replicates for France the results obtained by Autor et al. (2017b) based on US micro data. Each estimate is the result of a regression. Regressions are carried at the 3-digit sector classification level. The dependent variable is the change in labor share in value added of a given sector. Labor shares are defined as the ratio of the sum of workers' compensation and taxes paid on labor in a given sector over respectively total value added of this sector. The independent variable reports changes of different measures of concentration, based on firms share of sales. The estimation method in all columns is OLS, with time fixed effect. 
Table 7: Estimation Results

\begin{tabular}{|c|c|c|c|c|c|c|c|}
\hline & & \multicolumn{3}{|c|}{ All Industries } & \multicolumn{3}{|c|}{ Manufacturing } \\
\hline & & Nonhomothetic CES & CES & Cobb-Douglas & Nonhomothetic CES & CES & Cobb-Douglas \\
\hline \multirow[t]{2}{*}{ IT Nonhomotheticity } & $\epsilon$ & 0.389 & & & 0.477 & & \\
\hline & & $(0.011)$ & & & $(0.019)$ & & \\
\hline \multirow[t]{2}{*}{ Elasticity of substitution } & $\sigma$ & 0.225 & 0.125 & & 0.171 & 0.165 & \\
\hline & & $(0.012)$ & $(0.016)$ & & $(0.009)$ & $(0.013)$ & \\
\hline \multirow[t]{2}{*}{ Cost elasticity } & $\gamma$ & 0.947 & 0.978 & 1.001 & 0.954 & 1.014 & 1.022 \\
\hline & & $(0.004)$ & $(0.004)$ & $(0.004)$ & $(0.006)$ & $(0.005)$ & $(0.006)$ \\
\hline \multirow[t]{2}{*}{ Capital elasticity } & $\alpha$ & 0.074 & 0.068 & 0.070 & 0.182 & 0.166 & 0.167 \\
\hline & & $(0.005)$ & $(0.005)$ & $(0.005)$ & $(0.009)$ & $(0.008)$ & $(0.008)$ \\
\hline \multirow[t]{2}{*}{ Software elasticity } & $\beta$ & 0.113 & 0.185 & 0.015 & 0.120 & 0.148 & 0.303 \\
\hline & & $(0.029)$ & $(0.023)$ & $(0.038)$ & $(0.034)$ & $(0.028)$ & $(0.042)$ \\
\hline \multirow[t]{2}{*}{ Persistence of $\theta$} & $\rho_{\theta \theta}$ & 0.830 & 0.825 & 0.808 & 0.834 & 0.804 & 0.802 \\
\hline & & $(0.003)$ & $(0.003)$ & $(0.003)$ & $(0.005)$ & $(0.005)$ & $(0.005)$ \\
\hline \multirow[t]{2}{*}{ Persistence of $\theta$ wrt $\phi$} & $\rho_{\theta \phi}$ & -0.010 & -0.012 & & -0.008 & -0.014 & \\
\hline & & $(0.000)$ & $(0.001)$ & & $(0.001)$ & $(0.001)$ & \\
\hline \multirow[t]{2}{*}{ Persistence of $\phi$ wrt $\theta$} & $\rho_{\phi \theta}$ & -0.072 & -0.047 & & -0.066 & -0.048 & \\
\hline & & $(0.003)$ & $(0.003)$ & & $(0.004)$ & $(0.004)$ & \\
\hline \multirow[t]{2}{*}{ Persistence of $\phi$} & $\rho_{\phi \phi}$ & 0.898 & 0.908 & & 0.901 & 0.919 & \\
\hline & & $(0.001)$ & $(0.001)$ & & $(0.002)$ & $(0.001)$ & \\
\hline \multirow[t]{2}{*}{ Trend for $\theta$} & $\mu_{\theta}$ & 0.002 & 0.002 & -0.001 & 0.004 & 0.004 & 0.003 \\
\hline & & $(0.000)$ & $(0.000)$ & $(0.001)$ & $(0.000)$ & $(0.000)$ & $(0.000)$ \\
\hline \multirow[t]{2}{*}{ Trend for $\phi$} & $\mu_{\phi}$ & 0.008 & 0.008 & & -0.007 & -0.003 & \\
\hline & & $(0.001)$ & $(0.001)$ & & $(0.001)$ & $(0.001)$ & \\
\hline \multirow[t]{2}{*}{ Shifter for $\theta$} & $\eta_{\theta}$ & 0.590 & 0.626 & 0.718 & 0.479 & 0.658 & 0.662 \\
\hline & & $(0.014)$ & $(0.015)$ & $(0.013)$ & $(0.019)$ & $(0.021)$ & $(0.018)$ \\
\hline \multirow[t]{2}{*}{ Shifter for $\phi$} & $\eta_{\phi}$ & 0.677 & 0.185 & & 0.795 & 0.306 & \\
\hline & & $(0.021)$ & $(0.016)$ & & $(0.024)$ & $(0.017)$ & \\
\hline Observations & $\mathrm{N}$ & 302318 & 302318 & 307227 & 145966 & 145966 & 147471 \\
\hline
\end{tabular}

Note: Results of the estimation procedure for the pooled sample of all firms in (columns 1-3), and for the pooled sample of manufacturing firms (columns 4-6). Columns 2 and 5 present the estimated model parameters for a CES production function (where $\epsilon$ is constrained to be 0 ). Columns 3 and 6 present the estimated model parameters for a Cobb-Douglas production function (where $\sigma$ is additionally constrained to be 1). For details, see Section 5. 
Table 8: Estimation Results by Industry

\begin{tabular}{|c|c|c|c|c|c|c|}
\hline & $\epsilon$ & $\sigma$ & $\gamma$ & $\alpha$ & $\beta$ & $\mathrm{N}$ \\
\hline \multirow[t]{2}{*}{ Wholesale and retail trade } & 0.043 & 0.138 & 0.984 & 0.008 & -0.069 & 60,498 \\
\hline & $(0.017)$ & $(0.017)$ & $(0.008)$ & $(0.015)$ & $(0.023)$ & \\
\hline \multirow[t]{2}{*}{ Pharmaceuticals } & 0.232 & 0.390 & 0.684 & -0.137 & -0.742 & 1,527 \\
\hline & $(0.310)$ & $(0.337)$ & $(0.226)$ & $(0.411)$ & $(1.043)$ & \\
\hline \multirow[t]{2}{*}{ Legal, accounting and engineering } & 0.297 & -0.047 & 0.954 & 0.061 & 0.183 & 8,012 \\
\hline & $(0.122)$ & $(0.299)$ & $(0.023)$ & $(0.028)$ & $(0.200)$ & \\
\hline \multirow[t]{2}{*}{ Rubber and plastic products } & 0.304 & 0.106 & 0.985 & 0.225 & -0.083 & 15,363 \\
\hline & $(0.113)$ & $(0.238)$ & $(0.013)$ & $(0.020)$ & $(0.278)$ & \\
\hline \multirow[t]{2}{*}{ Research } & 0.374 & 0.426 & 0.917 & 0.036 & 0.034 & 3,817 \\
\hline & $(0.522)$ & $(0.195)$ & $(0.041)$ & $(0.036)$ & $(0.301)$ & \\
\hline \multirow[t]{2}{*}{ Machinery and equipments } & 0.451 & 0.371 & 0.967 & 0.145 & -0.364 & 11,946 \\
\hline & $(0.121)$ & $(0.128)$ & $(0.012)$ & $(0.020)$ & $(0.296)$ & \\
\hline \multirow[t]{2}{*}{ Transport equipments } & 0.480 & 0.036 & 0.947 & 0.107 & 0.321 & 6,024 \\
\hline & $(0.044)$ & $(0.061)$ & $(0.015)$ & $(0.031)$ & $(0.132)$ & \\
\hline \multirow[t]{2}{*}{ Textiles } & 0.525 & 0.219 & 0.919 & 0.134 & 0.203 & 9,770 \\
\hline & $(0.287)$ & $(0.215)$ & $(0.035)$ & $(0.033)$ & $(0.148)$ & \\
\hline \multirow[t]{2}{*}{ Publishing and motion pictures } & 0.546 & 0.503 & 0.941 & 0.039 & -0.865 & 6,345 \\
\hline & $(0.777)$ & $(1.049)$ & $(0.070)$ & $(0.042)$ & ( 4.217) & \\
\hline \multirow[t]{2}{*}{ Computers and electronics } & 0.558 & 0.067 & 0.971 & 0.132 & 0.452 & 5,560 \\
\hline & $(0.155)$ & $(0.209)$ & $(0.023)$ & $(0.044)$ & $(0.174)$ & \\
\hline \multirow[t]{2}{*}{ Basic Metals } & 0.574 & 0.054 & 0.981 & 0.169 & 0.231 & 30,397 \\
\hline & $(0.044)$ & $(0.096)$ & $(0.007)$ & $(0.011)$ & $(0.122)$ & \\
\hline \multirow[t]{2}{*}{ Wood, paper and printing } & 0.600 & 0.105 & 0.967 & 0.145 & 0.083 & 17,578 \\
\hline & $(0.153)$ & $(0.196)$ & $(0.013)$ & $(0.020)$ & $(0.199)$ & \\
\hline \multirow[t]{2}{*}{ Food products } & 0.614 & 0.357 & 0.954 & 0.237 & 0.164 & 19,735 \\
\hline & $(0.200)$ & $(0.165)$ & $(0.013)$ & $(0.020)$ & $(0.218)$ & \\
\hline \multirow[t]{2}{*}{ Transportation } & 0.696 & -0.448 & 0.955 & 0.051 & 0.911 & 19,793 \\
\hline & $(0.056)$ & $(0.094)$ & $(0.013)$ & $(0.015)$ & $(0.018)$ & \\
\hline \multirow[t]{2}{*}{ Electrical equipments } & 0.813 & 0.619 & 0.838 & -0.268 & -0.250 & 3,989 \\
\hline & $(0.261)$ & $(0.080)$ & $(0.114)$ & $(0.292)$ & $(0.669)$ & \\
\hline \multirow[t]{2}{*}{ Mining, energy and utilities } & 0.814 & 0.098 & 0.895 & 0.308 & 0.736 & 5,891 \\
\hline & $(0.135)$ & $(0.168)$ & $(0.028)$ & $(0.044)$ & $(0.187)$ & \\
\hline \multirow[t]{2}{*}{ Administrative and support } & 2.034 & -0.354 & 0.694 & 0.026 & 0.904 & 13,260 \\
\hline & $(0.127)$ & $(0.361)$ & $(0.052)$ & $(0.027)$ & $(0.079)$ & \\
\hline
\end{tabular}

Note: Results of the estimation procedure across 17 industries of the French market economy (level A38 of the NAF classification) in France. The last column indicates the number of firm-year observations corresponding to each sector. For details, see Section 5. 


\section{Table 9: Calibrated Parameters}

\begin{tabular}{|c|c|c|c|c|}
\hline Model Component & Parameter & & Value & \\
\hline \multirow[t]{5}{*}{ Production Function } & IT nonhomotheticity & $\epsilon$ & 0.39 & Estimated \\
\hline & Output Elasticity Parameter & $\gamma$ & 0.95 & Estimated \\
\hline & Capital Elasticity Parameter & $\alpha$ & 0.07 & Estimated \\
\hline & Elasticity of substitution & $\sigma$ & 0.22 & Estimated \\
\hline & Fixed Costs & $\psi$ & 0.10 & Calibrated \\
\hline \multirow[t]{3}{*}{ Productivity Process } & Persistence of Shocks & $\left(\rho_{\theta \theta}, \rho_{\phi \phi}\right)$ & $(0.83,0.90)$ & Estimated \\
\hline & Long-run Mean Productivities & $\left(\eta_{\theta}, \eta_{\phi}\right)$ & $(0.59,0.68)$ & Estimated \\
\hline & Variances of Innovations & $\left(x_{\theta}^{2}, x_{\phi}^{2}\right)$ & $(0.09,0.48)$ & Estimation \\
\hline \multirow[t]{6}{*}{ Entry \& Exit } & Distribution of Entry & $\left(\xi_{o}, \bar{\theta}_{o}\right)$ & $(2.80,8.12)$ & Estimation \\
\hline & & $x_{o}^{2}$ & $(2.10)$ & Estimation \\
\hline & & $\underline{\theta}_{0}$ & 1.84 & Calibrated \\
\hline & & $\bar{\phi}_{o}$ & 6.85 & Calibrated \\
\hline & Costs of Entry & $\chi$ & 0.10 & Calibrated \\
\hline & Exogenous Probability of Exit & $\delta$ & 0.04 & Calibrated \\
\hline \multirow[t]{2}{*}{ Demand } & Elasticity of Substitution & $\lambda$ & 5.09 & Calibrated \\
\hline & Discount Factor & e & 0.95 & Calibrated \\
\hline
\end{tabular}

Note: The calibrated and estimated parameters of the model and the source of information used for each parameter. For details, see Section 5. 


\section{Table 10: Calibrated Moments}

\begin{tabular}{llllll} 
& Moments & Parameters & Model & Data & Source \\
\hline \hline Targeted & Entrant Top \%1 $\theta$ & $\xi_{o}$ & 3.484 & 3.461 & EAE (Estimation) \\
& Entrant Top \%0.1 $\theta$ & $\xi_{o}$ & 4.307 & 4.277 & EAE (Estimation) \\
& Entrant Highest $\theta$ & $\bar{\theta}_{o}$ & 8.120 & 8.120 & EAE (Estimation) \\
& Share of Top 1\% of Firms in Sales & $\left(\lambda, \psi, \underline{\theta}_{o}, \bar{\phi}_{o}\right)$ & 0.592 & 0.593 & BRN+RSI \\
& Share of Top $\%$ of Firms in Sales & $\left(\lambda, \psi, \underline{\theta}_{o}, \bar{\phi}_{o}\right)$ & 0.753 & 0.774 & BRN+RSI \\
& Aggregate Labor Share & $\left(\lambda, \psi, \underline{\theta}_{o}, \bar{\phi}_{o}\right)$ & 0.748 & 0.706 & BRN+RSI \\
& Aggregate IT Intensity $(\bar{\Omega})$ & $\left(\lambda, \psi, \underline{\theta}_{o}, \bar{\phi}_{o}\right)$ & 0.037 & 0.038 & INSEE \\
& Mass of Firms & $\chi$ & 0.08 & 0.08 & BRN+RSI \\
& Rate of Exit of Large Firms & $\delta$ & 0.04 & 0.04 & BRN+RSI \\
\hline Untargeted & Unweighted Mean of Labor Share & - & 0.783 & 0.762 & BRN+RSI \\
& Unweighted Mean of IT Intensity & - & 0.003 & 0.002 & BRN+RSI \\
& S.D. of Log Sales & - & 1.213 & 1.435 & BRN+RSI \\
& S.D. of Log Employment & - & 1.211 & 1.188 & BRN+RSI \\
\hline
\end{tabular}

Note: The targeted moments based on the data and the model. EAE (Estimation) source dataset refers to the sample of EAE firms from 1996 to 2007. The four moments used for the calibration of $\left(\lambda, \psi, \underline{\theta}_{o}, \bar{\phi}_{o}\right)$ are taken from BRN+RSI or INSEE data in 1995. All remaining moments use BRN+RSI data from 1995 to 2007. For details, see Section 5. 


\section{Table 11: Calibration Results}

\begin{tabular}{lllll} 
Aggregate Variable & & Before & After & \\
\hline \hline Price of IT & $W$ & 0.0203 & 0.0075 & IT Price $\downarrow$ \\
Aggregate Output & $Y$ & 78.3 & 82.3 & Output $\uparrow$ \\
Price Index & $P$ & 0.0144 & 0.0135 & Competition $\uparrow$ \\
Mass of Firms & $N$ & 0.080 & 0.077 & Entry $\downarrow$ \\
\hline Aggregate Cost Elasticity & $\overline{\mathcal{E}}$ & 0.9645 & 0.9640 & Cost Elasticity $\approx$ \\
$\quad$ Within-Firm Contribution & & - & -0.0080 & $\downarrow$ \\
$\quad$ Reallocation Contribution & & - & 0.0075 & $\uparrow$ \\
Labor Share (Production) & $L S^{p r o d}$ & 0.748 & 0.749 & Labor Share $\approx$ \\
$\quad$ Within-Firm Contribution & & - & 0.021 & $\uparrow$ \\
$\quad$ & & - & -0.020 & $\downarrow$ \\
$\quad$ Reallocation Contribution & & 0.1670 & 0.1666 & Profits $\approx$ \\
Profit Share & $\Pi / R$ & 0.592 & 0.649 & Concentration $\uparrow$ \\
Share of Top 1\% of Firms in Sales & & 0.753 & 0.783 & Concentration $\uparrow$ \\
Share of Top 5\% of Firms in Sales & & & &
\end{tabular}

Note: For details, see Section 5. 


\section{Figures}

Figure 1: Rise of IT

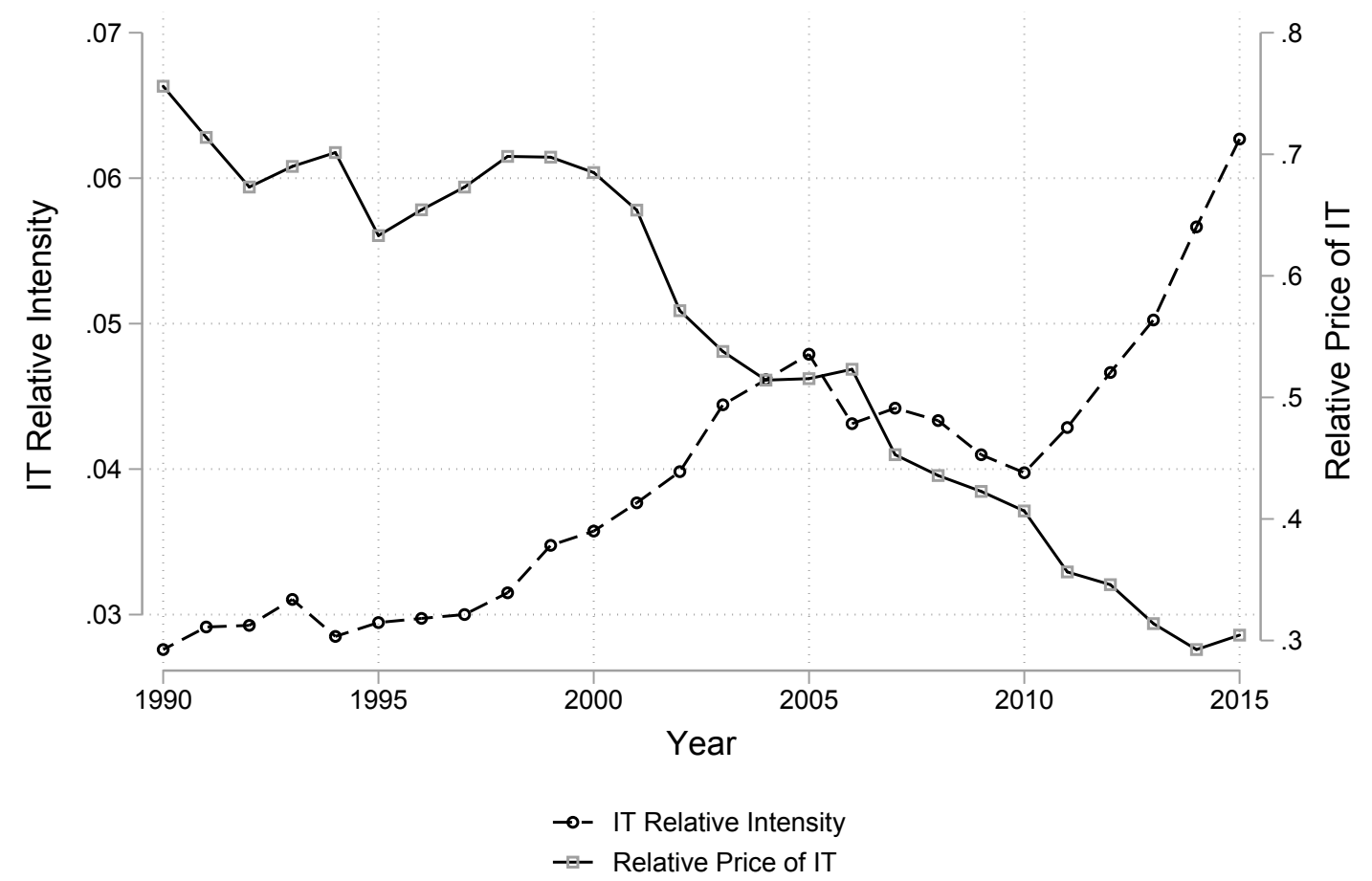

Note: This figure presents on the left axis the ratio of computing equipment capital to non ICT capital (excluding Dwellings), and on the right axis the user cost of computing equipment capital relative to the user cost of non ICT capital, in France, Market Economy. Source : EU KLEMS. 


\section{Figure 2: Rise in Concentration}

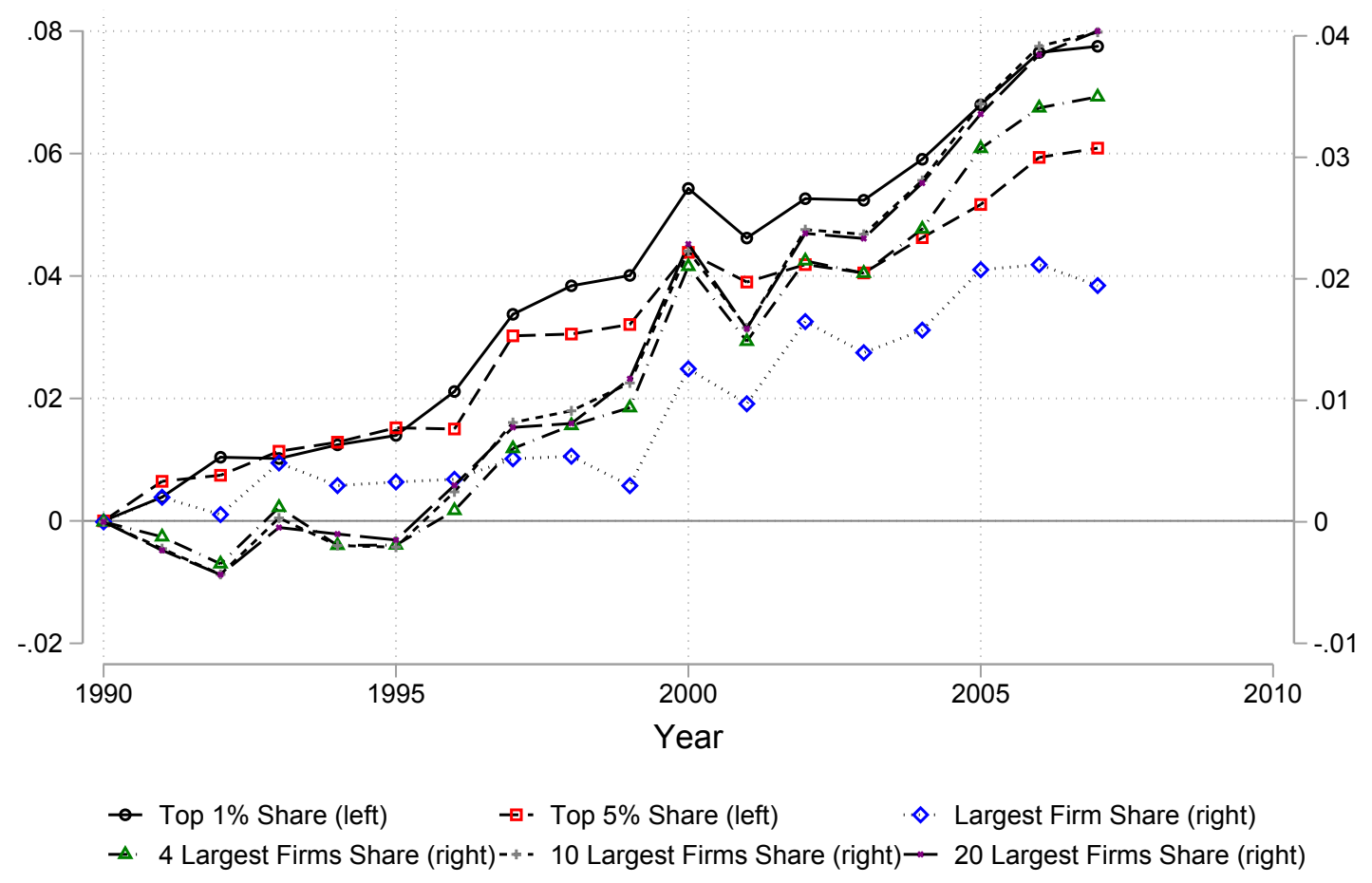

Note: This figure presents the sales weighted average across 3-digits industries of the cumulated change in concentration, measured at the industry level by the share of industry sales of the largest $1 \%, 5 \%, 1,4,10$ or 20 firms by sales market share. 
Figure 3: Labor Share

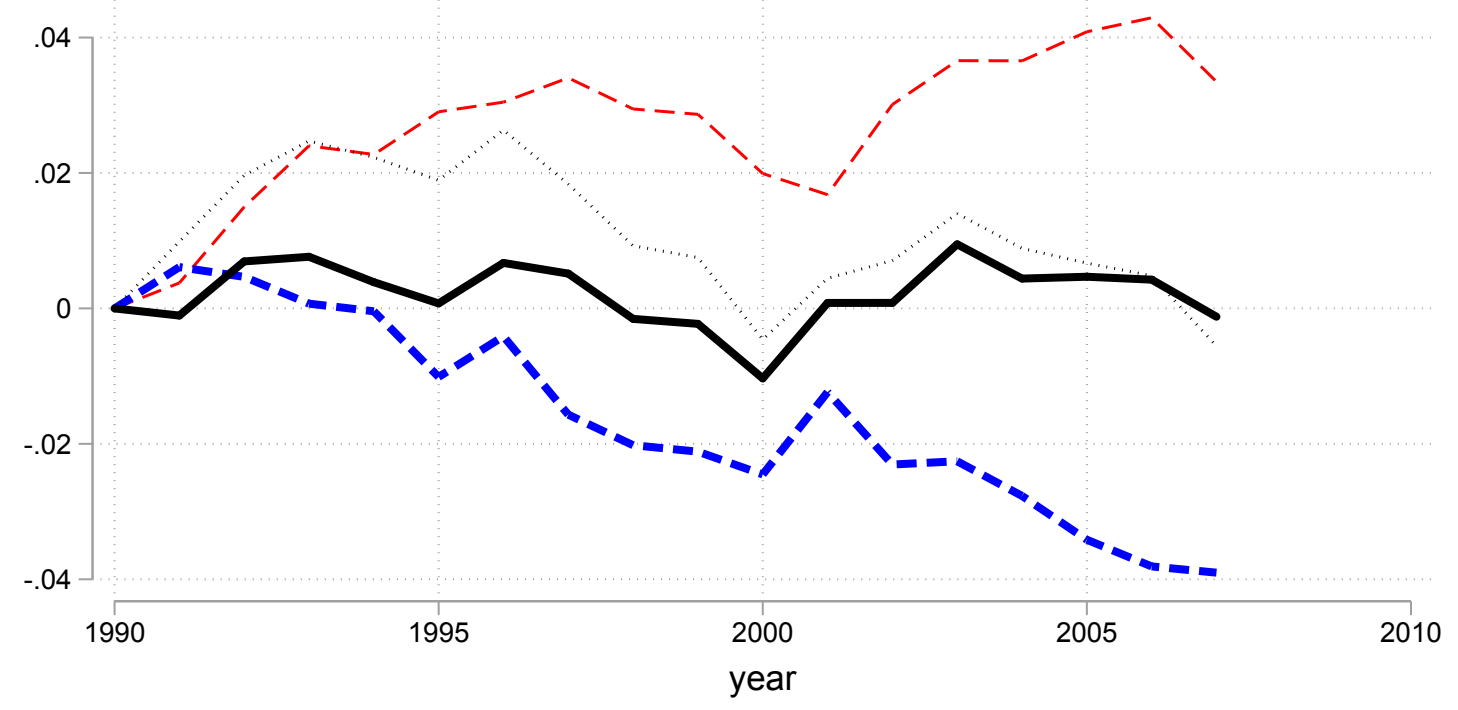

- - Within industries - within quantiles

- - Within industries - across quantiles

Within industries - total

- Aggregate (within + across industries)

Note: This figure presents the cumulated change in the total labor share, and the decomposition, across 2-digits industries. 
Figure 4: Correlation between 5-Year Change in Industry Labor Share and Concentration

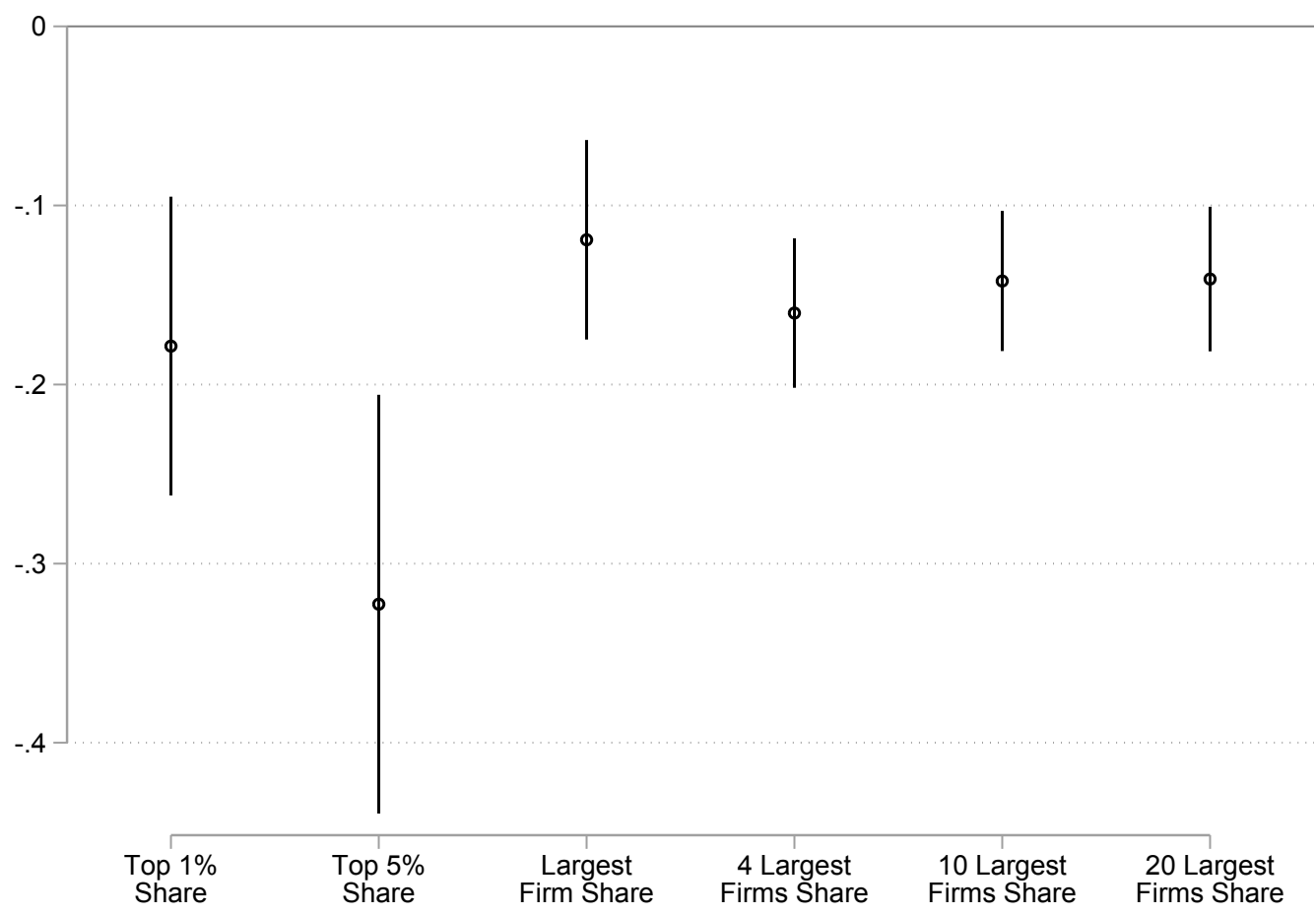

Note: This figure presents coefficients of separate regression of 5-Year Change in Industry Labor Share and Different Measures of Concentration, at the 3-digits level, including year fixed effects. 
Figure 5: Cross-sectional Relationship Between IT and Firm Size

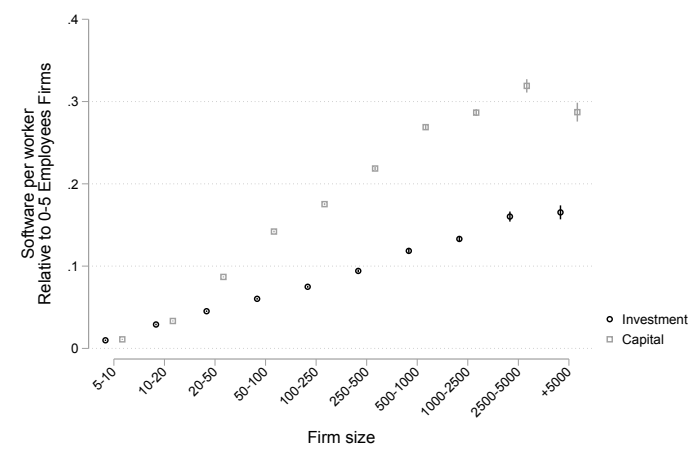

(a) Software Values (per worker)

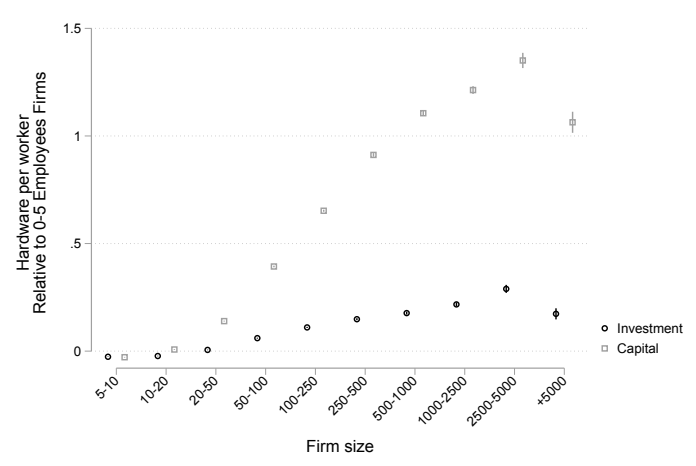

(c) Hardware Values (per worker)

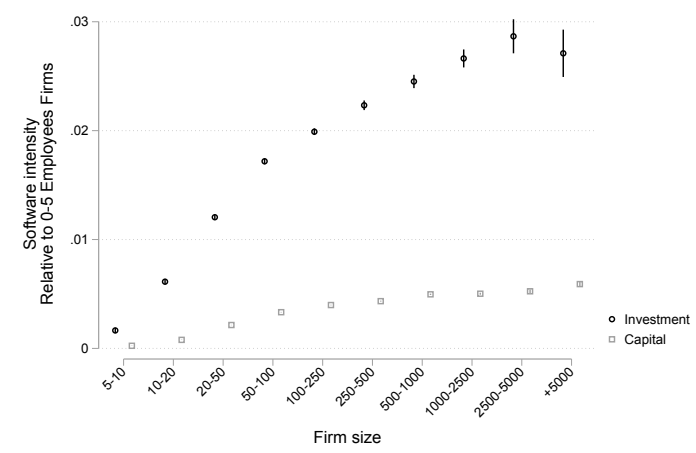

(b) Software Relative Intensity

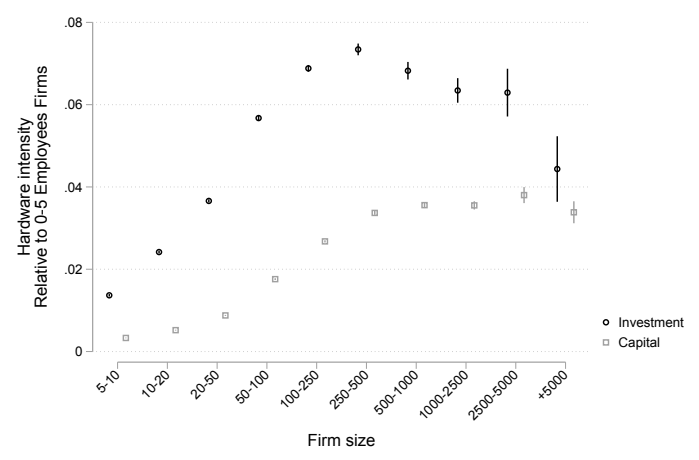

(d) Hardware Relative Intensity

Note: This figure reports the average of IT intensity by firm size. Averages are conditional on a set of flexible fixed effects constructed from the interaction of 3-digit industry codes and time dummies, and a full set of cohorts fixed effect (pre 1980, 1980-1993, 1993-1995 ... 2005-2007) and normalised age fixed effects. In the case of software, sample is all firms that were sampled in EAE (that year for investment, at least once for capital). In the case of hardware, sample is all firms that reported hardware investment lower than 0.99 times total investment. 
Figure 6: Cross-sectional Relationship Between Labor Share and Firm Size

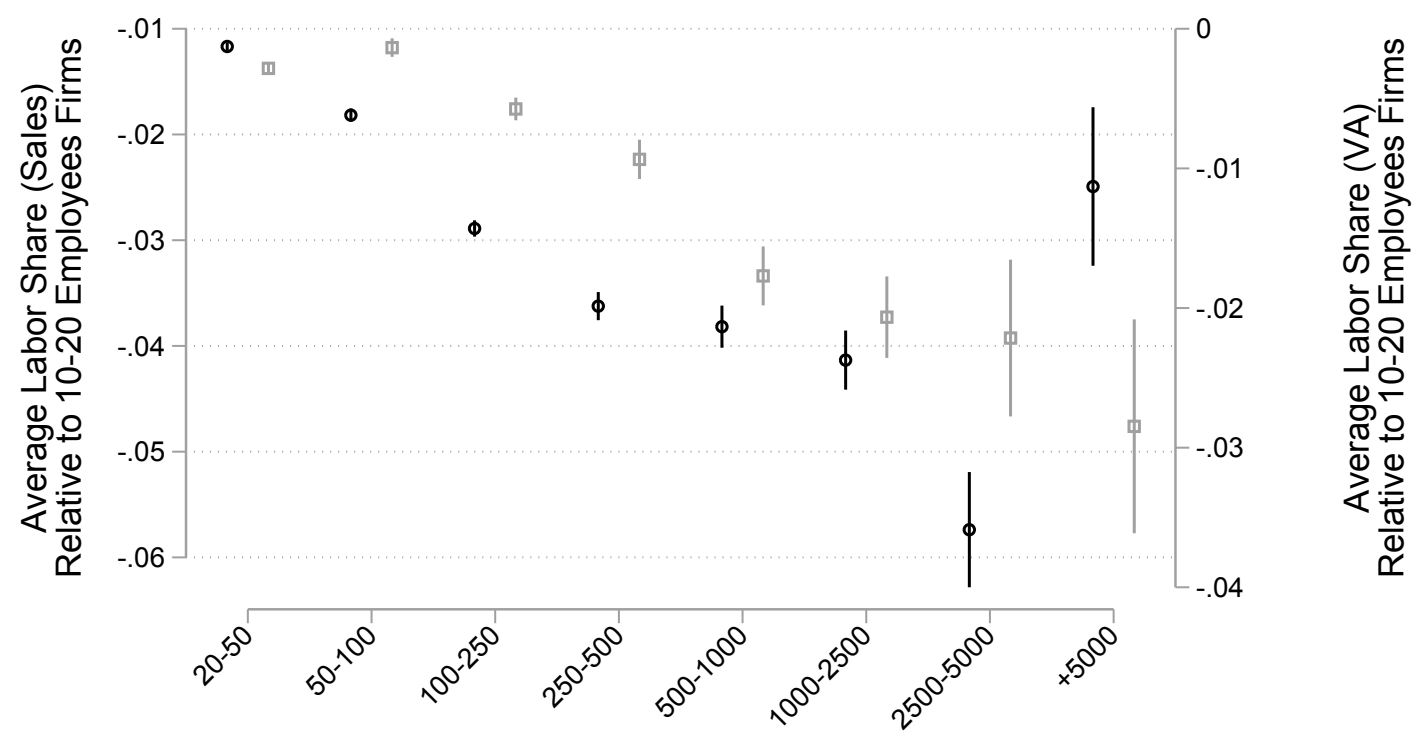

Firm size

- Labor Share (Sales)

$\square$ Labor Share (VA)

Note: This figure reports the conditional average of labor share (measured as the ratio of wage bill to either sales or value added) by firm size. Averages are conditional on a set of flexible fixed effects constructed from the interaction of 4-digit industry codes and time dummies. 
Figure 7: Estimates of the Parameter of Nonhomotheticity $\epsilon$

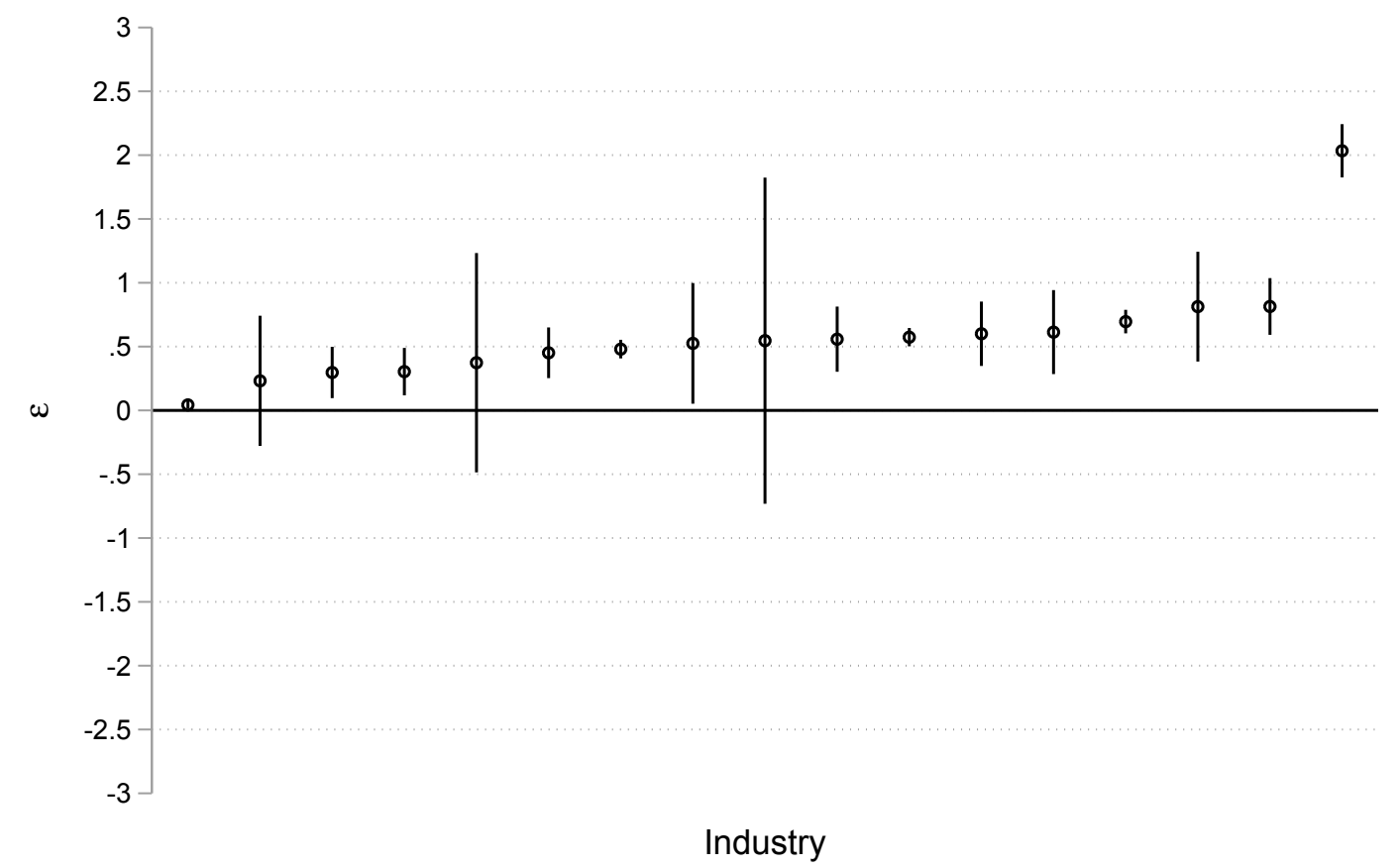

Note: This figure presents the estimated values of the parameter $\epsilon$ across 17 industries of the market economy (level A38 of the NAF classification) in France. The bands around the estimates show the $10 \%$ confidence intervals. Industries are sorted from lowest to largest $\epsilon$, as in table 8. 
Figure 8: Estimates of the Substitution Elasticity Parameter $\sigma$

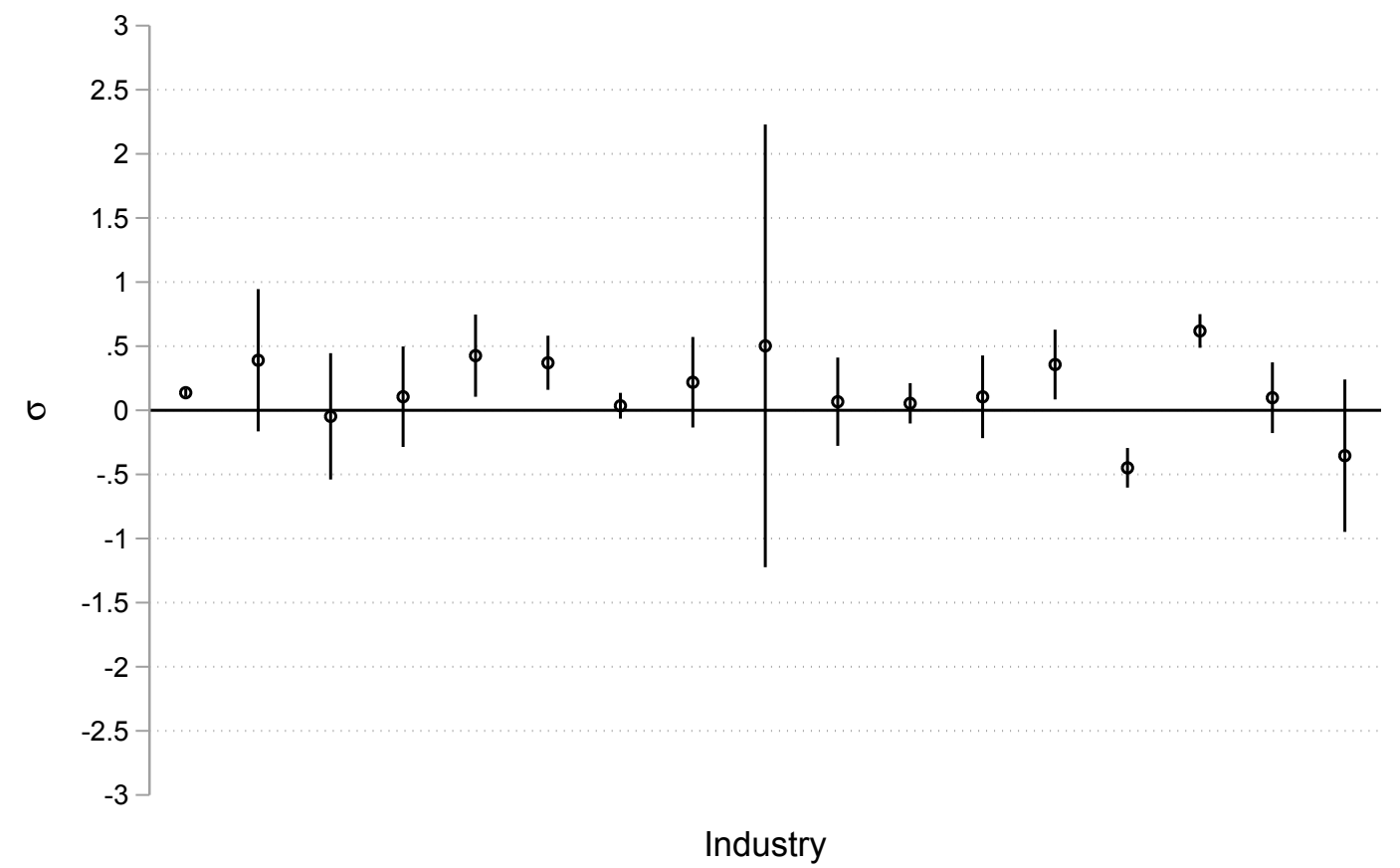

Note: This figure presents the estimated values of the parameter $\sigma$ across 17 industries of the market economy (level A38 of the NAF classification) in France. The bands around the estimates show the $10 \%$ confidence intervals. Industries are sorted from lowest to largest $\epsilon$, as in table 8. 
Figure 9: Estimates of the Cost Elasticity Parameter $\gamma$

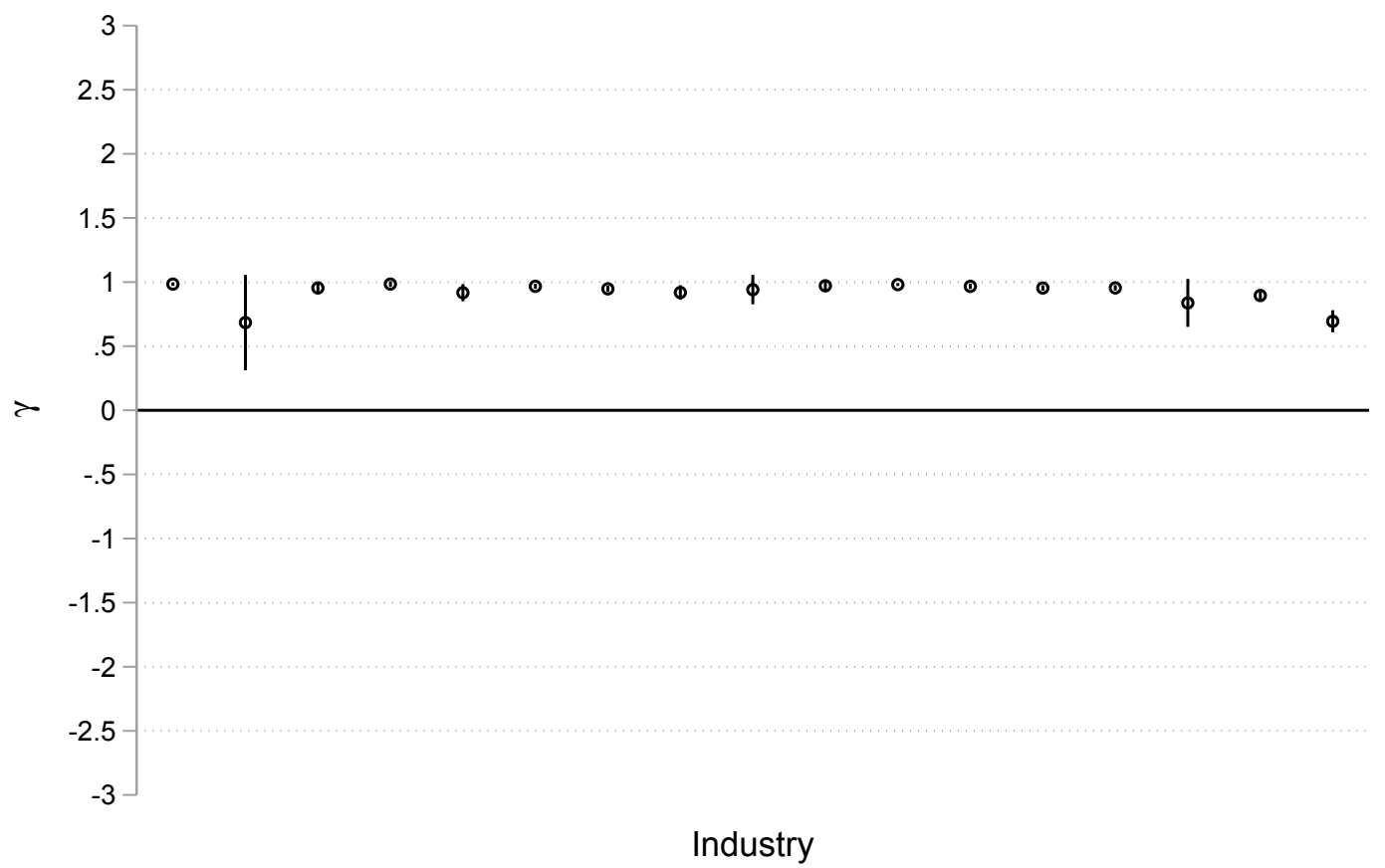

Note: This figure presents the estimated values of the parameter $\gamma$ across 17 industries of the market economy (level A38 of the NAF classification) in France. The bands around the estimates show the $10 \%$ confidence intervals. Industries are sorted from lowest to largest $\epsilon$, as in table 8. 
Figure 10: Responses of Different Firms to the Fall in IT Prices

(A) Heterogeneity in Output Response

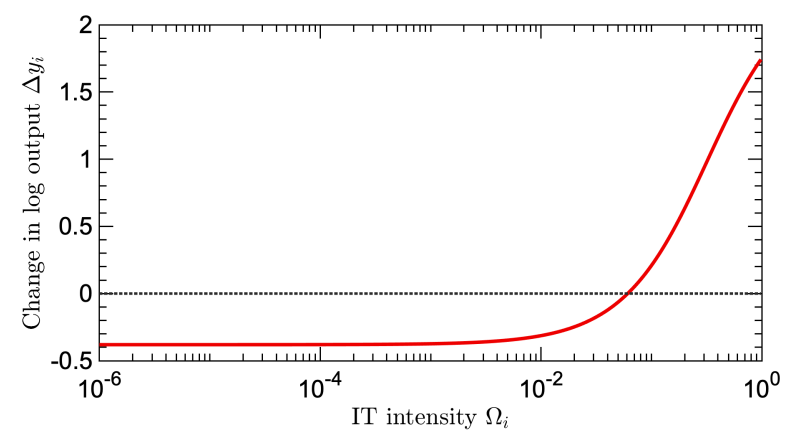

(C) Heterogeneity in Response of Share in Industry Costs

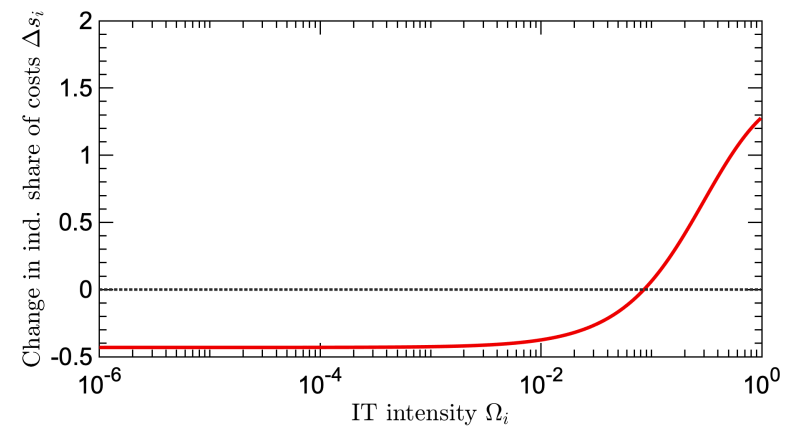

(B) Heterogeneity in Sales Response

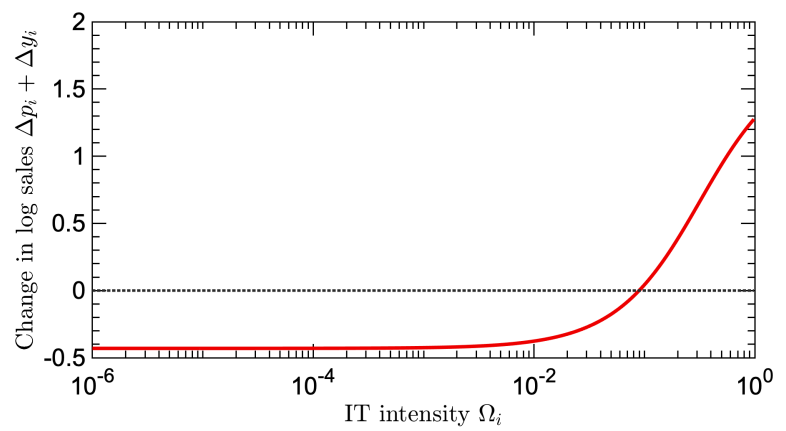

(D) Heterogeneity in Cost Elasticity Response

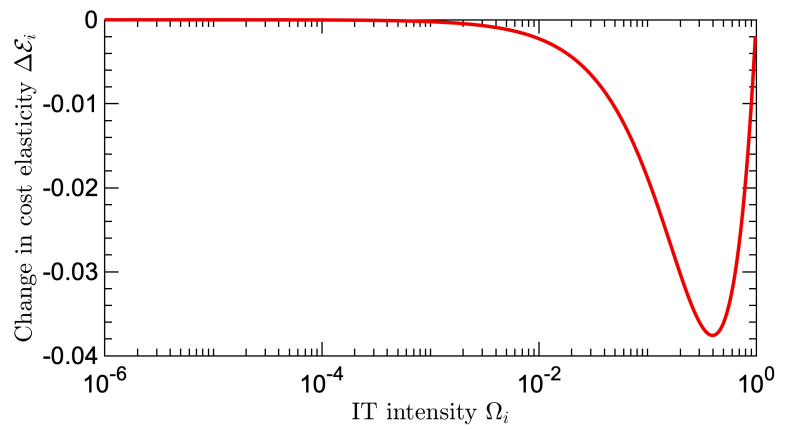




\section{A Nonhomothetic Demand and Returns to Scale}

In this section we examine the properties of general production functions that are compatible with nonhomothetic IT demand, that is,

$$
\frac{\partial \log \left(X_{I} / X_{N}\right)}{\partial \log Y}=\eta, \quad \eta>0
$$

The following lemma establishes two properties for the elasticities of substitution and scale of the production functions that give rise to nonhomothetic IT demand with a constant relative output elasticity.

Lemma 5. Consider a continuous, differentiable, and monotonically increasing production function $Y=$ $\mathcal{F}\left(X_{N}, X_{I}\right)$ such that the set $\left\{\left(X_{N}, X_{I}\right) \geq 0 \mid Y \leq \mathcal{F}\left(X_{N}, X_{I}\right)\right\}$ is strictly convex for all $Y$. Assume that the corresponding cost minimization problem yields factor demand functions satisfying Equation (??). Then, along any expansion path in the $\left(X_{N}, X_{I}\right)$-space $e^{51}$ the production function satisfies the following two properties:

1. The elasticity of substitution between IT and non-IT inputs is constant everywhere.

2. The production function is "not" homogeneous of a constant degree, that is, there is "no" $\epsilon>0$ such that for all $Z>0$ and all $\left(X_{N}, X_{I}\right)$ the production function satisfies $\mathcal{F}\left(Z X_{N}, Z X_{I}\right)=Z \epsilon \mathcal{F}\left(X_{N}, X_{I}\right)$.

Proof. See Appendix B.1.

We can alternatively state the result of Lemma 5 in terms of the properties of the cost function, when we fix relative factor input prices $W_{I} / W_{N}$. The first part of the lemma tells us that the elasticity of substitution $\partial \log \left(X_{I} / X_{N}\right) / \partial \log \left(W_{I} / W_{N}\right)$ only depends on relative input prices $W_{I} / W_{N}$, and not output $Y$. In other words, if we consider in the space of inputs $\left(X_{N}, X_{I}\right)$ paths characterized by a constant marginal rate of substitution, the normal vectors to this curve form parallel vectors everywhere along the curve.

More importantly, the second part says that the output elasticity of the cost function, which is the reciprocal of the scale elasticity, varies with the scale of the firm output $Y$. In other words, if the IT factor input has a higher output elasticity than the non-IT factor input, when firms change their scale of operation their scale elasticity is bound to change. Specifically, the lemma rules out a constant-returns-to-scale (CRS) production function.

We may naturally wonder whether the scale elasticity rises or falls with output. The next lemma shows that to answer this question we need to impose further structure on the production function. More specifically, the answer to this question hinges on whether the two inputs are gross complements or gross substitutes.

Lemma 6. Consider a production function $\mathcal{F}$ satisfying the conditions in Lemma 5. Assume, in addition, that the scale elasticity is constant in the limit that either input goes to zero, that is, there is some $\epsilon_{k}>0$ such that for all $Z>0$ we have

$$
\lim _{X_{k} \rightarrow 0} \frac{\mathcal{F}\left(Z X_{N}, Z X_{I}\right)}{\mathcal{F}\left(X_{N}, X_{I}\right)}=Z^{\epsilon_{k}}, \quad k \in\{N, I\} .
$$

\footnotetext{
${ }^{51}$ An expansion path is a curve with constant marginal rate of transformation $\mathcal{F}_{I} / \mathcal{F}_{N} \equiv\left(\partial \mathcal{F} / \partial X_{I}\right) /\left(\partial \mathcal{F} / \partial X_{N}\right)$.
} 
Then, if the elasticity of substitution is less (greater) than 1 and nonincreasing (nondecreasing) in the marginal rate of transformation $\mathcal{F}_{I} / \mathcal{F}_{N}$, the scale elasticity is monotonically decreasing (increasing) in output $Y$ along a curve with constant marginal rate of transformation.

Proof. See Appendix (B.1).

Lemma 6 shows that, under fairly mild conditions on the production function, the relationship between scale elasticity and firm size is monotonic and depends on the elasticity of substitution between IT and non-IT inputs. In particular, when the elasticity of substitution is constant, with an elasticity of substitution below 1, larger firms have higher scale elasticities. The opposite is the case with an elasticity of substitution greater than 1 . To better illustrate this result, below we will consider two extreme examples: the first being a production function with a zero elasticity of substitution between the two inputs and the second being the polar case with perfect substitutability. We will see that, as the firm size grows, the scale elasticity falls and rises in the first and second examples, respectively.

Example 1. Consider a nonhomothetic Leontief production function $Y=\mathcal{F}\left(X_{N}, X_{I}\right)$ defined implicitly through

$$
Y=\min \left\{X_{N}, Y^{-\eta} X_{I}\right\}, \quad \eta>0 .
$$

In any cost minimizing solution, we have $Y=X_{N}=X_{I}^{1 /(1+\eta)}$, which implies $X_{I} / X_{N}=Y^{\eta}$ satisfying condition (48). Given factor prices $\left(W_{N}, W_{I}\right)$, the corresponding cost function is given byC $\left(W_{N}, W_{I} ; Y\right)=$ $W_{N} Y+W_{I} Y^{1+\eta}$. Therefore, the output elasticity of costs, which is the reciprocal of the scale elasticity, satisfies

$$
\frac{\partial \log C}{\partial \log Y}=1+\eta \Omega_{I}\left(W_{N}, W_{I} ; Y\right),
$$

where we have defined $\Omega_{I}\left(W_{N}, W_{I} ; Y\right) \equiv W_{I} Y^{\eta} /\left(W_{N}+W_{I} Y^{\eta}\right)$ as the cost share of IT-inputs. This share is monotonically increasing in the level of output $Y$, implying that the output elasticity of costs is increasing in output.

Example 2. Consider a linear production function $Y=\mathcal{F}\left(X_{N}, X_{I}\right)$ defined as

$$
Y=X_{N}+Y^{\eta} X_{I}, \quad 0<\eta<1
$$

Although strictly speaking, this production function does not satisfy condition (48), its factor demand and cost functions demonstrate quasi-nonhomothetic behavior. In particular, when the scale of output is small enough to satisfy $W_{I} / W_{N} \geq Y^{\eta}$, we have $X_{N}=Y$ and $X_{I}=0$. On the other hand, when the scale of output is large enough such that $W_{I} / W_{N}<Y^{\eta}$, we have $X_{N}=0$ and $X_{I}=Y^{1-\eta}$. The corresponding cost function is

$$
C\left(W_{N}, W_{I} ; Y\right)= \begin{cases}W_{N} Y, & W_{I} / W_{N} \geq Y^{\eta} \\ W_{I} Y^{1-\eta}, & W_{I} / W_{N} \leq Y^{\eta}\end{cases}
$$


In stark contrast to Example 1, in this case the output elasticity of costs falls as output rises. With $W_{I} / W_{N} \geq$ $Y^{\eta}$, the production function has constant returns to scale whereas for $W_{I} / W_{N}<Y^{\eta}$, the scale elasticity is $1 /(1-\eta)$ strictly greater than 1 .

The intuition for the result above is as follows. As output rises, Equation (48) implies that IT inputs grow faster than non-IT inputs because of their higher output elasticity. The rise in the IT inputs raises the marginal product of the non-IT inputs, which means that we have to further raise the non-IT input in order to again equalize the marginal product and the non-IT factor price. When the elasticity of substitution is below 1 , the required rise in the non-IT input is sufficiently high to make the cost function increasingly convex as the output rises. The situation is reverse when the elasticity of substitution is greater than 1 .

\section{B Derivations and Proofs}

\section{B.1 Proofs}

Lemma. See Lemma 1.

Proof. We provide the proof for a generalized version of the lemma, for a nonhomothetic CES production function with $J$ inputs $\left\{X_{j}\right\}_{j=1}^{J}$, where output $Y$ satisfies $\sum_{j}\left(\frac{X_{j}}{Y^{\epsilon}}\right)^{\frac{\sigma-1}{\sigma}}=1$. Equation (6) corresponds to the case of $\epsilon_{N}=\gamma$ and $\epsilon_{I}=\gamma+\epsilon$. The cost function $\mathcal{C}$ then satisfies $\mathcal{C}(Y)^{1-\sigma}=\sum_{j}\left(Y^{\epsilon_{j}} W_{j}\right)^{1-\sigma}$ where $W_{j}$ is the factor price of input $j$, and the cost elasticity is given by $\mathcal{E}(Y)=\sum_{j}\left(\frac{W_{j}}{\mathcal{C}} Y^{\epsilon_{j}}\right)^{1-\sigma} \epsilon_{j}$.

We can write the second order derivative of the cost function as

$$
\begin{aligned}
\mathcal{C}^{\prime \prime}(Y) & =\left(\frac{\mathcal{C}}{Y} \mathcal{E}\right)^{\prime} \\
& =\mathcal{E} \frac{\mathcal{C}}{Y^{2}}\left(\frac{Y \mathcal{C}^{\prime}}{\mathcal{C}}-1\right)+\frac{\mathcal{C}}{Y} \mathcal{E}^{\prime}, \\
& =\mathcal{E} \frac{\mathcal{C}}{Y^{2}}\left(\mathcal{E}-1+\frac{Y \mathcal{E}^{\prime}}{\mathcal{E}}\right),
\end{aligned}
$$

where $\mathcal{E}$ is the cost elasticity function defined above. The 2 nd order scale elasticity is then given by

$$
\begin{aligned}
\frac{Y \mathcal{E}^{\prime}}{\mathcal{E}} & =\frac{Y}{\mathcal{E}} \frac{d}{d Y}\left(\sum_{j}\left(\frac{W_{j}}{\mathcal{C}} Y^{\epsilon_{j}}\right)^{1-\sigma} \epsilon_{j}\right), \\
& =\frac{1-\sigma}{\mathcal{E}}\left(\sum_{j}\left(\frac{W_{j}}{\mathcal{C}} Y^{\epsilon_{j}}\right)^{1-\sigma} \epsilon_{j}\left(\epsilon_{j}-\frac{Y \mathcal{C}^{\prime}}{\mathcal{C}}\right)\right), \\
& =\frac{1-\sigma}{\mathcal{E}}\left(\sum_{j} \Omega_{j} \epsilon_{j}^{2}-\mathcal{E}^{2}\right),
\end{aligned}
$$


where $\Omega_{j}$ is the factor intensity defined by $\Omega_{j} \equiv\left(Y^{\epsilon_{j}} W_{j} / \mathcal{C}\right)^{1-\sigma}$. We can write the expression within the parentheses as the variance of the parameters $\left\{\epsilon_{j}\right\}_{j=1}^{J}$ under the distribution implied by factor shares $\left\{\Omega_{j}\right\}_{j=1}^{J}$, defined as $\mathcal{V}(Y) \equiv \sum_{j} \Omega_{j}(Y)\left[\epsilon_{j}-\mathcal{E}(Y)\right]^{2}$. Note that in the case of $\left(\epsilon_{N}=\gamma, \epsilon_{I}=\gamma+\epsilon\right)$, this variance expression leads to Equation (12). Putting everything together, we find the following expression for the second derivative of the cost function

$$
\mathcal{C}^{\prime \prime}(Y)=\mathcal{E} \frac{\mathcal{C}}{Y^{2}}\left[\mathcal{E}\left(1+(1-\sigma) \frac{\mathcal{V}}{\mathcal{E}^{2}}\right)-1\right]
$$

Lemma. See Lemma 2.

Proof. First, let us rewrite problem (17) as

$$
\Pi_{i}=\max _{Y_{i}} \mathcal{R}\left(Y_{i}\right)-e^{-\theta_{i}} \mathcal{C}\left(Y_{i} ; e^{-\phi_{i}} W\right)-\psi
$$

where $\mathcal{R}\left(Y_{i}\right) \equiv P\left(Y_{i} / Y\right)^{-1 / \lambda} Y_{i}$ is the firm revenue function. The first order condition is given by $\mathcal{R}^{\prime}\left(Y_{i}\right)-e^{-\theta_{i}} \mathcal{C}^{\prime}\left(Y_{i}\right) \leq 0$. The goal is to ensure that for all $\left(\theta_{i}, \phi_{i}\right)$, there is a unique $Y_{i}$ that satisfies this condition with equality.

First, we show that the condition is always satisfied with equality at least for one value of $Y_{i}$. Given Assumption 1, we find that

$$
\begin{aligned}
\lim _{Y_{i} \rightarrow 0} \frac{\mathcal{C}^{\prime}\left(Y_{i}\right)}{Y_{i}^{\gamma-1}} & =\lim _{Y_{i} \rightarrow 0} \mathcal{E}_{i}\left(1+\left(e^{-\phi_{i}} W\right)^{1-\sigma} Y_{i}^{\epsilon(1-\sigma)}\right)^{\frac{1}{1-\sigma}}=\gamma, \\
\lim _{Y_{i} \rightarrow \infty} \frac{\mathcal{C}^{\prime}\left(Y_{i}\right)}{Y_{i}^{\gamma+\epsilon-1}} & =\lim _{Y_{i} \rightarrow \infty} \mathcal{E}_{i}\left(\left(e^{-\phi_{i}} W\right)^{1-\sigma}+Y_{i}^{-\epsilon(1-\sigma)}\right)^{\frac{1}{1-\sigma}}=(\gamma+\epsilon) e^{-\phi_{i}} W
\end{aligned}
$$

where we have used the notation $\mathcal{E}_{i} \equiv \mathcal{E}\left(Y_{i} ; e^{-\phi_{i}} W\right)$. Given the assumption $-\frac{1}{\lambda}<\gamma-1$, we have the following limits for the first order condition:

$$
\mathcal{R}^{\prime}\left(Y_{i}\right)-e^{-\theta_{i}} \mathcal{C}^{\prime}\left(Y_{i} ; e^{-\phi_{i}} W\right) \longrightarrow \begin{cases}P\left(1-\frac{1}{\lambda}\right)\left(\frac{Y_{i}}{Y}\right)^{-1 / \lambda}-\gamma e^{-\theta_{i}} Y_{i}^{\gamma-1} \rightarrow \infty, & Y_{i} \rightarrow 0, \\ P\left(1-\frac{1}{\lambda}\right)\left(\frac{Y_{i}}{Y}\right)^{-1 / \lambda}-(\gamma+\epsilon) \frac{W_{I}}{e^{\theta_{i}}} Y_{i}^{\gamma+\epsilon-1} \rightarrow-\infty, & Y_{i} \rightarrow \infty\end{cases}
$$

herefore, the first order condition has at least one zero for any finite pair $\left(\theta_{i}, \phi_{i}\right)$ and any finite combinations of $(P, Y, W)$.

Consider now one such a solution $Y_{i}^{*}$ for $\left(\theta_{i}, \phi_{i}\right)$ and $(P, Y, W)$ satisfying

$$
\mathcal{R}^{\prime}\left(Y_{i}^{*}\right)-e^{-\theta_{i}} \mathcal{C}^{\prime}\left(Y_{i}^{*} ; e^{-\phi_{i}} W\right)=\left(1-\frac{1}{\lambda}\right) P Y^{\lambda}\left(Y_{i}^{*}\right)^{-\frac{1}{\lambda}}-\mathcal{E}_{i} \frac{\mathcal{C}\left(Y_{i}^{*} ; e^{-\phi_{i}} W\right)}{e^{\theta_{i}} Y_{i}^{*}}=0
$$


To ensure that this zero indeed corresponds to a maximum, we need to examine the second order condition. Using Equations (??) and (11), we find

$$
\begin{aligned}
\mathcal{R}^{\prime \prime}\left(Y_{i}^{*}\right)-e^{-\theta_{i}} \mathcal{C}^{\prime \prime}\left(Y_{i}^{*} ; e^{-\phi_{i}} W\right) & =-\frac{1}{\left(Y_{i}^{*}\right)^{2}}\left\{\frac{1}{\lambda}\left(1-\frac{1}{\lambda}\right) P Y^{\lambda}\left(Y_{i}^{*}\right)^{1-\frac{1}{\lambda}}+\mathcal{E}_{i} \frac{\mathcal{C}\left(Y_{i}^{*} ; e^{-\phi_{i}} W\right)}{e^{\theta_{i}}}\left[\mathcal{E}_{i}\left(1+(1-\sigma) \frac{V_{i}}{\mathcal{E}_{i}^{2}}\right)-1\right]\right\} \\
& =-\left(1-\frac{1}{\lambda}\right) P Y^{\lambda}\left(Y_{i}^{*}\right)^{-\frac{1}{\lambda}-1}\left\{\frac{1}{\lambda}+\mathcal{E}_{i}\left(1+(1-\sigma) \frac{V_{i}}{\mathcal{E}_{i}^{2}}\right)-1\right\}
\end{aligned}
$$

where we have used the notation $V_{i} \equiv \mathcal{V}\left(Y_{i} ; e^{-\phi_{i}} W\right)$. The expression above leads to the following condition

$$
1-\frac{1}{\lambda}<\mathcal{E}_{i}\left(1+(1-\sigma) \frac{V_{i}}{\mathcal{E}_{i}^{2}}\right) .
$$

The next step is to show that the solution $Y_{i}^{*}$ above is unique. We can rewrite Equation (52) as

$$
\mathcal{C}^{\prime}\left(Y_{i}^{*} ; e^{-\phi_{i}} W\right)\left(Y_{i}^{*}\right)^{1 / \lambda}=\left(1-\frac{1}{\lambda}\right) P Y^{\lambda} e^{\theta_{i}}
$$

To ensure that there is only $Y_{i}^{*}$ satisfying the equation above, it is sufficient to show that function $\mathcal{L}(Y) \equiv$ $\mathcal{C}^{\prime}(Y) Y^{\frac{1}{\lambda}}$ is monotonic. Computing the derivative, we find

$$
\begin{aligned}
\mathcal{L}^{\prime}(Y) & =\mathcal{C}^{\prime \prime}(Y) Y^{\frac{1}{\lambda}}+\frac{1}{\lambda Y} \mathcal{C}^{\prime}(Y) Y^{\frac{1}{\lambda}} \\
& =\mathcal{C}^{\prime}(Y) Y^{\frac{1}{\lambda}-1}\left(\frac{1}{\lambda}+\frac{Y \mathcal{C}^{\prime \prime}}{\mathcal{C}^{\prime}}\right), \\
& =\mathcal{C}^{\prime}(Y) Y^{\frac{1}{\lambda}-1}\left(\frac{1}{\lambda}+\mathcal{E}\left(1+(1-\sigma) \frac{\mathcal{V}}{\mathcal{E}^{2}}\right)-1\right),
\end{aligned}
$$

where we have used Equation (51).

Now, first consider the case of $0<\sigma<1$. In this case, one can verify that the restriction $1-\frac{1}{\lambda}<\gamma$ is sufficient to satisfy all the conditions above required for the existence and uniqueness of the solution. Now define $\epsilon_{N} \equiv \gamma$ and $\epsilon_{I} \equiv \gamma+\epsilon$. In the case of $\sigma>1$, we can bound the term involving the coefficient of variation as

$$
\frac{\mathcal{V}}{\mathcal{E}}<\min \left\{\frac{1}{4} \frac{\left(\epsilon_{N}-\epsilon_{I}\right)^{2}}{\epsilon_{I}}, \epsilon_{N}-\epsilon_{I}\right\},
$$

where the first term comes from the fact that upper bound on the variance term is given by $\frac{1}{4}\left(\max \left\{\epsilon_{N}, \epsilon_{I}\right\}-\min \left\{\epsilon_{N}, \epsilon_{I}\right\}\right)^{2}=$ $\frac{1}{4}\left(\epsilon_{N}-\epsilon_{I}\right)^{2}$, and the second term from the fact that $\epsilon_{N}^{2}(1-\Omega)+\epsilon_{I}^{2} \Omega \leq \epsilon_{N} \bar{\epsilon}$. We can then write

$$
\begin{aligned}
\mathcal{E}-(\sigma-1) \frac{\mathcal{V}}{\mathcal{E}^{2}} & >\bar{\epsilon}_{i}-(\sigma-1) \min \left\{\frac{1}{4} \frac{\left(\epsilon_{N}-\epsilon_{I}\right)^{2}}{\epsilon_{I}}, \epsilon_{N}-\epsilon_{I}\right\}, \\
& \geq \epsilon_{I}-(\sigma-1) \min \left\{\frac{1}{4} \frac{\left(\epsilon_{N}-\epsilon_{I}\right)^{2}}{\epsilon_{I}}, \epsilon_{N}-\epsilon_{I}\right\} .
\end{aligned}
$$


In this case, one can verify that, in addition to the restriction $1-\frac{1}{\lambda}<\epsilon_{I}$, the following restriction is sufficient to satisfy the existence and uniqueness conditions laid out above:

$$
(\sigma-1) \min \left\{\frac{1}{4} \frac{\left(\epsilon_{N}-\epsilon_{I}\right)^{2}}{\epsilon_{I}}, \epsilon_{N}-\epsilon_{I}\right\}<\epsilon_{I}-\left(1-\frac{1}{\lambda}\right) .
$$

Finally, taking the derivative of the first-order condition with respect to $e^{\theta_{i}}$, we find:

$$
\left[\mathcal{R}^{\prime \prime}\left(Y_{i}^{*}\right)-\frac{1}{Z} \mathcal{C}^{\prime \prime}\left(Y_{i}^{*}\right)\right] \frac{\partial Y_{i}}{\partial e^{\theta_{i}}}=-\frac{1}{e^{2 \theta_{i}}} \mathcal{C}^{\prime}\left(Y_{i}\right)
$$

As we saw the second order condition ensures that $\mathcal{R}^{\prime \prime}\left(Y_{i}\right)-e^{-\theta_{i}} \mathcal{C}^{\prime \prime}\left(Y ; e^{-\phi_{i} W}\right)<0$ at the optimum, which implies that $\frac{\partial Y}{\partial e^{\theta}}>0$. Since the inverse demand function of decreasing, it follows that the optimal price is decreasing in $\theta_{i}$. Showing the same result for $\phi_{i}$ is straightforward.

\section{Derivations for Definition 1.}

Let us start with a cost minimization problem of the firm:

$$
\begin{aligned}
\min & W_{L} L_{i}+W_{K} K_{i}+W_{S} S_{i}+W_{H} H_{i} \\
Y_{i} & \geq \mathcal{F}\left(e^{\theta_{i}+\phi_{i}} X_{N, i}, e^{\theta_{i}} X_{I, i}\right) \\
X_{N, i t} & \leq K_{i}^{\alpha} L_{i}^{1-\alpha} \\
X_{I, i} & \leq S_{i}^{\beta} H_{i}^{1-\beta} .
\end{aligned}
$$

Using f.o.c's for $K_{i}$ and $L_{i}$, we find that $W_{L}=(1-\alpha) \mu_{N, i}\left(K_{i} / L_{i}\right)^{\alpha}$ and $W_{K}=\alpha \mu_{N, i}\left(L_{i} / K_{i}\right)^{1-\alpha}$ where $\mu_{N, i}$ is the Lagrange multiplier corresponding to the constraint on the non-IT input bundle. Applying the normalization $\left(W_{L, t} /(1-\alpha)\right)^{1-\alpha}\left(W_{K, t} / \alpha\right)^{\alpha}$, we find that $\mu_{N, i}=1$ and $X_{N, i}=W_{L} L_{i}+W_{K} K_{i}$. Since capital to labor ratios are equalized across all firms, we know that $\bar{K} / \bar{L}=K_{i} / L_{i}$ and $\bar{X}_{N} \equiv \int X_{N, i} d i=$ $\bar{K}^{\alpha} \bar{L}^{1-\alpha}$. Applying the same argument to the f.o.c.'s for $S_{i}$ and $H_{i}$, we find that $W_{S} S_{i}=\beta W X_{I, i}, W_{H} H_{i}=$ $(1-\beta) W X_{I, i}$, and $\bar{X}_{I} \equiv \int X_{I, i}=\bar{S}^{\beta} \bar{H}^{1-\beta}$.

We can now write the labor and capital market clearing conditions

$$
\begin{aligned}
W_{L} \bar{L} & =(1-\alpha) \bar{X}_{N}, \\
W_{K} \bar{K} & =\alpha \bar{X}_{N} .
\end{aligned}
$$

and combine them to find market clearing condition for the non-IT input as:

$$
\begin{aligned}
\bar{X}_{N} & =W_{L} \bar{L}+W_{K} \mathrm{~K}, \\
& =N\left[\psi+\iint(1-\widetilde{\Omega}(\theta, \phi ; P, Y, W)) \widetilde{C}(\theta, \phi ; P, Y, W) g(\theta, \phi) d \theta d \phi\right]+N_{o} \delta \chi .
\end{aligned}
$$


The market clearing condition for the IT inputs follows similarly.

\section{Derivations for Equations (36) and (37).}

First, note that we have $\Omega_{i}=\left(Y_{i}^{\gamma+\epsilon} e^{-\phi_{i} W / \mathcal{C}_{i}}\right)^{1-\sigma}$, and therefore:

$$
\begin{aligned}
& \frac{\partial \log \Omega_{i}}{\partial w}=(1-\sigma)\left(1-\frac{\partial c_{i}}{\partial w}\right)=(1-\sigma)\left(1-\Omega_{i}\right) \\
& \frac{\partial \log \Omega_{i}}{\partial y_{i}}=(1-\sigma)\left(\gamma+\epsilon-\frac{\partial c_{i}}{\partial y_{i}}\right)=(1-\sigma)\left(\gamma+\epsilon-\mathcal{E}_{i}\right)=(1-\sigma) \epsilon\left(1-\Omega_{i}\right) .
\end{aligned}
$$

where in the first and second lines we have used $y_{i}$ and $c_{i}$ to refer to the $\log$ of output $Y_{i}$ and costs $C_{i}$, respectively. Recall that we have $\mathcal{C}_{i}=e^{-\theta_{i}} Y_{i}^{\gamma}\left(1+\left(Y_{i}^{\epsilon} e^{-\phi_{i} W}\right)^{1-\sigma}\right)^{1 /(1-\sigma)}$, implying $\partial c_{i} / \partial w=\Omega_{i}$. We now substitute the expressions above in a first-order approximation of the change in the cost elasticity $\mathcal{E}_{i}$ as the result of the log change $\Delta w$ in the relative price of IT:

$$
\begin{aligned}
\Delta \mathcal{E}_{i} & \approx \frac{\partial \mathcal{E}_{i}}{\partial w} \Delta w+\frac{\partial \mathcal{E}_{i}}{\partial y} \Delta y_{i}, \\
& =\epsilon\left(\frac{\partial \Omega_{i}}{\partial w} \Delta w+\frac{\partial \Omega_{i}}{\partial y} \Delta y_{i}\right), \\
& =\epsilon \Omega_{i}\left(\frac{\partial \log \Omega_{i}}{\partial w} \Delta w+\frac{\partial \log }{\partial y} \Delta y_{i}\right), \\
& =(1-\sigma) \epsilon \Omega_{i}\left[\left(1-\Omega_{i}\right) \Delta w+\left(\gamma+\epsilon-\mathcal{E}_{i}\right) \Delta y_{i}\right], \\
& =(1-\sigma) \epsilon \Omega_{i}\left[\left(1-\Omega_{i}\right) \Delta w+\epsilon\left(1-\Omega_{i}\right) \Delta y_{i}\right],
\end{aligned}
$$

where the last equality leads to Equation (36). Noting that $S_{i}=C_{i} g_{i} / \bar{C}$ then leads to Equation (37).

Lemma. See Lemma 3.

Proof. Let us write Equation (19) as:

$$
\left(\frac{Y_{i}}{Y}\right)^{-\frac{1}{\lambda}}=\frac{\lambda}{\lambda-1} \frac{\mathcal{C}^{\prime}\left(Y_{i} ; e^{-\phi_{i} W}\right)}{e^{\theta_{i} P}} .
$$

Rewriting the equation in logarithm terms and differentiating, we find:

$$
-\frac{1}{\lambda}\left(\Delta y_{i}-\Delta y\right) \approx \frac{\partial m c}{\partial y} \Delta y_{i}+\frac{\partial m c}{\partial w} \Delta w-\Delta p
$$

where, as before, we have used the small cap letters to denote log functions. This will lead to Equation (38). To derive Equations (39) and (40), we first note that $M C_{i}=\mathcal{E}_{i} \mathcal{C}_{i} / Y_{i}$. It follows that:

$$
\frac{\partial m c_{i}}{\partial w}=\frac{\partial c_{i}}{\partial w}+\frac{\partial \log \mathcal{E}_{i}}{\partial w}
$$




$$
\begin{aligned}
& =\Omega_{i}+\frac{\epsilon}{\mathcal{E}_{i}} \frac{\partial \Omega_{i}}{\partial w}, \\
& =\Omega_{i}+\frac{\epsilon \Omega_{i}}{\gamma+\epsilon \Omega_{i}} \frac{\partial \log \Omega_{i}}{\partial w}, \\
& =\Omega_{i}\left(1+(1-\sigma) \epsilon \frac{1-\Omega_{i}}{\gamma+\epsilon \Omega_{i}}\right),
\end{aligned}
$$

where in the last equality we have substituted the expression for $\frac{\partial \log \Omega_{i}}{\partial w}$ from above. Similarly, we have:

$$
\begin{aligned}
\frac{\partial m c_{i}}{\partial y_{i}} & =\frac{\partial c_{i}}{\partial y_{i}}-1+\frac{\partial \log \mathcal{E}_{i}}{\partial y_{i}}, \\
& =\mathcal{E}_{i}-1+\frac{\epsilon}{\mathcal{E}_{i}} \frac{\partial \Omega_{i}}{\partial y_{i}} \\
& =\gamma-1+\Omega_{i} \epsilon+\frac{\epsilon \Omega_{i}}{\gamma+\epsilon \Omega_{i}} \frac{\partial \log \Omega_{i}}{\partial y_{i}}, \\
& =\gamma-1+\Omega_{i} \epsilon\left(1+(1-\sigma) \epsilon \frac{1-\Omega_{i}}{\gamma+\epsilon \Omega_{i}}\right) .
\end{aligned}
$$

Lemma. See Lemma 4.

Proof. Consider the problem of the firm that starts period $t$ with stock productivity state variables $\left(\theta_{i t}, \phi_{i t}\right)$ and stocks of non-IT capital, hardware, and softare $\left(K_{i t-1}, H_{i t-1}, S_{i t-1}\right)$ (as expected, we will see that the stock of software $S_{t-1}$ is not a state variable):

$$
\begin{aligned}
V_{t}\left(\theta_{i t}, \phi_{i t}, K_{i t-1}, H_{i t-1}, S_{i t-1}\right)= & \max _{Y_{i t}, L_{i t}, K_{i t}, S_{i t}, H_{i t}} \mathcal{P}\left(Y_{i t}\right) Y_{i t}-W_{t} L_{i t}-Q_{t}\left(S_{i t}-S_{i t-1}\left(1-\delta_{S}\right)\right) \\
& \quad-\mathcal{C}_{t}^{K}\left(K_{i t} ; K_{i t-1}\right)-\mathcal{C}_{t}^{H}\left(H_{i t} ; H_{i t-1}\right)+\frac{1}{1+r_{t}} \mathbb{E}_{\theta_{i t+1}, \phi_{i t+1}}\left[V _ { t + 1 } \left(\theta_{i t+1}, \phi_{i t+1}, K_{i t}, H_{i t}\right.\right. \\
\text { subject to: } Y_{t}= & F\left(e^{\theta_{i t}} K_{t}^{\alpha} L_{t}^{1-\alpha}, e^{\phi_{i t}+\theta_{i t}} S_{t}^{\beta} H_{t}^{1-\beta}\right)
\end{aligned}
$$

where $\mathcal{P}\left(Y_{i t}\right)$ denotes the demand function (potentially downward sloping), $\delta_{S}$ is the depreciation rate of software capital, and $\mathcal{C}_{t}^{K}$ and $\mathcal{C}_{t}^{H}$ are generic functions that capture potential adjustment costs for dynamic inputs $K_{i t}$ and $H_{i t}$, respectively. Based on assumption 5, we assume no adjustment costs for software capital and therefore the firm faces software investment at price $Q_{t}$.

Conditional on the optimal $Y_{t}$, and defining $\Lambda_{t}$ to be the Lagrange multiplier corresponding to the constraint on $Y_{t}$, we find:

$$
Q_{t}=\Lambda_{i t} \frac{\partial Y_{i t}}{\partial X_{N, i t}} \frac{\partial X_{N, i t}}{\partial S_{i t}}+\frac{1}{1+r_{t}} \mathbb{E}_{\theta_{i t+1}, \phi_{i t+1}}\left[\frac{\partial}{\partial S_{i t}} V_{t+1}\left(\theta_{i t+1}, \phi_{i t+1}, K_{i t}, H_{i t}, S_{i t}\right) \mid \mathcal{I}_{i t}\right] .
$$


We can also compute the partial derivative of the value function simply as:

$$
\frac{\partial}{\partial S_{i t}} V_{t+1}\left(\theta_{i t+1}, \phi_{i t+1}, K_{i t}, H_{i t}, S_{i t}\right)=\left(1-\delta_{S}\right) Q_{t+1}
$$

Therefore, we can define the user cost of software (the effective price of software capital) as follows

$$
\begin{aligned}
W_{S, i t} & \equiv Q_{t}-\frac{1-\delta_{S}}{1+r_{t}} Q_{t+1} \\
& =Q_{t}\left(1-\frac{1-\delta_{S}}{1+r_{t}} \frac{Q_{t+1}}{Q_{t}}\right), \\
& =Q_{t}\left(1-R_{S, t}^{-1}\right)
\end{aligned}
$$

where $R_{S, t}$ is the required rate of return for software investments.

Based on the derivations above, we can redefine the problem as that of a firm with four state variables $\left(\theta_{i t}, \phi_{i t}, K_{i t}, H_{i t}\right)$ and with:

$$
\begin{aligned}
V_{t}\left(\theta_{i t}, \phi_{i t}, K_{i t-1}, H_{i t-1}\right)= & \max _{Y_{i t}, L_{i t}, K_{i t}, S_{i t}, H_{i t}} \mathcal{P}\left(Y_{i t}\right) Y_{i t}-W_{t} L_{i t}-W_{S, t} S_{i t} \\
& \quad-\mathcal{C}_{t}^{K}\left(K_{i t} ; K_{i t-1}\right)-\mathcal{C}_{t}^{H}\left(H_{i t} ; H_{i t-1}\right)+\left(1-\delta_{t}\right) \mathbb{E}_{\theta_{i t+1}, \phi_{i t+1}}\left[V_{t+1}\left(\theta_{i t+1}, \phi_{i t+1}, K_{i t}, H_{i t}\right) \mid \mathcal{I}_{i t}\right. \\
\text { subject to: } Y_{i t}= & F\left(e^{\theta_{i t}} K_{i t}^{\alpha} L_{i t}^{1-\alpha}, e^{\phi_{i t}} e^{\theta_{i t}} S_{i t}^{\beta} H_{i t}^{1-\beta}\right)
\end{aligned}
$$

Let us now look at the first order conditions with respect to the two flexible inputs:

$$
\begin{aligned}
& W_{L, t}=\Lambda_{i t} \frac{\partial Y_{i t}}{\partial X_{N, i t}} \frac{\partial X_{N, i t}}{\partial L_{i t}}=\Lambda_{i t} \frac{Y_{i t}}{X_{N, i t}} \frac{1}{\mathcal{E}_{i t}}\left(\frac{e^{\theta_{i t} X_{N, i t}}}{Y_{i t}^{\gamma}}\right)^{1-\frac{1}{\sigma}}(1-\alpha) \frac{X_{N, i t}}{L_{i t}}, \\
& W_{S, t}=\Lambda_{i t} \frac{\partial Y_{i t}}{\partial X_{I, i t}} \frac{\partial X_{I, i t}}{\partial S_{i t}}=\Lambda_{i t} \frac{Y_{i t}}{X_{I, i t}} \frac{1}{\mathcal{E}_{i t}}\left(\frac{e^{\theta_{i t}+\phi_{i t} X_{I, i t}}}{Y_{i t}^{\gamma+\epsilon}}\right)^{1-\frac{1}{\sigma}} \beta \frac{X_{I, i t}}{S_{i t}},
\end{aligned}
$$

where $W_{L, t}$ and $W_{S, t}$ are the wage rate and the rental price of software, respectively, and $\Lambda_{i t}$ is the marginal cost of production for the firm. First, we divide the two equations Equations (55) and (56) and rewrite them as

$$
\begin{aligned}
\frac{W_{S, t}}{W_{L, t}} & =\frac{\beta}{1-\alpha} \frac{L_{i t}}{S_{i t}}\left(e^{\phi_{i t}} \frac{X_{I, i t}}{X_{N, i t}}\left(Y_{i t}^{*}\right)^{\epsilon_{N}-\epsilon_{I}}\right)^{1-\frac{1}{\sigma}}, \\
& =\frac{\beta}{1-\alpha}\left(\frac{S_{i t}}{L_{i t}}\right)^{-\frac{1}{\sigma}}\left(e^{\phi_{i t}} \frac{\left(H_{i t} / S_{i t}\right)^{1-\beta}}{\left(K_{i t} / L_{i t}\right)^{\alpha}} Y_{i t}^{\epsilon}\right)^{1-\frac{1}{\sigma}} .
\end{aligned}
$$

We now write this equation in first differences to find:

$$
s_{i t}-l_{i t}=\sigma\left(w_{L, t}-w_{S, t}\right)+(\sigma-1)\left[\phi_{i t}-\epsilon y_{i t}-\alpha\left(k_{i t}-l_{i t}\right)+(1-\beta)\left(b_{i t}-s_{i t}\right)\right] .
$$




\section{Decompositions of the Labor Share}

In this section, we will present the details of the decompositions of labor share presented in Section 3. These decompositions are done at two levels: first we decompose the aggregate changes in labor share to the within and across industries components. Next, we decompose the industry-level changes in labor share to within and across quantiles components, where quantiles of labor share are specific to each year and each industry.

Let $k \in\{1, \cdots, K\}$ be some industry classification (e.g., 3 digits in micro data), $Y$ stands for value added, $L$ for wage bill, and $\Lambda$ for the labor share defiend as $L / Y$. Also, let $S_{k}$ and $\Lambda_{k}$ stand for the share of the industry in total value added and the industy average labor share, defined as $L_{k} / Y_{k}$, respectively. Define for any varible $X$ :

$$
\begin{aligned}
\Delta X_{t} & \equiv X_{t}-X_{t-1}, \bar{X}_{t} \equiv \frac{1}{2}\left(X_{t}+X_{t-1}\right), \\
\Delta_{T} X & \equiv X_{T}-X_{0}
\end{aligned}
$$

where $T$ is the last period and 0 is the first period. Our first decomposition is: ${ }^{52}$

$$
\Delta_{T} \Lambda \equiv \underbrace{\sum_{t=1}^{T} \sum_{k} \bar{S}_{k t} \Delta \Lambda_{k t}}_{\text {within industry }}+\underbrace{\sum_{t=1}^{T} \sum_{k} \Delta S_{k t} \bar{\Lambda}_{k t}}_{\text {across industries }} .
$$

Next, we focus on changes in the industry-level labor shares. Our aim is to decompose the changes in the industry-level labor share to the shifts in the distribution of firms labor shares and the changes in market shares of firms along the distribution. Let $p$ denote a probability, we can write the industry-level labor share as

$$
\Lambda_{k t} \equiv \int_{0}^{1} S_{k t}(p) \Lambda_{k t}(p) d p,
$$

where $\Lambda_{k t}(p)$ is the average labor share of firms between the $(p-1)$-th and $p$-th quantile in the labor share distribution in industry- $k$ at time $t$ and $S_{k t}(p)$ denotes their share of industry- $k$ value added at time $t$. We

\footnotetext{
${ }^{52}$ This is simply because:
}

$$
\begin{aligned}
& \Delta\left(S_{t} \Lambda_{t}\right)=\bar{S}_{t} \Delta \Lambda_{t}+\Delta S_{t} \bar{\Lambda}_{t} \\
& \Delta_{T}(S \Lambda)=\sum_{t=1}^{T} \Delta\left(S_{t} \Lambda_{t}\right) .
\end{aligned}
$$


can now decompose ${ }^{53}$

$$
\Delta \Lambda_{k t}=\underbrace{\int_{0}^{1} \bar{S}_{k t}(p) \Delta \Lambda_{k t}(p) d p}_{\text {Within quantile }}+\underbrace{\int_{0}^{1} \Delta S_{k t}(p) \bar{\Lambda}_{k t}(p) d p}_{\text {Across quantiles }}
$$

We now summarize the within-industry component change in aggregate labor share into the following components:

1. The cross quantiles component:

$$
\sum_{t=1}^{T} \sum_{k} \bar{S}_{k t} \int_{0}^{1} \Delta S_{k t}(p) \bar{\Lambda}_{k t}(p) d p
$$

2. The within quantile component:

$$
\sum_{t=1}^{T} \sum_{k} \bar{S}_{k t} \int_{0}^{1} \bar{S}_{k t}(p) \Delta \Lambda_{k t}(p) d p
$$

\section{Estimation}

\section{D.1 Setting Up the GMM Estimation}

Let $\boldsymbol{D}$ stand for the observed data and $\boldsymbol{\rho} \equiv\left(\rho_{\theta}, \rho_{\phi}\right)$ for the vector of persistence coefficients. We can write the $2 J$-dimensional vector of moments $\boldsymbol{g}\left(\boldsymbol{D}_{i t} ; \varsigma, \boldsymbol{\rho}\right)$ as

$$
\begin{aligned}
& g_{j}\left(\boldsymbol{D}_{i t} ; \boldsymbol{\varsigma}, \boldsymbol{\rho}\right) \equiv b_{j i t-1}\left(\Theta_{i t}(\boldsymbol{\varsigma})-\rho_{\theta \theta} \Theta_{i t-1}(\boldsymbol{\varsigma})-\rho_{\theta \phi} \Phi_{i t-1}(\boldsymbol{\varsigma})\right), j \leq J, \\
& g_{j}\left(\boldsymbol{D}_{i t} ; \boldsymbol{\varsigma}, \boldsymbol{\rho}\right) \equiv b_{j i t-1}\left(\Phi_{i t}(\boldsymbol{\varsigma})-\rho_{\phi \theta} \Theta_{i t-1}(\boldsymbol{\varsigma})-\rho_{\phi \phi} \Phi_{i t-1}(\boldsymbol{\varsigma})\right), j \geq J+1,
\end{aligned}
$$

where $b_{j i t-1} \in \mathcal{I}_{i t-1}$ is each of the instruments and function $\Phi$ defines IT biased productivity as a function of observed data and model parameters

\footnotetext{
${ }^{53}$ As emphasized by Kehrig and Vincent (2017), this decomposition is conceptually distinct from standard within and cross firm decompositions. Let $\Omega_{k t}$ be the set of firms active in time $t$, and $\bar{\Omega}_{k t}$ be the set of firms common between time $t$ and $t-1, \Omega_{k t}^{+}$the set of new firms at time $t$, and $\Omega_{k t}^{-}$the set of firms exiting between time $t$ and $t+1$. We can then write:

$$
\Delta \Lambda_{k t} \equiv \underbrace{\sum_{i \in \Omega_{t}^{-}} \bar{S}_{i t} \Delta \Lambda_{i t}}_{\text {within firm }}+\underbrace{\sum_{i \in \Omega_{k t}^{-}} \Delta S_{i t} \bar{\Lambda}_{i t}}_{\text {cross firm }}+\underbrace{\left(\sum_{i \in \Omega_{k t}^{+}} S_{i t} \Lambda_{i t}-\sum_{i \in \Omega_{k t-1}^{-}} S_{i t-1} \Lambda_{i t-1}\right)}_{\text {net entry }},
$$
}

where again shares are computed within the industy. 


$$
\Phi\left(\boldsymbol{D}_{i t} ; \varsigma\right)=\frac{1}{\sigma-1}\left(\sigma \widehat{w}_{i t}+s_{i t}-l_{i t}\right)+\epsilon y_{i t}+\alpha\left(k_{i t}-l_{i t}\right)-(1-\beta)\left(b_{i t}-s_{i t}\right),
$$

while function $\Theta$ is the corresponding function for factor symmetric productivity:

$$
\Theta\left(\boldsymbol{D}_{i t} ; \boldsymbol{\varsigma}\right) \equiv \gamma y_{i t}+\frac{\sigma}{1-\sigma} \log \left[e^{\frac{\sigma-1}{\sigma}\left(\alpha k_{i t}+(1-\alpha) l_{i t}\right)}+e^{\frac{\sigma-1}{\sigma}\left(\beta s_{i t}+(1-\beta) h_{i t}-\epsilon y_{i t}+\Phi\left(\widehat{w}_{i t}, l_{i t}, k_{i t}, s_{i t}, h_{i t}, y_{i t} ; \boldsymbol{\varsigma}\right)\right)}\right],
$$

where $\widehat{w}_{i t} \equiv w_{S, t}-w_{L i, t}$ is the relative price of software. User cost of software $w_{S, t}$ has no unit (euros per euros of software capital). Wage $w_{L i, t}$ is in thousand euros per worker, $l_{i t}$ is number of workers, and $y_{i t}$, $k_{i t}, s_{i t}, h_{i t}$ are in thousand euros. This units should be reflected in the values used for calibration.

The GMM estimator is then given by

$$
(\widehat{\boldsymbol{\varsigma}}, \widehat{\boldsymbol{\rho}}) \equiv \underset{(\boldsymbol{\varsigma}, \boldsymbol{\rho})}{\operatorname{argmax}}\left[\sum_{i t} \boldsymbol{g}\left(\boldsymbol{D}_{i t} ; \boldsymbol{\varsigma}, \boldsymbol{\rho}\right)\right]^{\prime} \widehat{\boldsymbol{\Xi}}\left[\sum_{i t} \boldsymbol{g}\left(\boldsymbol{D}_{i t} ; \boldsymbol{\varsigma}, \boldsymbol{\rho}\right)\right]
$$

where $\widehat{\boldsymbol{\Xi}}$ is a $J \times J$ full-rank matrix. Alternatively, we can write

$$
\boldsymbol{g}_{i t}(\varsigma, \boldsymbol{\rho}) \equiv B_{i t}^{\prime} \boldsymbol{e}_{i t}(\varsigma, \boldsymbol{\rho})
$$

where we have defined define $\boldsymbol{b}_{i t-1} \equiv\left(b_{1, i t-1}, \cdots, b_{J, i t-1}\right)^{\prime}$ and

$$
\boldsymbol{B}_{i t} \equiv\left(\begin{array}{cc}
\boldsymbol{b}_{i t-1} & \mathbf{0} \\
\mathbf{0} & \boldsymbol{b}_{i t-1}
\end{array}\right), \quad \boldsymbol{e}_{i t} \equiv\left(\begin{array}{c}
\Theta_{i t}(\boldsymbol{\varsigma})-\rho_{\theta \theta} \Theta_{i t-1}(\boldsymbol{\varsigma})-\rho_{\theta \phi} \Phi_{i t-1}(\boldsymbol{\varsigma}) \\
\Phi_{i t}(\boldsymbol{\varsigma})-\rho_{\phi \theta} \Theta_{i t-1}(\boldsymbol{\varsigma})-\rho_{\phi \phi} \Phi_{i t-1}(\boldsymbol{\varsigma})
\end{array}\right)
$$

We use a nonlinear system 2SLS estimator $\left(\widehat{\boldsymbol{\varsigma}}^{0}, \widehat{\boldsymbol{\rho}}^{0}\right)$, setting

$$
\widehat{\Xi} \equiv\left(\frac{1}{N T} \sum_{i t} \boldsymbol{B}_{i t}^{\prime} \boldsymbol{B}_{i t}\right)^{-1}
$$

\section{D.2 Initializing Parameter Estimates}

To find reasonable initial parameters for the optimization step in the GMM estimation, we use a cascading series of intuitive simplifications of the model to lead the optimizer to the relevant parts of the parameter space. A key step in this approach is a log-linear approximation of the production function that helps create a bridge between the GMM moment conditions derived from our model with those typically used under the assumption of a Cobb-Douglas production function. More specifically, this approximation gives us a $\log$-linear expression for the factor-symmetric productivity function $\theta_{i t}=\widetilde{\Theta}\left(\boldsymbol{D}_{i t} ; \varsigma\right)$ that we use in lieu of Equation (64). We will discuss this approximation in Section D.3 below. 


\section{D.3 Log-Linear Approximation for the Factor-Symmetric Productivity Function}

Recall the evolution of productivities in Equation (16) and consider a firm $i$ in industry $j$ with a stationary distribution of productivities $G_{j}$. The Markov process of productivity states in this industry for each firm converges to a long-run distribution of productivities with industry-level mean values $\left(\theta_{j} \equiv \mathbb{E}_{G_{j}}[\theta], \phi_{j} \equiv \mathbb{E}_{G_{j}}[\phi]\right)$. Similarly, let inputs $\left(K_{j}, L_{j}, H_{j}, S_{j}\right)$ be the corresponding mean values of inputs for a firm with the corresponding mean productivity states. Log-linearizing the production function around the average industry level gives us

$$
\begin{aligned}
&\left(\gamma+\Omega_{j} \epsilon\right)\left(y_{i t}-y_{j}\right) \approx \Omega_{j} {\left[\beta\left(s_{i t}-s_{j}\right)+(1-\beta)\left(b_{i t}-b_{j}\right)+\left(\phi_{i t}-\phi_{j}\right)\right] } \\
&+\left(1-\Omega_{j}\right)\left[\alpha\left(k_{i t}-k_{j}\right)+(1-\alpha)\left(l_{i t}-l_{j}\right)\right]+\theta_{i t}-\theta_{j},
\end{aligned}
$$

where we have defined $\Omega_{j} \equiv\left(e^{\phi_{j}+\theta_{j}} X_{I, j} / Y_{j}^{\gamma+\epsilon}\right)^{1-1 / \sigma}$ and, as before, used small cap letter to denote the logarithms of the corresponding variables.

We can rewrite the expression above in a form that resembles the Cobb-Douglas production function:

$$
y_{i t} \approx \gamma_{1} k_{i t}+\gamma_{2} l_{i t}+\gamma_{3} s_{i t}+\gamma_{4} h_{i t}+\tilde{\theta}_{i t}
$$

where we have defined:

$$
\begin{aligned}
\gamma_{1} & \equiv \frac{\alpha\left(1-\Omega_{j}\right)}{\gamma+\Omega_{j} \epsilon}, \\
\gamma_{2} & \equiv \frac{(1-\alpha)\left(1-\Omega_{j}\right)}{\gamma+\Omega_{j} \epsilon}, \\
\gamma_{3} & \equiv \frac{\beta \Omega_{j}}{\gamma+\Omega_{j} \epsilon}, \\
\gamma_{4} & \equiv \frac{(1-\beta) \Omega_{j}}{\gamma+\Omega_{j} \epsilon}, \\
\tilde{\theta}_{i t} & \equiv\left(\gamma_{1}+\gamma_{2}+\gamma_{3}+\gamma_{4}\right) \theta_{i t}+\left(\gamma_{3}+\gamma_{4}\right) \phi_{i t}+\tilde{\theta}_{j}, \\
\tilde{\theta}_{j} & \equiv-\left(\left(\gamma_{1}+\gamma_{2}+\gamma_{3}+\gamma_{4}\right) \theta_{j}+\left(\gamma_{3}+\gamma_{4}\right) \phi_{j}\right)+\left[y_{j}-\left(\gamma_{1} k_{j}+\gamma_{2} l_{j}+\gamma_{3} s_{j}+\gamma_{4} h_{j}\right)\right] .
\end{aligned}
$$

Let us also define a scaling of the IT-biased productivity and rewrite the cost minimization condition as:

$$
\begin{aligned}
\tilde{\phi}_{i t} & \equiv(\sigma-1) \phi_{i t}, \\
& =s_{i t}-l_{i t}+\sigma \widehat{w}_{t}+(\sigma-1)\left[\epsilon y_{i t}+\alpha\left(k_{i t}-l_{i t}\right)-(1-\beta)\left(b_{i t}-s_{i t}\right)\right] .
\end{aligned}
$$


Now, we substitute Equations (61) and (62) with:

$$
\begin{aligned}
\widetilde{\Theta}\left(\boldsymbol{D}_{i t} ; \gamma\right) & \equiv y_{i t}-\left(\gamma_{1} k_{i t}+\gamma_{2} l_{i t}+\gamma_{3} s_{i t}+\gamma_{4} h_{i t}\right) \\
\widetilde{\Phi}\left(\boldsymbol{D}_{i t} ; \sigma, \epsilon, \gamma\right) & \equiv s_{i t}-l_{i t}+\sigma \widehat{w}_{i t}+(\sigma-1)\left[\epsilon y_{i t}+\frac{\gamma_{1}}{\gamma_{1}+\gamma_{2}}\left(k_{i t}-l_{i t}\right)-\frac{\gamma_{4}}{\gamma_{3}+\gamma_{4}}\left(b_{i t}-s_{i t}\right)\right] .
\end{aligned}
$$

Next, note that we can write:

$$
\begin{aligned}
& \left(\begin{array}{c}
\tilde{\theta}_{i t} \\
\tilde{\phi}_{i t}
\end{array}\right)=\boldsymbol{B}\left(\begin{array}{c}
\theta_{i t} \\
\phi_{i t}
\end{array}\right)+\left(\begin{array}{c}
\tilde{\theta}_{j} \\
0
\end{array}\right)
\end{aligned}
$$

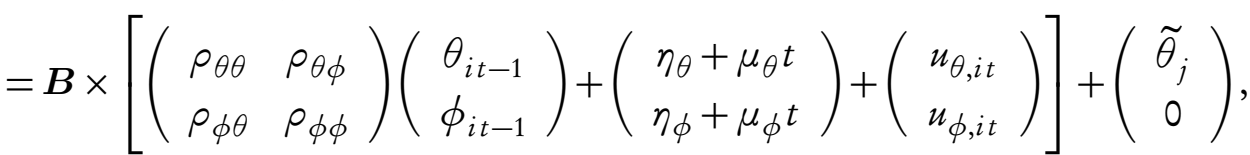

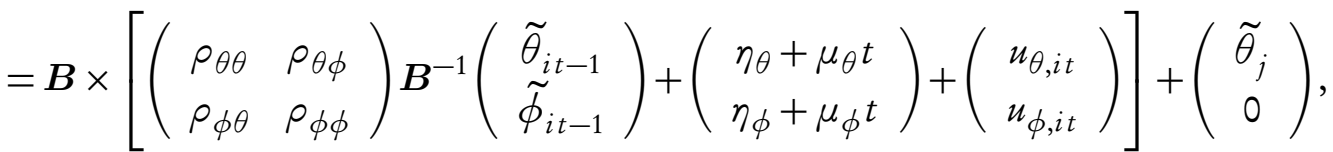

$$
\begin{aligned}
& =\left(\begin{array}{cc}
\rho \tilde{\theta} \tilde{\theta} & \rho \tilde{\theta} \tilde{\phi} \\
\rho \tilde{\phi} \tilde{\theta} & \rho \tilde{\phi} \tilde{\phi}
\end{array}\right)\left(\begin{array}{c}
\tilde{\theta}_{i t-1} \\
\tilde{\phi}_{i t-1}
\end{array}\right)+\left(\begin{array}{c}
\eta_{\tilde{\theta}}+\mu_{\tilde{\theta}} t \\
\eta_{\tilde{\phi}}+\mu_{\tilde{\phi}}^{t}
\end{array}\right)+\left(\begin{array}{c}
u_{\tilde{\theta}, i t} \\
u_{\tilde{\phi}, i t}
\end{array}\right) \text {, }
\end{aligned}
$$

where we have defined the matrix

$$
\boldsymbol{B} \equiv\left(\begin{array}{cc}
\gamma_{1}+\gamma_{2}+\gamma_{3}+\gamma_{4} & \gamma_{3}+\gamma_{4} \\
0 & \sigma-1
\end{array}\right)
$$

and we have

$$
\begin{aligned}
\left(\begin{array}{cc}
\rho \tilde{\theta} \tilde{\theta} & \rho_{\tilde{\theta} \tilde{\phi}} \\
\rho \tilde{\phi} \tilde{\theta} & \rho_{\tilde{\phi} \tilde{\phi}}
\end{array}\right) & \equiv \boldsymbol{B}\left(\begin{array}{cc}
\rho_{\theta \theta} & \rho_{\theta \phi} \\
\rho_{\phi \theta} & \rho_{\phi \phi}
\end{array}\right) \boldsymbol{B}^{-1}, \\
\left(\begin{array}{c}
\eta_{\tilde{\theta}}+\mu_{\tilde{\theta}} t \\
\eta_{\tilde{\phi}}+\mu_{\tilde{\phi}} t
\end{array}\right) & \equiv \boldsymbol{B}\left(\begin{array}{c}
\eta_{\theta}+\mu_{\theta} t \\
\eta_{\phi}+\mu_{\phi} t
\end{array}\right)+\left(\begin{array}{c}
\tilde{\theta}_{j} \\
0
\end{array}\right), \\
\left(\begin{array}{c}
u_{\tilde{\theta}, i t} \\
u_{\tilde{\phi}, i t}
\end{array}\right) & \equiv \boldsymbol{B}\left(\begin{array}{c}
u_{\theta, i t} \\
u_{\phi, i t}
\end{array}\right) .
\end{aligned}
$$

\section{D.4 Algorithm for Solving the Problem}

Our initialization procedure is as follows. We first ignore the dynamic nature of the productivity processes and the heterogeneity of software relative price $\widehat{w}_{i t}$ and estimate separately the following two simplified versions of Equations (64) and (65) with linear 2SLS:

$$
y_{i t}=\gamma_{1}^{0} k_{i t}+\gamma_{2}^{0} l_{i t}+\gamma_{3}^{0} s_{i t}+\gamma_{4}^{0} h_{i t}+v_{\theta, i t}^{0},
$$




$$
s_{i t}-l_{i t}=\gamma_{5}^{0} y_{i t}+\gamma_{6}^{0}\left(k_{i t}-l_{i t}\right)+\gamma_{7}^{0}\left(s_{i t}-h_{i t}\right)+v_{\phi, i t}^{0} .
$$

We estimate Equation (66), instrumenting $s_{i t}, l_{i t}, h_{i t}$ and $k_{i t}$ by their lagged values, and Equation (67), instrumenting $y_{i t}, k_{i t} l_{i t}$, and $h_{i t}-s_{i t}$ by their lagged values. We retrieve the predicted values of the initial residuals $\widetilde{\theta}_{i t}^{0}=v_{\theta, i t}^{0}$ and $\widetilde{\phi}_{i t}^{0}=v_{\phi, i t}^{0}$ and estimate by OLS the persistence, trends and shifters from the joint productivity process:

$$
\left(\begin{array}{c}
\tilde{\theta}^{0}{ }_{i t} \\
\widetilde{\phi}^{0}{ }_{i t}
\end{array}\right)=\left(\begin{array}{cc}
\rho_{\tilde{\theta} \tilde{\theta}}^{0} & \rho_{\tilde{\theta} \tilde{\phi}}^{0} \\
\rho_{\tilde{\phi} \tilde{\theta}}^{0} & \rho_{\tilde{\phi} \tilde{\phi}}^{0}
\end{array}\right)\left(\begin{array}{c}
\tilde{\theta}^{0}{ }_{i t-1} \\
\widetilde{\phi}^{0}{ }_{i t-1}
\end{array}\right)+\left(\begin{array}{c}
\eta_{\tilde{\theta}}^{0}+\mu_{\tilde{\theta}}^{0} t \\
\eta_{\tilde{\phi}}^{0}+\mu_{\tilde{\phi}}^{0} t
\end{array}\right)+\left(\begin{array}{c}
u_{\tilde{\theta}_{, i t}^{0}}^{0} \\
u_{\tilde{\phi}, i t}^{0} \\
\tilde{\phi}^{0}
\end{array}\right) .
$$

Second, we iterate the following step : armed with estimates from step $\tau-1$, we $\rho$-differentiate Equations (66) and (67):

$$
\begin{aligned}
& \Delta_{\rho_{\theta \theta}^{\tau-1} y_{i t}}-\rho_{\theta \phi}^{\tau-1} \widetilde{\phi^{\tau-1}}=\Delta_{\rho_{\theta \theta}^{\tau-1}}\left(\gamma_{1}^{\tau} k_{i t}+\gamma_{2}^{\tau} l_{i t}+\gamma_{3}^{\tau} s_{i t}+\gamma_{4}^{\tau} h_{i t}+v_{\theta, i t}^{\tau}\right), \\
& \Delta_{\rho_{\phi \phi}^{\tau-1}}\left(s_{i t}-l_{i t}\right)-\Delta_{\rho_{\phi \phi}^{\tau-1}} b_{i t}^{\tau}-\rho_{\phi \theta}^{\tau-1} \widetilde{\theta \tau-1}_{i t-1}=\Delta_{\rho_{\phi \phi}^{\tau-1}}\left(\gamma_{5}^{\tau} y_{i t}+\gamma_{8}^{\tau}\left[\widehat{w}_{i t}+b_{i t}^{\tau}\right]+v_{\phi, i t}^{\tau}\right),
\end{aligned}
$$

where we define $\Delta_{\rho} x_{i t}=x_{i t}-\rho x_{i t}$ and $b_{i t}^{\tau}=\frac{\gamma_{1}^{\tau}}{\gamma_{1}^{\tau}+\gamma_{2}^{\tau}}\left(k_{i t}-l_{i t}\right)+\frac{\gamma_{4}^{\tau}}{\gamma_{3}^{\tau}+\gamma_{4}^{\tau}}\left(s_{i t}-b_{i t}\right)$. We estimate separately Equation (68) then Equation (69) with linear 2SLS. As in the initial step, we retrieve the predicted values of the initial residuals $\widetilde{\theta}_{i t}=v_{\theta, i t}^{\tau}$ and $\widetilde{\phi}^{\tau}{ }_{i t}=v_{\phi, i t}^{\tau}$ and estimate by OLS the persistence, trends and shifters from the joint productivity process:

$$
\left(\begin{array}{c}
\widetilde{\theta}_{i t}^{\tau} \\
\widetilde{\phi}^{\tau}{ }_{i t}
\end{array}\right)=\left(\begin{array}{cc}
\rho_{\tilde{\theta} \tilde{\theta}}^{\tau} & \rho_{\tilde{\theta} \tilde{\phi}}^{\tau} \\
\rho_{\tilde{\phi} \tilde{\theta}}^{\tau} & \rho_{\tilde{\phi} \tilde{\phi}}^{\tau}
\end{array}\right)\left(\begin{array}{c}
\widetilde{\theta}^{\tau}{ }_{i t-1} \\
\widetilde{\phi}^{\tau}{ }_{i t-1}
\end{array}\right)+\left(\begin{array}{c}
\eta_{\tilde{\theta}}^{\tau}+\mu_{\tilde{\theta}}^{\tau} t \\
\eta_{\widetilde{\phi}}^{\tau}+\mu_{\tilde{\phi}}^{\tau} t
\end{array}\right)+\left(\begin{array}{c}
u_{\tilde{\theta}, i t}^{\tau} \\
u_{\widetilde{\phi}, i t}^{\tau}
\end{array}\right) .
$$

We stop the iterative procedure when the maximum of the absolute differences of all parameters of the productivity process between steps $\tau-1$ and $\tau$ is below 0.01 or the number of iterations reaches 20 . In practice, this procedure converges in less than three steps. In the final step $\tau_{f}$, we compute the following parameter values:

$$
\begin{aligned}
\epsilon^{\tau_{f}} & =\frac{\gamma_{5}^{\tau_{f}}}{1+\gamma_{8}^{\tau_{f}}} \\
\sigma^{\tau_{f}} & =-\gamma_{8}^{\tau_{f}}
\end{aligned}
$$

Third, we estimate simultaneously Equations (64) and (65) by two-step GMM using $\gamma_{1}^{\tau_{f}}, \gamma_{2}^{\tau_{f}}, \gamma_{3}^{\tau_{f}}, \gamma_{4}^{\tau_{f}}$, $\epsilon^{\tau_{f}}, \sigma^{\tau}, \rho_{\tilde{\theta} \tilde{\theta}}^{\tau}, \rho_{\tilde{\theta} \tilde{\phi}}^{\tau}, \rho_{\tilde{\phi} \tilde{\theta}}^{\tau}, \rho_{\tilde{\phi} \tilde{\phi}}^{\tau}, \eta_{\tilde{\theta}}^{\tau}, \mu_{\tilde{\theta}}^{\tau}, \eta_{\tilde{\phi}}^{\tau}$, and $\mu_{\tilde{\phi}}^{\tau}$ as initial guesses. Fourth, we estimate simultaneously Equations (62) and (61) by two-step GMM results from the third step as an initial guess. ${ }^{54}$

\footnotetext{
${ }^{54}$ In both these steps, we use $t, s_{i t-1}, l_{i t-1}, h_{i t-1}, k_{i t-1}, \widetilde{\theta}_{i t-1}$ and $\widetilde{\phi}_{i t-1}$ as instruments for the first equation, and $t, y_{i t-1}, k_{i t-1}-l_{i t-1}, h_{i t-1}-s_{i t-1}, \tilde{\theta}_{i t-1}, \widetilde{\phi}_{i t-1}$ and the local wage instrument $z_{i t}$ as instruments for the second equation.
} 


\section{E Appendix: Data}

In this section, we describe the procedure we use to merge our different data sources, to clean the resulting dataset of outliers, and to compute the firm level capital stock for each asset-type.

\section{E.1 Data Cleaning}

We start with the BRN RSI files from 1989 to 2007, in which we drop firms that have invalid SIREN using the cross-validation algorithm used to generate SIREN numbers. They correspond to firms whose self-reported SIREN identifiers do not match the SIREN identifiers recorded by INSEE. We then collapse observations that are not unique in terms of SIREN-year. They correspond to firms that appear in both BRN and RSI regimes in the same year. Finally we drop 382,854 observations for which we cannot build industry codes. This leaves us with 31,698,412 firm-year observations. We use this data (labelled "BRN+RSI"), keeping observations with positive sales, value-added, employment and labor costs and excluding agriculture, real estate, finance and the public sector, to compute the decomposition of labor shares, concentration and some calibration moments from Table 10.

We then merge with the EAE datasets, using firm's SIREN numbers-the French unique firm identifiers. We keep all firms that are present in the BRN files at least once and drop all other observations (RSI only firms amount to 17,684,072 observations, with average sales of $102 \mathrm{~K} €$, against 3,848 $\mathrm{K} €$ for BRN firms sample, and unmatched EAE amount to 502,384 observations, with average sales of 3,809 $\mathrm{K} €$, against 2,693,772 observations and 13,583 $\mathrm{K} €$ for matched $\mathrm{EAE}$ observations). At this point, we have in total 14,014,340 firm-year observations.

In the EAE files, the missing values for the software investment are coded as 0 . We adopt the following cleaning strategy to ensure that we distinguish actual Os from missing data. We impute as missing software investment of firms that report 0 investment and are below the corresponding threshold described above according to the same data reported in the EAE survey for the end of the previous fiscal year.

To compute our measures of firm scale, we then merge with the DADS and Customs datasets at the firm level. There are 21,537,688 firm-year observations in the DADS from 1994 to 2007, and 7,718,739 of those observations will be matched with our sample of BRN firms. Of the 13,818,949 unmatched observations, $6,344,533$ of those corresponds to RSI firms that we already dropped. DADS covers all employers with salaried workers, so include non-profits, household and public employers, and many firms that operates in sectors not well covered by the BRN-RSI fiscal regime. Matched observations have on average 36 employees according to the DADS, against 10 employees for unmatched firms. Conversely, there are 3,327,481 BRN firm-year observations unmatched in the DADS over the 1994-2007 period, and those firms have less than 2 employees according to the BRN-RSI data. This shows that our data is broadly representative of firms with more than a few employees, operating in the private sector.

There are 1,465,048 firm-year observations in the Customs data from 1995 to 2007, and 1,036,525 of those correspond to firms in our sample of BRN firms. Of the 428,523 unmatched observations, 136,821 
are RSI only firms that we already dropped. Matched observations declare total exports of $3.1 \mathrm{M} €$ on average, against $1.7 \mathrm{M} €$ for unmatched customs firms.

We then drop observations with negative values added (8.51\% of observations), negative wage bill (34 observations), no employee (19.4\% of observations), book capital per employee relative to the industry average that is outside of the $99.99 \%$ probability range of a fitted distribution $(0.28 \%$ of observations) and observations in the top $0.1 \%$ for total investment per employee. Table 1 reports summary statistics for the remaining sample of 6,6110,529 observations for firms that appear in the BRN at least once ("BRN firms"), $2,495,553$ of which corresponds to firms that are sampled in the EAE dataset at least once ("EAE firms"). ${ }^{55}$ We use this data to gather our micro-level facts from section 3, restricting our sample to the 1,338,935 EAE observations (respectively 2,495,553 observations corresponding to EAE firms) when studying software investment (respectively capital).

Finally, in the estimation, we further restrict our sample to EAE firms observations from 1996 to 2007 with positive software, hardware, and non-IT capital, positive labor and value added, and for which the location of the firm's headquarter is known. These last restrictions bring the number of observations in our estimation sample to 302,318 .

\section{E.2 Building Measures of Capital Stock}

To compute levels of capital stocks from the investment variables, we apply the Perpetual Inventory Method. For each asset-type $j$ for which measures of investment is available for each firm $i$ and at time $t$, we build capital stocks using the following recursive formula:

$$
K_{j, i, t}=K_{j, i, t-1}\left(1-\delta_{j}\right)+\frac{I_{j, t}}{W_{j, t}}
$$

where $W_{j, t}$ stands for the price deflator for asset-type $j$ at time $t$, and $\delta_{j}$ for the depreciation rate in assettype $j$. Below, we discuss how we initialize this recursive formula for each asset-type and for each firm. We also discuss where we obtain the information on price deflators and depreciation rates from.

To build total capital stocks we make the choice of summing over the assets to obtain total capital stock, instead of apply this formula to total investment. The main reason we make this choice is that it allows us to fully take into account the heterogeneity of investment composition across firms, instead of applying a common price and depreciation rate. For software investment, firms that are not sampled in the EAE some years have missing software investment values for those years. Moreover, even when sampled in the EAE, firms might not report software investment if sampled with a simplified questionnaire. Similarly, there are gaps in the coverage of firms in the BRN files, either because they are included in RSI (which we observe) or because they did not file a tax form that year to either regime (which we do not observe). In all these cases, we have no information about asset-specific investment during those years. Because our construction of the capital stock is based on a recursive formula, we impute missing investment to be 0 .

\footnotetext{
${ }^{55}$ We report the representativeness of the data in the online appendix.
} 


\section{Initialization}

In 1989 ( $t-0)$, we impute firms starting values of capital in each asset type assuming first that our sample's ratio of total investment to total capital is equal to the aggregate ratio of investment $\bar{I}_{j, 0}^{s}$ to capital $\bar{K}_{j, 0}^{s}$ for each of the 38 industries $s$ :

$$
\sum_{i \in s} K_{j, i, 0}=\frac{\sum_{i \in s} I_{j, i, 0}}{\bar{I}_{j, 0}^{s}} \times \bar{K}_{j, 0}^{s}
$$

Where $\frac{\sum_{i \in s} I_{j, i, 0}}{\bar{I}_{j, 0}^{s}}$ is typically below 1 (46.9\% on average, see online appendix). Then, we assume that the share of the firm's capital $j$ in our sample's industry level capital $j$ is the same as the share of the firm's propensity to invest in that asset in our sample's industry-level investment. Because most firms invest zero in a given year, we compute each firm's propensity to invest in asset $j$ as that firm's average investment in $j I_{j, i, 0}^{m}$ for the years we do observe. In other words, at time 0 , the imputed value for firm $i$ in industry $s$ is inferred then given by :

$$
K_{j, i, 0}=\frac{\sum_{i \in s} I_{j, i, 0}^{m}}{\sum_{i \in s} I_{j, i, 0}^{m}} \times \frac{\sum_{i \in s} I_{j, i, 0}}{\bar{I}_{j, 0}^{s}} \times \bar{K}_{j, 0}^{s} .
$$

For the aggregate industry levels of capital and investment, we rely on the series provided by INSEE at the 38 industries level. We use net values of capital in current prices, which already account for previous years' capital depreciation. ${ }^{56}$

\footnotetext{
${ }^{56}$ We report the resulting aggregate capital stocks by broad industries in the online appendix.
} 